Running head: PEER INFLUENCE IN CHILDHOOD AND ADOLESCENCE

\title{
A Meta-Analysis of Longitudinal Peer Influence Effects in Childhood and Adolescence
}

Matteo Giletta*1,2, Sophia Choukas-Bradley*3, Marlies Maes ${ }^{4,5,6}$, Kathryn P. Linthicum ${ }^{7}$, Noel A.

$$
\operatorname{Card}^{8} \text { and Mitchell J. Prinstein } 9
$$

*The first two authors contributed equally to this work and first authorship is shared.

${ }^{1}$ Department of Developmental, Personality and Social Psychology, Ghent University

${ }^{2}$ Department of Developmental Psychology, Tilburg University

${ }^{3}$ Department of Psychological and Brain Sciences, University of Delaware

${ }^{4}$ School Psychology and Development in Context, KU Leuven, Belgium

${ }^{5}$ Research Foundation Flanders (FWO), Belgium

${ }^{6}$ Youth Studies, Utrecht University, the Netherlands

${ }^{7}$ Department of Psychology, Florida State University

${ }^{8}$ Department of Human Development and Family Science, University of Georgia

${ }^{9}$ Department of Psychology and Neuroscience, University of North Carolina at Chapel Hill

(C) 2021, American Psychological Association. This paper is not the copy of record and may not exactly replicate the final, authoritative version of the article. Please do not copy or cite without authors' permission. The final article will be available, upon publication in Psychological Bulletin, via its DOI: 10.1037/bul0000329

Preparation of this manuscript was supported by grants from the Netherlands Organization for Scientific Research (NWO; \#451-15-004) awarded to Matteo Giletta, and from the National Institute of Child Health and Human Development (1R01 HD055342) to Mitch Prinstein. We thank Whitney (Brechwald) Guerry, Shahar Gur, Patrick Rock, and Christopher Sheppard for their valuable contributions to earlier stages of the project, as well as Belén Fernández-Castilla for her support with the analytic approach. Finally, we thank all authors who provided us with information about their studies for this meta-analysis.

Correspondence concerning this article should be addressed to either Matteo Giletta, Department of Developmental, Personality, and Social Psychology, Ghent University, Henri Dunantlaan 2, B-9000, Ghent, Belgium, Phone: (+32) 0926464 23, Email: matteo.giletta@ugent.be; or Sophia Choukas-Bradley, Department of Psychology, University of Delaware, 105 The Green, University of Delaware, Newark, DE 19716, USA, Phone: (+1) 302-831-2271, Email:_ scb@udel.edu.

Body Word Count: 25,592 (inclusive of references, tables, \& figures) 


\title{
PEER INFLUENCE IN CHILDHOOD AND ADOLESCENCE
}

\begin{abstract}
For decades, psychological research has examined the extent to which children's and adolescents' behavior is influenced by the behavior of their peers (i.e., peer influence effects). This review provides a comprehensive synthesis and meta-analysis of this vast field of psychological science, with a goal to quantify the magnitude of peer influence effects across a broad array of behaviors (externalizing, internalizing, academic). To provide a rigorous test of peer influence effects, only studies that employed longitudinal designs, controlled for youths' baseline behaviors, and used “external informants" (peers' own reports or other external reporters) were included. These criteria yielded a total of 233 effect sizes from 60 independent studies across four different continents. A multilevel meta-analytic approach, allowing the inclusion of multiple dependent effect sizes from the same study, was used to estimate an average cross-lagged regression coefficient, indicating the extent to which peers' behavior predicted changes in youths' own behavior over time. Results revealed a peer influence effect that was small in magnitude $(\dot{\beta}=0.08)$ but significant and robust. Peer influence effects did not vary as a function of the behavioral outcome, age, or peer relationship type (one close friend vs. multiple friends). Time lag and peer context emerged as significant moderators, suggesting stronger peer influence effects over shorter time periods, and when the assessment of peer relationships was not limited to the classroom context. Results provide the most thorough and comprehensive synthesis of childhood and adolescent peer influence to date, indicating that peer influence occurs similarly across a broad range of behaviors and attitudes.
\end{abstract}

Keywords: Peer influence; peer relationships; childhood; adolescence; meta-analysis 
PEER INFLUENCE IN CHILDHOOD AND ADOLESCENCE

Public Significance Statement

This meta-analysis suggests that in childhood and adolescence, peer influence occurs across a wide range of behaviors and attitudes. The strength of the peer influence effect was small but significant and robust, and it was found to be similar for externalizing, internalizing, and academic behaviors. 
PEER INFLUENCE IN CHILDHOOD AND ADOLESCENCE

\section{A Meta-Analysis of Longitudinal Peer Influence Effects in Childhood and Adolescence}

Social scientists frequently discuss peer influence effects. Sometimes referred to as peer socialization or peer contagion effects across various literatures (e.g., Dishion \& Tipsord, 2011; see Laursen, 2018), scholars in many disciplines have noted that individuals' attitudes and behaviors may be strongly affected by exposure to others' attitudes or behaviors, perhaps especially if individuals admire or are interpersonally close to these putative agents of influence (e.g., Newcomb, 1950). This phenomenon has been discussed frequently among developmental psychologists who are interested in the extent to which social interactions influence youths' developmental trajectories (e.g., Brechwald \& Prinstein, 2011), among clinical psychologists to understand symptom transmission among acquaintances and friends (e.g., Joiner \& Katz, 1999), as well as among social and health psychologists who aim to understand social influences that affect personal values and beliefs, affective states, and health-related behaviors (e.g., Berger et al., 2019; Blanton et al., 2008; Gibbons et al., 1995, Prentice \& Miller, 1993).

The study of peer influence is not restricted to psychological science, however. Epidemiologists and public health scholars frequently cite peer influence effects as relevant to the transmission of risk or safety behaviors within large social networks or communities (e.g., Christakis \& Fowler, 2007). Economists discuss peer influence effects as "multipliers" of the effects of prevention investments, based on the assumption that the costs will pay dividends not only to direct recipients but also to their closest peers (e.g., Epple \& Romano, 1998; Gilleskie \& Zhang, 2009; Hoxby, 2000). Criminologists have revealed strong peer influence effects among prison cellmates who are more likely to engage in one another's crimes upon release (e.g., Stevenson, 2017), and educators consider peer influence effects among deviant peers when aggregating students who may be at risk for truancy (e.g., Obsuth et al., 2017). In addition, 


\section{PEER INFLUENCE IN CHILDHOOD AND ADOLESCENCE}

political scientists have long used peer influence models to understand how attitudes toward political candidates and voting behaviors may spread within districts, and marketers frequently rely on peer influence as a key tactic to promote favorable attitudes towards specific products and services. Within the last decade, the effects of peer influence have perhaps been most evident in the emerging science on social media usage, with preliminary results suggesting that individuals' posts, "likes," and forwarded messages yield quantitative metrics that quite explicitly, and perhaps influentially (Nesi et al., 2017; Sherman et al., 2016), convey peers' attitudes, possibly more saliently than ever before (Nesi et al., 2018a, 2018b).

Peer influence effects have been revealed across the lifespan, with significant results among toddlers and early school-aged children (e.g., Haun \& Tomasello, 2011), as well as among the elderly (e.g., Seguin, 1973). Yet both theoretical and empirical work have suggested that childhood and adolescence likely represent developmental periods during which peer influence effects may prove most salient; indeed, the majority of published research on peer influence is among youth. Previous reviews of the peer influence literature among youth have been offered to discuss peer influence theories (e.g., Albert et al., 2013; Brechwald \& Prinstein, 2011; Brown et al., 2008; Laursen, 2018; Prinstein \& Dodge, 2008) and systematic reviews and meta-analyses of peer influence effects related to specific outcomes have been conducted (e.g., substance use, Henneberger et al., 2020; smoking, Liu et al., 2017; alcohol use, Leung et al., 2014; weight-related behaviors, Badaly, 2013; Marcos et al., 2013; antisocial behavior, Gallupe et al., 2019; Sijtsema \& Lindenberg, 2018). But no comprehensive meta-analysis has attempted to quantify the magnitude of peer influence effects among children and adolescents across different behaviors, which is an important omission in the literature. To date, the extent to which peers can influence youth behaviors remains unknown, leading to significant redundancy in 


\section{PEER INFLUENCE IN CHILDHOOD AND ADOLESCENCE}

research questions that have been examined, and, conversely, unnoticed fundamental gaps that sorely require further exploration (see Prinstein \& Giletta, 2020 for a brief review). An initial goal of this study, therefore, was to characterize this vast field of psychological science, quantify the size of peer influence effects, and better understand how peer influence has been examined among youth. Moreover, this study aimed to examine five relevant factors that may moderate the strength of peer influence effects: type of behavior, peer relationship type, peer context, youths' age, and the time lag between reports of peers' and youths' own behaviors or attitudes.

As noted above, psychological scientists often use the term peer "socialization" interchangeably with "peer influence.” Yet those terms are not necessarily synonyms; socialization refers to the transmission of skills necessary for competent functioning in society, whereas peer influence refers to a broader set of "processes whereby one child affects, or is affected by, another" (Laursen, 2018; p. 447). Thus, the term peer influence has a more neutral connotation which does not imply whether the resulting change in behavior is good or bad (Laursen, 2018). Throughout this article, we use the term "peer influence," consistent with this definition.

\section{Theoretical Perspectives on Peer Influence}

Most extant theories of peer influence have relied on both behavioral and identity-related frameworks (for more extensive reviews, see Brechwald \& Prinstein, 2011; Laursen, 2018). From a behavioral perspective, the concept of peer influence is grounded in social learning theory, which posits that individuals learn to emulate the behaviors modeled by people around them, especially if those behaviors are socially rewarded (e.g., Bandura, 1971, 1973). Other behavioral theories highlight the role of reference groups in shaping social norms and, in turn, individuals' attitudes and behaviors (e.g., Newcomb, 1950). In childhood and especially in 


\section{PEER INFLUENCE IN CHILDHOOD AND ADOLESCENCE}

adolescence, one's peers serve as important reference groups, with adolescents learning which behaviors are viewed favorably by observing their peers. For example, adolescents are more likely to engage in alcohol use if this behavior is valued and associated with popularity in the peer context (Helms et al., 2014), or if this behavior is socially rewarded in the context of dyadic interactions (e.g., "deviancy training”; see Dishion et al., 1996; see also Bagwell \& Bukowski, 2018).

Identity theories highlight how conforming to peer influence can provide a positive sense of self-regard. During childhood and especially during adolescence, peer feedback, approval, and belonging are important factors contributing to self-concept and identity development (see Brechwald \& Prinstein, 2011). Conforming to the behaviors and attitudes of one's valued peers may be intrinsically rewarding because it can provide a favorable sense of self (Abrams \& Hogg, 1990; Brechwald \& Prinstein, 2011; Festinger, 1945; Gibbons et al., 2003). For example, if an adolescent's friends value risk-taking behaviors, then engaging in such behaviors may improve one's self-concept by allowing individuals to feel more aligned with admired peers. Consistent with this notion, work from developmental neuroscience suggests that conforming to peers (Sherman et al., 2016) and taking risks when peers are present (Chein et al., 2011) are also rewarding at the neural level.

\section{Empirical Research on Peer Influence in Childhood and Adolescence}

The proliferation of research regarding peer influence effects in psychological science can be credited in large part to seminal articles published more than four decades ago by both Cohen and Kandel (Cohen, 1977; Kandel, 1978; Kandel et al., 1978), which first articulated two social processes explaining the notably high behavioral correspondence between adolescents and their peers: selection and socialization effects. Selection effects reflect the tendency for 


\section{PEER INFLUENCE IN CHILDHOOD AND ADOLESCENCE}

individuals to form acquaintances with others who already possess similar interests and proclivities (Cohen, 1977; Kandel, 1978). The concept of selection is grounded in earlier work demonstrating that individuals tend to view others with similar attitudes and values more favorably, which has been referred to as the similarity-attraction effect (e.g., Byrne, 1961). Substantial research now has confirmed that among children and adolescents, similarities in demographic (e.g., gender, ethnicity; Kao \& Joyner, 2004; Martin et al., 2013) and behavioral characteristics (e.g., academic achievement, risk behavior engagement; Mercken et al., 2012; Smirnov \& Thurner, 2017) indeed are reliable determinants of friendship formation. In this metaanalysis, we examine the body of work focused on understanding socialization effects, which as noted previously, we refer to as "peer influence" effects.

Questions regarding peer influence effects have captured psychological scientists' attention in the 40 years since Kandel's and Cohen's studies, with substantial energy dedicated towards the study of a wide range of behavioral outcomes. Yet remarkably little is known regarding the strength of peer influence effects, perhaps because many different methodological approaches have been employed to understand peer influence scientifically. Experimental paradigms have been used in research among youth to understand how peer influences may affect attitudes towards dangerous, illegal, or risky behaviors (e.g., Allen et al., 2006). For example, in an experimental "chat-room" based study, adolescents viewing risk-endorsing attitudes communicated by popular grademates in their school (who were in fact "electronic confederates") were more likely to endorse those attitudes themselves and also were more likely to engage in actual aggressive behavior as compared to adolescents who viewed identical norms ostensibly reported by less popular grademates (Cohen \& Prinstein, 2006). Similar experimental paradigms have also been used to demonstrate the peer influence of adolescents' prosocial 
PEER INFLUENCE IN CHILDHOOD AND ADOLESCENCE

attitudes (e.g., Choukas-Bradley et al., 2015). Furthermore, experimental work has demonstrated that adolescents, but not adults, are more likely to engage in risky driving (using a simulated driving game) when being observed by peers (Gardner \& Steinberg, 2005; Chein et al., 2011). Experimental approaches such as these have offered a unique opportunity to examine discrete interpersonal processes that may be most relevant for understanding peer influence effects, often while exerting a high level of experimental control and random assignment across conditions to yield causal conclusions. Unfortunately, however, experimental approaches often lack ecological validity, limiting applications to contexts in which peer influence may actually occur, or to consequential behavioral outcomes.

A more common methodological approach is found in investigations that use surveybased (i.e., observational) data to understand peer influence effects. By assessing youths' own behavior and peers' behavior, it is possible to investigate a wide range of behavioral outcomes, including aggressive behavior, substance use, or even self-injurious behaviors that would be more challenging to examine in the lab. When survey-based designs are used in a longitudinal framework, they offer the opportunity to infer peer influence effects, by observing whether youths' behaviors change over time as a function of their peers' behavior, while rigorously controlling for prior behavioral levels and similarity. Although such study designs cannot determine causal processes or directly assess active forms of peer influence such as peer pressure (see Laursen, 2018), they allow the investigation of behaviors that cannot be feasibly or ethically manipulated in the lab, and they represent influence as it occurs among youth in real-world interactions over time, thus maximizing ecological validity.

These survey-based studies represent the most common form of assessing peer influence within psychological science. To date, thousands of studies have utilized non-experimental, 
PEER INFLUENCE IN CHILDHOOD AND ADOLESCENCE

survey-based designs to study peer influence, contributing to a common perception that the magnitude of peer influence effects is large, and that influence processes are broadly relevant to a wide range of potential youth and an array of behavioral outcomes. Importantly, however, this claim has not yet been examined meta-analytically, and there are reasons to suspect that the effects of peer influence may be poorly estimated in prior work.

Two main notable variations in how survey-based studies have been used to infer peer influence effects warrant careful consideration to determine the magnitude of these effects. First, many prior survey-based studies examining peer influence have relied on cross-sectional designs rather than prospective longitudinal approaches, making the identification of selection versus influence effects impossible. Indeed, when concurrent associations are observed between youths' and peers' behaviors, behavioral similarity could be the result of peer influence processes (i.e., peers' behaviors predicted youths' own behaviors), but it also is possible that such similarity preceded and contributed to the formation of the relationships between youth and their peers (i.e., youth selected peers who displayed behaviors similar to their own).

Second, prior research examining the potentially influential effects of peers on youths' own behavior has often relied exclusively on youths' self-report, which may provide overestimates of peer influence effects due to problems related to shared method variance and individuals' perceptual biases. For example, a common approach may involve asking an adolescent to report their own behavior, such as alcohol use, and also to report their perceptions of their best friend's alcohol use at an initial time point; these values are then used to predict adolescents' own alcohol use months or years later (e.g., Engels et al., 1999). Another similar approach asks youth to report the extent to which they affiliate with peers who engage in a particular behavior, with this measure of "peer norms" then used as a predictor of future behavior 


\section{PEER INFLUENCE IN CHILDHOOD AND ADOLESCENCE}

(e.g., D'Amico \& McCarthy, 2006). While such approaches offer an excellent opportunity to examine prospective associations between youths' perceptions of their friends' behavior (e.g., alcohol use) and their own behavior, there is ample theoretical and empirical evidence to suggest that perceptions are poor estimates of others' behavior, and in fact may be highly influenced by one's own preexisting attitudes or behavior. Sociologists and social psychologists have explained this phenomenon as being driven by perceptive biases, referred to as false consensus effects or projection biases, suggesting that individuals tend to project their own behaviors onto others, thereby overestimating the similarities between themselves and others (see Gottfredson \& Hirschi, 1987; Haynie, 2001; Marks \& Miller, 1987; Ross et al., 1977). Research from developmental and social psychology provides evidence for this phenomenon. For example, higher levels of adolescents' deviant behavior are significantly associated with over-estimations of their best friends' deviant behavior (Prinstein \& Wang, 2005). Thus, studies that rely on participants' perceptions of peers' behavior may overestimate peer influence effects.

To overcome these limitations, more rigorous longitudinal peer influence studies (a) ask youth to identify their most meaningful peer affiliations (e.g., friendships), often using peer nomination methods, and then (b) assess youths' and their peers' behaviors either through youths' and their peers' own self-report, or by gathering information about target youths' and peers' behaviors from an external source (e.g., school records, teacher report). These approaches allow researchers to obtain information about peers' behavior by linking target youths' data with their peers' data and without relying on youths' perceptions. Although rarer, these studies offer a particularly stringent test of peer influence effects.

\section{Peer Influence Moderators}


13 PEER INFLUENCE IN CHILDHOOD AND ADOLESCENCE

To date, no prior study has offered a meta-analysis of peer influence effects throughout childhood and adolescence across a range of behavioral outcomes from the psychological literature. Meta-analyzing this broad body of work on peer influence offers a unique and valuable opportunity to identify the conditions when peer influence effects may be most powerful. Thus, a second goal of our study was to examine whether the type of behavior, peer relationship type, peer context, age, and time lag served as moderators of peer influence effects.

First, peer influence effects have been documented for a wide array of behaviors and attitudes (Brechwald \& Prinstein, 2011); yet it remains unclear whether peers may influence some behavioral outcomes more strongly than others. The majority of research conducted among youth focused on examining peer influence effects in relation to externalizing behaviors (e.g., aggression, substance use). As noted earlier, this work often has been guided by social learning theories (e.g., Bandura, 1973) suggesting that individuals are most likely to emulate observable behavior and norms that are associated with direct or vicarious reinforcements (Bandura, 1971). Indeed, many externalizing behaviors, such as aggression, substance use, and other riskbehavior, are more likely to occur in the presence of peers than privately (e.g., Chein et al., 2011), are often discussed openly among youth (e.g., Dishion et al., 1996), and tend to be associated with perceived or actual social rewards (e.g., peer approval, peer status), especially during adolescence (e.g., Allen et al., 2005; Mayeux et al., 2008).

Another body of research has examined the interpersonal transmission of academic attitudes and behaviors (e.g., homework completion, school grades) among youth. Given the extended periods of structured peer interaction within the school context and the associations between academic acumen and reputations among peers (e.g., Juvonen \& Murdock, 1995; Véronneau et al., 2010), it is not surprising that many researchers have found that peers may also 
PEER INFLUENCE IN CHILDHOOD AND ADOLESCENCE

exert influence on youths' scholastic outcomes (e.g., Wentzel et al., 2004). Finally, drawing from theoretical and empirical work among adults, more recent developmental research has also provided evidence for peer influence of youths' internalizing symptoms. For instance, supporting interpersonal theories of depression (e.g., Coyne, 1976; Joiner, 1994), several studies have shown that depressive symptoms may be transmitted within adolescents' friendships (e.g., Giletta et al., 2011; Schwartz-Mette \& Rose, 2012). Although evidence of peer influence effects has been found for all these broad outcome domains, it should be noted that while externalizing behaviors have been consistently related to peer rewards, especially in adolescence, academic outcomes, and in particular, internalizing symptoms, not only may be less visible among peers but are also generally less likely to be subject to external social reinforcements (e.g., high peer status). Notably, these differences may also affect the magnitude of peer influence effects.

The type and context of peer relationships were reflected in two additional moderators examined in this study. Youth might be influenced in the context of many types of close relationships. In studies of peer influence among youth, the influence of one specific close friend is often examined; studies variously refer to this influencer as one's "closest friend" (e.g., Allen et al., 2012), "best friend" (e.g., Reitz et al., 2006), or "very best friend” (e.g., Prinstein, 2007), among other terms. Yet, other studies assess the influence of multiple friends, either through identifying friend groups with a social cognitive map procedure (e.g., Ellis \& Zarbatany, 2007) or through aggregating the reports of more than one friend (e.g., Li et al., 2017). We examined whether differences might emerge in peer influence effects based on these differentiations of peer relationship type, given the possibility that close friends may exert especially strong influence (Bagwell \& Bukowski, 2018). In addition, it is important to consider that peer relationships also occur across different contexts, yet, perhaps for methodological or sampling 
PEER INFLUENCE IN CHILDHOOD AND ADOLESCENCE

convenience, most prior research has focused on peer affiliations within the school context.

While many studies provide limited rosters of classmates (e.g., Vitaro et al., 2007) or grademates (e.g., Prinstein, 2007), other studies allow participants to provide the names of their peers, either across one's whole school (e.g., Hogue \& Steinberg, 1995) or beyond the school (e.g., Poulin et al., 1999). Given that youth may have salient and influential relationships that go beyond the school context (Giletta et al. 2011; Laursen, 2018; Vandell et al., 2005), we examined whether broader peer contexts (e.g., allowing nominations beyond one's school) would be associated with stronger peer influence effects than more restricted contexts (e.g., classroom).

A fourth theory-based moderator examined in this study was participants' age.

Developmental theories suggest that as children transition to adolescence, peer relationships become primary sources for intimate disclosure, social support, and reflected appraisal processes, with peer feedback paramount for identity development (Harter et al., 1996). Indeed, adolescence is a developmental period characterized by decreasing reliance on parents and an increasing reliance on peers (Steinberg \& Silverberg, 1986). A complex set of biological, social, and psychological changes lead adolescents to spend more unsupervised time with peers (Lam et al., 2014) and to engage in behaviors that will lead to social rewards in the form of peer approval and peer status (Dahl et al., 2018), which in turn are central to adolescents' sense of self (Harter et al., 1996). Recent empirical work from developmental affective neuroscience highlights (early) adolescence as a period characterized by rapid and complex changes in social cognition and motivation, which increase the salience of peers (Nelson et al., 2016) and sensitivity to social reward (e.g., peer approval) as well as social punishment (e.g., peer rejection, Kilford et al., 2016; Knoll et al., 2015). For instance, results from experimental studies suggest that, as compared to both children and adults, early adolescents demonstrate heightened sensitivity to 
PEER INFLUENCE IN CHILDHOOD AND ADOLESCENCE

their peers' evaluations (e.g., Blakemore, 2018; Somerville et al., 2013) and increased reward sensitivity in the presence of peers (e.g., Chein et al., 2011). Thus, developmental changes in early adolescence may reflect heightened peer influence effects (Laursen, 2018).

A final factor that may moderate the magnitude of peer influence effects is the time lag between assessments (see Card, 2019). Typically, longitudinal investigations of peer influence include annual or semi-annual assessment waves. Data collected at follow-up waves might include adolescents' and peers' estimation of their frequency of a specific behavior or attitude since the time of the prior data collection wave, which commonly is several months to a year prior. Frequently, a similar procedure is used at the next data collection wave. As more time passes between assessment waves, it is likely that the initial effects of peer influence may fade, whether due to friendships dissolving, as these relationships decrease in closeness or intensity (Meter \& Card, 2016), or to a broader array of influences becoming powerful in the interim. Thus, the time lag between assessments was also examined as a moderator of peer influence (see Card, 2019).

\section{The Current Study}

This study offers the first meta-analytic review and synthesis of empirical child and adolescent peer influence studies from multiple domains of psychological science. Specifically, this study aimed to synthesize and meta-analyze the existing literature on observational studies of peer influence among children and adolescents, with the goal of quantifying the magnitude of peer influence effects. To provide a rigorous test of peer influence effects, and to ensure that estimates were not affected by possible selection effects and perceptual biases, we restricted effect sizes to those from studies that (a) used a prospective longitudinal design and (b) measured affiliations with peers, combined with reports of peers' attitudes or behaviors based either on 
PEER INFLUENCE IN CHILDHOOD AND ADOLESCENCE

peers' own self-reports or on external reports (e.g., teacher reports or sociometric ratingsreports not relying on the target youths' perceptions of peers' behaviors). We included any study that focused on youth, provided at least two repeated assessments of youths' behavior, and used both peer affiliation assessments and "external informant" reports.

Synthesizing the literature to provide an estimate of the magnitude of peer influence effects was a primary goal. We also aimed to determine whether the magnitude of effects would be equally strong, across different behavioral outcomes, peer relationships, peer contexts, ages, and spans of time. Based on existing evidence suggesting powerful peer influence effects across each type of behavior examined (e.g., Gallupe et al., 2019; Liu et al., 2017; Wentzel et al., 2004), no formal hypotheses were offered regarding the moderating effects of behavioral outcome; nevertheless, we explored the possibility that peer influence effects may be larger for externalizing outcomes than for academic and internalizing outcomes given theoretical and empirical work suggesting that externalizing behaviors may be more easily observable and especially rewarded by peers (e.g., Mayeux et al., 2008). Regarding peer relationship type, we hypothesized that peer influence effects would be stronger among close friendships (as opposed to a group of peers/friends), given high levels of intimacy, sharing, and disclosure within close friendships, which may allow friends access to and influence over feelings and behaviors that are not necessarily accessible to the broader peer group (Bagwell \& Bukowski, 2018; Laursen, 2018). Additionally, regarding peer context, we hypothesized that peer influence effects would be stronger when nominations were not constrained to one's school, given prior evidence that friendships confined to school settings may be less influential (Giletta et al., 2011; see also Laursen, 2018). We further hypothesized that peer influence effects would be stronger among (early) adolescents than among younger children, considering the profound developmental 
PEER INFLUENCE IN CHILDHOOD AND ADOLESCENCE

changes occurring during this life period. Research indicates that early adolescents (approximately 12-14 years) may be particularly sensitive to their peers, more than children or mid-late adolescents (e.g., Knoll et al., 2015; van Hoorn, van Dijk, Guroglu, et al., 2016); thus, we also tested the hypothesis that peer influence peaks in early adolescence and declines in the subsequent years, by examining a curvilinear pattern. Finally, it was hypothesized that the duration between data collection waves would be inversely associated with the magnitude of peer influence effects, such that shorter time lags would be associated with larger effect sizes. In addition to these main moderators, we also explored the effects of additional descriptive moderators (i.e., publication type, publication year, country of data collection, gender, ethnicity, and report type).

\section{Method}

\section{Literature Search}

To identify eligible studies, we searched the electronic database, PsycINFO, for peerreviewed studies and dissertations. The literature search was conducted in June 2018. The following search string was used: ((“peer influence” OR "peer contagion” OR "peer effects” OR “peer socialization" OR "peer selection" OR “friend* selection” OR "friend* socialization" OR "friend* effects" OR "friend* contagion" OR "friend* influence") OR (peer AND (selection OR socialization))). The literature search was limited to studies classified as "under 18 " in age. In addition to these key words, a separate search was conducted to identify studies by the following authors: J.P. Allen, C.M. Barry, K.E. Bauman, T.J. Berndt, M. Brendgen, W.M. Bukowski, D.M. Capaldi, A.H.N. Cillessen, T.J. Dishion, R.C. Engels, S.T. Ennett, P. Ferguson, M. Gerrard, F.X. Gibbons, W.W. Hartup, D.B. Kandel, T.E. Moffitt, M.J. Prinstein, L. Steinberg, K.A. Urberg, F. Vitaro, and K. Wentzel. Finally, additional records ( $n=170$; see Figure 1$)$ were identified by 
PEER INFLUENCE IN CHILDHOOD AND ADOLESCENCE

examining the reference lists of other studies. To reduce and test for the presence of publication bias (e.g., McLeod \& Weisz, 2004), dissertations that matched search terms and met inclusion criteria were included after being cross-referenced against published work. As shown in the PRISMA (Moher et al., 2009) flowchart in Figure 1, these searches resulted in the identification of 5,273 unique reports that were screened for eligibility based on the inclusion and exclusion criteria described below, first examining only the titles and abstracts and, when necessary, the full article text.

\section{Inclusion and Exclusion Criteria}

The aim of this meta-analysis was to quantify the magnitude of peer influence effects on youths' behaviors, symptoms, and attitudes, using only studies that (a) utilized longitudinal designs and (b) assessed peer affiliations to avoid relying on the target youths' report of peers' behaviors. We reviewed all potentially eligible studies to identify whether they met the following inclusion criteria.

\section{Empirical studies based on quantitative survey data}

Only empirical studies based on quantitative survey data were included. We excluded qualitative review studies (e.g., Ryan, 2000), prior domain-specific meta-analytic reviews (e.g., Badaly, 2013), and studies that included only qualitative methods (e.g., Suleiman \& Deardorff, 2015). We excluded dissertations only if the work was subsequently published; in this case, we used the peer-reviewed published study rather than the original dissertation. We also excluded studies in which participants had been exposed to any form of experimental manipulation or intervention program (e.g., Valente et al., 2007), as these may have altered the peer influence effects under examination.

\section{Published in English}


PEER INFLUENCE IN CHILDHOOD AND ADOLESCENCE

Only studies that were published in English were included.

\section{Youth participants}

Studies were excluded if the mean age of participants at baseline was over 18 years.

\section{Community samples}

Given our interest in understanding normative peer influence processes in the context of community settings (e.g., schools), studies were excluded if they examined peer influence in clinical settings (e.g., inpatient treatment).

\section{Longitudinal study designs}

Only longitudinal studies were included that measured target youths' behaviors at two or more time points, and that included an initial time point in which both target and peer behavior were assessed simultaneously. Studies were excluded if they only had a single time point or if they included more than one time point but did not have an initial time point that allowed accounting for the prior similarity between the target youths' and peers' behavior (see point 8 , Necessary statistics provided). Although two-time point studies are sometimes viewed as contributing less information about longitudinal processes than studies with three or more waves of data (Curran \& Bauer, 2011), the inclusion of these studies aligns with most existing peer influence research, which has predominantly focused on examining influence effects across two (consecutive) time points. Moreover, the decision to include two-time point studies also is consistent with previous meta-analytic work utilizing a cross-lagged regression approach (e.g., Khazanov \& Ruscio, 2016; Maes et al., 2019) because with this approach, effect sizes can be computed between any two given assessments (see Effect Sizes Calculation section).

\section{Peer affiliations}




\section{PEER INFLUENCE IN CHILDHOOD AND ADOLESCENCE}

Studies were included only if they used a procedure to identify peer affiliations (e.g., friendships), such that target youths' behaviors could be linked with peers' actual (i.e., not as perceived by the target youth) behaviors. Two main approaches are commonly used to identify peer affiliations, and studies that used either were included. First, the majority of studies use traditional sociometric nomination procedures (see Cillessen \& Bukowski, 2018), in which participants nominate the peers whom they consider to be friends or close peers. Typically, youth are asked to provide or select names of peers in their own school, and often within their own classroom or grade within that school. For example, students may be provided with a roster with all students' names in their classroom or grade, and then asked to nominate the peers whom they consider to be best friends, friends, or peers they often spend time with. Subsequently, the peers' behavior (e.g., best friend's alcohol use, average across all friends' alcohol use), typically as reported by the peers themselves, is linked to the target youth who nominated these peers as affiliates. Most studies included in this meta-analysis used this approach ${ }^{1}$.

A second approach, used by a smaller number of studies, is the Social Cognitive Map (SCM; Cairns et al., 1985) method, in which participants report not only about their own personal peer groups but also about other peer groups they know through everyday interactions and observations (see Kindermann \& Vollet, 2014). For example, youth are asked to identify all existing peer groups in their schools — even the ones they are not part of — by listing all names of each group's members. All participants' nominations are then aggregated in a co-nomination matrix, yielding information about the frequency with which each pair of participants was identified as being part of the same group, from which eventually peer groups are identified via

\footnotetext{
${ }^{1}$ Only a very small number of studies that used procedures to identify peer affiliations directly assessed romantic relationship partners to examine peer influence effects (Simon et al., 2008). Therefore, these studies were excluded as peer influence processes may work differently in these relationships.
} 


\section{PEER INFLUENCE IN CHILDHOOD AND ADOLESCENCE}

statistical tests (Cairns et al., 1985; Kindermann \& Vollet, 2014). Finally, similarly to

sociometric nomination procedures, for each participant, a peer group behavior can be computed by averaging across all group members' behaviors.

Studies that relied on targets' self-reports of their peers' behaviors (i.e., perceptions of peers' behaviors) were excluded. Moreover, studies were also excluded if they measured descriptive peer norms within broad social contexts, such as the classroom or school contexts (e.g., proportion of students who reported drinking in a classroom; Scholte et al., 2012), without directly assessing peer affiliations. Social norms may differ substantially across peer groups within a classroom, and those peer group-specific norms, rather than the broader classroom norms, are expected to be particularly relevant to influence behavior.

\section{Target youth and peer behaviors}

Studies were included if the same behavior was assessed for both the target youths and their peers using the same type of report (e.g., self-report from both target and peer; sociometric ratings of the behaviors of both target and peer; teacher reports on the behavior of both target and peer $)^{2}$. We operationalized behavior as any broad range of behaviors (e.g., substance use), symptoms (e.g., depressive symptoms), and attitudes (e.g., academic motivation), with one category exception: we excluded characterological traits, such as personality traits (e.g., Borghuis et al., 2017). Studies were included if peers' behaviors were operationalized as frequencies or levels (e.g., friends' frequency of tobacco use, friends' levels of academic motivation), as well as the percentage of friends who had engaged in the behavior (e.g., percentage of friends who used tobacco; French, Purwono, \& Rodkin, 2014), as long as the

\footnotetext{
${ }^{2}$ In a small number of studies, the same behavior was measured for both the target youths and peers using the same report type, but it was assessed with slightly different measures. We considered these studies to meet inclusion criteria, in cases where the measures used were highly similar. For example, we included a study by Vitaro et al. (2011), in which teachers rated target adolescents' and friends' aggression using highly overlapping, but not identical, measures of aggressive behavior.
} 
PEER INFLUENCE IN CHILDHOOD AND ADOLESCENCE

targets' and peers' behaviors were assessed in the same manner (e.g., using the same report type).

Studies were excluded if different behaviors were reported for the target versus peer or in cases where different types of reporters provided information about target versus peer behavior, as these measurement differences likely reduced the effect sizes. For example, a study by Vitaro and colleagues was excluded because they assessed the target adolescent's behavior (i.e., delinquent behaviors) via self-report, whereas the peer behavior (i.e., aggressivenessdisturbance) was assessed through sociometric nominations (Vitaro et al., 2000). We also excluded studies in which the target youths' behavior was assessed differently across time (e.g., different report type was used over time). ${ }^{3}$ Finally, we excluded initiation studies (i.e., studies in which participants were only included in the baseline sample if they had previously never engaged in the behavior under investigation), as these studies ask fundamentally different questions about peer influence (e.g., Kandel et al., 1978).

\section{Necessary statistics provided}

Studies were included if they provided three zero-order correlations (or if correlations could be obtained from authors; see Contacting Authors section): (a) between Time 1 target and Time 1 peer behavior (to determine the baseline concurrent association), (b) between Time 1 target and Time 2 target behavior (to determine the stability of the target's behavior over time), and (c) between Time 1 peer and Time 2 target behavior (to determine peer influence over time). We also included studies reporting information sufficient to compute these three correlations; for instance, for a few studies (e.g., Fisher \& Bauman, 1988; Kandel, 1978), correlations could be

\footnotetext{
${ }^{3}$ We considered the behavior to have been consistently measured over time in the rare cases in which a change in the measure was based on developmental considerations. For example, in one study by Goodwin and colleagues, the Children's Depression Inventory (Kovacs, 1992) was used in grade 6 and the Beck Depression Inventory Short Form (Beck \& Beck, 1972) was administered in grades 7 to 11 (Goodwin et al., 2012).
} 
PEER INFLUENCE IN CHILDHOOD AND ADOLESCENCE

computed based on contingency tables of dichotomous variables (see Card, 2012). Moreover, in a minority of cases, the standardized estimate (and associated standard error) representing the effect of peers' behavior at Time 1 on the target behavior at Time 2 was used in the absence of correlations, if it resulted from linear regression models that only adjusted for the target behavior at Time 1 (e.g., Kindermann, 1993), or from path analyses within a longitudinal actor-partner interdependence model (APIM) framework (e.g., Hiatt et al., 2017).

We excluded studies for which (a) a correlation between the target's and peer's behavior at an initial time point was not available, (b) the stability of the target's behavior over time could not be determined, or (c) correlations were not zero-order (i.e., controlled for third variables) or standardized estimates were adjusted for covariates other than the target behavior at Time 1. Although requiring all three zero-order correlations or unadjusted estimates represents rather strict inclusion criteria, limiting analyses to these studies allowed us to provide the most precise estimate of peer influence effects possible and to properly compare effect sizes across studies (Card, 2019). Finally, studies that utilized stochastic actor-based modeling (Snijders et al., 2010) as the analytic approach, a longitudinal social network approach that has become popular among peer influence researchers in the last decade (see, for example, Veenstra et al., 2013), were also excluded, due to several reasons: First, although in these studies peer affiliations are measured, correlations between the target youth and peer behavior are typically not reported and cannot be directly retrieved. The main reason is that in stochastic actor-based models, network data are not reduced at the individual level (i.e., peer affiliations are not used to create an individual-level variable reflecting peer behavior; Steglich et al., 2010), but the whole network of relationship ties is analyzed and linked to behavioral changes over time. Because in these studies a peer behavior variable is not directly available, we also decided not to contact the corresponding 
PEER INFLUENCE IN CHILDHOOD AND ADOLESCENCE

authors to ask for the needed correlations. Furthermore, these models have several basic assumptions that strongly differ from the ones of more traditional analytic techniques. For example, because of the continuous-time assumption (see Snijders et al., 2010), in these models, peer influence effects are estimated through the simulation of unobserved changes occurring between two (or more) discrete time points. Thus, from these models, it is not possible to extract effect sizes that are comparable to the ones derived from more traditional analytic techniques.

\section{Data Extraction and Coding}

Studies were coded for information needed for the computation of effect sizes and moderation analyses. For each report, to compute the effect size, we extracted the three abovementioned correlations (or an equivalent standardized estimate; see point 8 , Necessary statistics provided). Furthermore, we recorded the sample size associated with the longitudinal peer influence effect. In doing so, we used a conservative approach; for example, for each study, we recorded the $n$ that reflected the smallest sample size for longitudinal associations used in analyses (see Card, 2019). Finally, studies were coded on the following moderators, discussed further below: (a) type of behavior, (b) peer relationship type, (c) peer context, (d) mean age, (e) time lag, (f) publication type, (g) publication year, (h) country, (i) gender, (j) ethnicity, and (k) report type. The codebook and coded data are available on the Open Science Framework (https:// osf.io/e9tk5/?view only=c73230f71b4240b48bef5f8a283ce0f1 ).

Each study was coded by Ph.D.-level psychologists (the two first authors). In the first round, the two authors independently double-coded 20 of the studies, with high agreement across all cells (97.9\%). Codes were discussed and discrepancies were resolved through discussion between the two authors. In the second round, the remaining reports were divided across the two 
PEER INFLUENCE IN CHILDHOOD AND ADOLESCENCE

authors, and in regular coding meetings, any questions or concerns from the coding author were discussed with the other author before arriving at a final decision.

We aimed to maximize the number of effect sizes across the broadest possible range of behaviors, and also to maximize the sample sizes for those effect sizes, without including redundant information that would bias our ultimate estimates. To do so, we used multiple strategies. First, if within the same study multiple correlations could be extracted for more than one behavior, we included them all. Second, if studies used multiple waves of data, correlations were extracted across all time points (e.g., Time 1 peer and Time 3 target behavior, Time 2 peer and Time 3 target behavior), whenever they allowed computing additional effect sizes. Finally, if two or more studies used overlapping data from the same study (e.g., the National Longitudinal Study of Adolescent to Adult Health - Add Health), we included both if they yielded unique effect sizes; that is, if either they reported on different behaviors or they focused on different time points. Yet in the case of reports that utilized data from the same study and examined the same behavior (or highly overlapping behaviors) and/or the same time points, we prioritized the report that included the larger sample size and/or the greater number of effect sizes (e.g., more time points), and/or for which correlations could be extracted (see also Contacting Authors section). In cases where the same $n$ was reported, we prioritized peer-reviewed publications over dissertations and reports that had been published earlier over those published more recently.

Contacting authors. If a study did not provide sufficient information for us to code an effect size, we contacted the corresponding author (as well as other authors in cases where the corresponding author's email address was not deliverable). Notably, a large number of reports used data from Add Health, and several of them examined peer influence effects in relation to the same (or highly similar) behaviors. Thus, to maximize the possible $n$ for each effect size, we 


\section{PEER INFLUENCE IN CHILDHOOD AND ADOLESCENCE}

contacted authors in cases where one study reported a larger $n$ for a specific behavior but did not provide sufficient information to calculate the effect size for that behavior (even if that information was available from a study using a smaller $n$ ).

Overall, 61 authors were contacted; 42 responded, of which 22 (36\% of the contacted authors) provided correlations that allowed us to compute additional effect sizes for our metaanalysis. Most authors who declined requests for additional information reported they no longer had access to the data.

Main moderators. We coded five main moderators: type of behavior, peer relationship type, peer context, participants' mean age, and time lag between assessments.

Type of behavior. In our initial coding, we coded each specific type of behavior (see Table 1 for all behaviors), including symptoms (e.g., depressive symptoms) and attitudes (e.g., academic motivation). Subsequently, behaviors were collapsed into three broader categories (i.e., externalizing, internalizing, academic) to allow for moderation analyses (see Results section).

Peer relationship type. Studies were coded based on the type of friendship assessed. This coding originally began with three codes: best friend, friend, and multiple/group of friends. But eventually, the first two codes were combined, resulting in two final codes: close friend and multiple friends. It was difficult to differentiate between the original "best friend" versus "friend" codes due to heterogeneity in how these types of friendships were operationalized and defined for participants. For example, studies' definitions of "best friend" ranged from asking participants to nominate their "very best friend" (e.g., Prinstein, 2017), "best friend" (e.g., Reitz et al., 2006), or "closest friend" (e.g., Allen et al., 2012). Other times, specific friendship definitions were provided for adolescents. For example, in Poulin and colleagues' (1999) study, participants were asked to nominate "the kid with whom you spend the most amount of time" (p. 
PEER INFLUENCE IN CHILDHOOD AND ADOLESCENCE

46), which was defined as "friend." On the other hand, Allen and colleagues (2012) provided this specific example for participants of "closest friend": "people you know well, spend time with and who you talk to about things that happen in your life" (p. 339); and this further detail was provided in the study: "For adolescents who had difficulty naming a closest friend, it was explained that naming their 'closest' friends did not mean that they were necessarily very close to this friends [sic], just that they were close to this friend relative to other acquaintances they might have" (p. 339).

Ultimately, the "close friend" code was used if participants nominated a close friend, best friend, or another type of friend. The "multiple friend" code was used if peer groups were identified (e.g., through social cognitive maps) or if participants nominated more than one friend, whose behaviors were then averaged.

Peer context. Studies were also coded based on the context within which peer affiliations could be identified. We coded the peer context as classroom if nominations were restricted to the participant's class at school (e.g., using a classroom roster); grade if nominations could include anyone within the participant's grade at school (e.g., using a grade-wide roster); school, if nominations could include any student at one's school, regardless of grade (typically involving an open-ended nomination system in which participants provide names; e.g., Hogue \& Steinberg, 1995); or not limited to school, in cases where participants could nominate peers from outside their school (e.g., in some lab-based studies; Poulin et al., 1999). This variable was not coded for studies in which the peer context was not reported, was not clear, or if different groups within the sample had different peer contexts (e.g., classroom nominations for one grade of students and gradewide nominations for another grade; Schwartz-Mette \& Rose, 2012). Importantly, we used all available data from each study in determining the appropriate peer context code. For example, 


\section{PEER INFLUENCE IN CHILDHOOD AND ADOLESCENCE}

some studies used schoolwide nominations but only analyzed data based on friendships within grade (e.g., Birkett \& Espelage, 2015); in these cases, we coded the peer context as gradewide.

Mean age. Mean age at baseline was recorded. If the mean age was not reported, we used reports of the grade to make inferences based on the mean age of children in that grade. For example, in a study conducted in the U.S. in which adolescents were in grade 5 and age was not reported, we used the formula of grade +5.5 to calculate mean age of 10.5 years. Moreover, for multi-wave studies, participants' age was also recorded for the follow-up assessments in which the peers' and target youths' behaviors were concurrently measured, as these assessments served as baseline points to estimate additional effect sizes. For example, in a three-wave study, age at Time 2 was recorded as it provided information to estimate the peer influence effect from Time 2 to Time 3.

Time lag. We recorded months between consecutive waves (e.g., months between Time 1 and Time 2). As discussed above, in cases of multi-wave studies, we coded all possible effect sizes across multiple waves (e.g., Time 1 to Time 3, Time 2 to Time 3), and thus we calculated time lag accordingly (e.g., months between Time 1 and Time 3). This variable was recoded into years for moderation analyses.

Other moderators. We also coded the following additional moderators: publication type, publication year, country, gender, ethnicity, and report type.

Publication type. Reports were coded as peer-reviewed journal articles or dissertations.

Publication year. Year of publication was recorded.

Country. Studies were coded with two-letter country codes as determined by the International Organization for Standardization (see Table 1 for all countries). Subsequently, due to the small number of effect sizes available for some countries, for moderation analyses three 
PEER INFLUENCE IN CHILDHOOD AND ADOLESCENCE

main categories were created, representing the three continents where studies were conducted (i.e., North America, Europe, Asia).

Gender. Proportion of female participants at baseline was recorded.

Ethnicity. Ethnicity was coded in several ways. First, we used a categorical approach to code whether the sample primarily reflected a majority or minority ethnic group within the context of the study's country. If $75 \%$ or more of the sample was from the ethnic majority group of that country, we coded this as majority ethnicity. When $75 \%$ or more of the sample was from an ethnic minority group in that country, we coded it as minority ethnicity. Other studies were coded as mixed ethnicity (for example, if $60 \%$ of the sample was from the ethnic majority group in the country). To maximize our ability to examine ethnicity as a moderator, we drew reasonable conclusions about ethnicity wherever possible; for example, for a sample in China that did not describe the ethnicity of the sample, we assumed the sample was predominantly comprised of youth from the majority ethnicity and used the code majority ethnicity (e.g., Luo, 2001). As only one study was eventually coded as including a minority ethnicity sample, in moderation analyses, majority ethnicity samples were compared to mixed ethnicity samples.

Next, when the relevant information was available, we used a continuous approach to code the percentage of the sample that was White (see also Colich, Rosen, Williams, \& McLaughlin, 2020; van Eldik et al., 2020). Additionally, for studies in the U.S., we coded the percentage of the sample that was African American/Black, Latinx/Hispanic, and Asian American; this was only coded for samples in the U.S., where race/ethnicity was commonly reported using these categories. These variables were used as continuous in analyses.

Report type. We recorded the report type used to assess youth behavior (e.g., self-report, peer-report, teacher-report; see Table 2). 


\section{PEER INFLUENCE IN CHILDHOOD AND ADOLESCENCE}

\section{Effect Sizes Calculation}

To examine peer influence effects over time, a cross-lagged regression approach was used (see also Khazanov \& Ruscio, 2016; Maes et al., 2019; Sowislo \& Orth, 2013). This approach allows for the examination of the effect of peers' behavior on subsequent target youths' behavior (i.e., cross-lagged effect), adjusting for the stability of the target youths' behavior over time and the cross-sectional correlation between the target youths' and peers' behaviors at Time 1. Thus, this approach yields information about whether peers' behavior is associated with changes over time in youths' behavior while controlling for possible selection effects—which are assumed to be accounted for by the initial concurrent association between peers' and youths' behavior (Haynie \& Osgood, 2005). Because of this advantage, cross-lagged approaches have traditionally been the most commonly used to infer peer influence effects in observational (i.e., non-experimental) research with longitudinal data. In this meta-analysis, a standardized regression coefficient, reflecting the cross-lagged effect, was computed for each study using three zero-order correlations (see point 8 , Necessary statistics provided) according to the following equation (Becker, 1992, p. 359):

$\beta_{1}=\frac{r_{y x 1-i r_{y x 2} r_{x 1 \times 2}}}{1-r_{x 1 \times 2}^{2}} i$

In this equation, $\beta_{1}$ represents the standardized regression weight of $\mathrm{X}_{1}$ (i.e., the peers' behavior at Time 1) predicting Y (i.e., the target youths' behavior at Time 2), controlling for the effect of $\mathrm{X}_{2}$ (i.e., the target youths' behavior at Time 1). To compute the sampling variances for the standardized regression coefficients, the formulation presented in Becker $(1992,2009)$ was used. As this calculation requires several steps, a designated R code was utilized (see Fernández, Constantin, Giletta, \& Maes, 2020), which allowed the computation of both the effect sizes representing standardized regression coefficients and their corresponding sampling variances. 


\section{PEER INFLUENCE IN CHILDHOOD AND ADOLESCENCE}

\section{Statistical Analyses}

Two main sets of analyses were conducted. First, to examine the magnitude of peer influence effects across all studies, the average cross-lagged regression coefficient was estimated. Subsequently, moderation analyses were conducted to examine the extent to which the cross-lagged regression coefficients, reflecting peer influence effects, varied as a function of each study moderator, in particular, type of behavior, peer relationship type, peer context, participants' age, and the time lag between assessments.

For the majority of the studies included in this meta-analysis, multiple effect sizes could be extracted based on the same sample: for example, when peer influence was examined for multiple behaviors or across multiple time points (see Data Extraction and Coding section). Thus, these effect sizes were not independent, violating the independence assumption of traditional meta-analytic approaches (i.e., fixed and two-level random-effects models). To deal with data dependency, a multilevel approach was used in combination with the robust variance estimation (RVE) method (Hedges et al., 2010; Tipton, 2015). First, multilevel meta-regression models were estimated, thus allowing the inclusion of multiple effect sizes extracted from the same study by explicitly accounting for the possible dependencies among them (Hox et al., 2002; van den Noortgate et al., 2015). Specifically, a four-level random-effects model was conducted to estimate the average cross-lagged regression effect. In this model, beyond random sampling variance, which is also considered in traditional random-effects meta-analyses (i.e., Level 1; sampling variation of the observed effect sizes around the "true" population effect sizes, based on a function of sample size), three additional sources of variance were estimated. Level 2 reflected the variance between effects sizes based on the same measurement waves within the same study (e.g., effect sizes for alcohol and tobacco use from Time 1 to Time 2, in the same 


\section{PEER INFLUENCE IN CHILDHOOD AND ADOLESCENCE}

study). Level 3 reflected the variance between effects sizes based on different measurement waves within the same study (e.g., effect sizes reflecting peer influence from Time 1 to Time 2 and from Time 2 to Time 3, in the same study). Level 4 reflected between-study variance, that is, the variance between effects sizes from different studies.

Subsequently, the RVE method with small sample adjustment (Tipton, 2015) was used to correct the standard errors a posteriori (Fernández-Castilla et al., 2020; Tipton et al., 2019). A first advantage of applying the RVE method is that by correcting the standard errors of the coefficients in the regression models, it is robust to standard errors that are misestimated, which may arise from the interdependent nature of observations within a sample, a common problem in peer influence research (Laursen, 2005). More importantly, it has been shown that applying the RVE method a posteriori yields confidence intervals that have an adequate Type I error rate, even when models are misspecified (Fernández-Castilla et al., 2020). Thus, inferential tests for the mean and moderating effects were all based on the RVE method, using $t$-statistics with Satterthwaite degrees of freedom and corresponding 95\% confidence intervals (CI).

To estimate the average magnitude of peer influence effects, an unconditional four-level random-effects model was estimated and heterogeneity in the effect sizes was examined. Specifically, we examined how the total variance was decomposed across the four different levels. Because the sampling variance depends on the size of the study, there is no single value available, so the median sampling variance was used for these calculations. Subsequently, conditional models were estimated by including each moderator separately as a predictor in the four-level model. Finally, a multivariate conditional model was conducted in which the effects of the five main moderators (i.e., type of behavior, peer relationship type, peer context, mean age, and time lag) were examined simultaneously, given that the possible correlation between 


\section{PEER INFLUENCE IN CHILDHOOD AND ADOLESCENCE}

moderators may modify their effects. For example, given age differences in some of the behaviors examined (e.g., older youth reporting higher levels of substance use), univariate analyses could yield spurious effects or mask actual ones.

Because some of the studies included in this meta-analysis utilized multi-wave longitudinal designs (e.g., Goodwin et al., 2012; Véronneau et al., 2010), effect sizes were also computed between nonconsecutive time points (e.g., the cross-lagged effect of peers' behavior at Time 1 on youths' own behavior at Time 3; see also Data Extraction and Coding section). This approach maximized the number of included effect sizes and offered the opportunity to better examine the extent to which peer influence effects varied depending on the time lag between assessments. Yet because nonconsecutive time points typically spanned longer periods, including these effect sizes also may have reduced the actual average cross-lagged regression coefficient ${ }^{4}$. To address this issue, we also ran a supplemental set of analyses in which all models, conditional and unconditional, were estimated using only effect sizes calculated between consecutive assessments.

All analyses were conducted in R software (Version 3.6.3; R Core Team, 2020).

Multilevel meta-regression models were estimated with the metafor package (Viechtbauer, 2010), using the restricted maximum likelihood (REML) procedure (Assink \& Wibbelink, 2016), with the effect sizes weighted by the inverse sampling variance. The RVE method was applied using the robumeta package (Fisher et al., 2017) and the clubSandwich package (Pustejovsky, 2018). The R scripts are available on the Open Science Framework (https://osf.io/e9tk5/? view_only $=\mathrm{c} 73230 \mathrm{f} 71 \mathrm{~b} 4240 \mathrm{~b} 48 \mathrm{bef5f8a283ce0f1})$.

\footnotetext{
${ }^{4}$ The inclusion of effect sizes from nonconsecutive time points may have also yielded a somewhat biased representation of the current peer influence field given that most studies, even those using multi-wave designs, estimated peer influence effects only between consecutive time points, which typically spanned 6 or 12 months.
} 


\section{PEER INFLUENCE IN CHILDHOOD AND ADOLESCENCE}

Publication bias. The presence of publication bias was examined in three ways. First, we visually inspected funnel plots. In the absence of publication bias, these plots are shaped as a symmetric funnel, suggesting that as sample size increases, studies converge around the true mean (Sterne et al., 2005). Second, we regressed effect sizes on study weights, by adding the inverse sampling variance of the effect sizes as a moderator to the model. The presence of publication bias is suggested by a significant and sizable association between effect sizes and inverse variance, such that results yielding small effect sizes with small inverse variances (i.e., small sample sizes) are likely to be nonsignificant and less likely to be reported. Third, we examined whether the effect sizes were systematically different in published studies versus unpublished papers (i.e., dissertations). In the absence of publication bias, no differences should be observed, indicating larger effect sizes are not reported in published studies (versus unpublished papers).

\section{Sample Description}

\section{Results}

Overall, 71 reports (62 peer-reviewed articles and 9 dissertations) published between 1978 and $2017(M d n=2010)$ met inclusion criteria and provided information to calculate at least one effect size. The resulting 233 effect sizes $(k)$ derived from 60 independent studies $(n)(M=$ 3.88 effect sizes per study, $S D=9.38, M d n=2$, range $=1-72$ ). These studies were conducted in 10 different countries, approximately half in the U.S. $(n=34)$, with the other studies being conducted in Europe ( $n=15$; e.g., Netherlands, Sweden, and Finland), Canada $(n=6)$, and Asia ( $n=5$; China, Hong Kong, and Indonesia). A total of 47,423 participants ( $M d n=52 \%$ girls) were included in the present analyses, with sample sizes varying from 81 to 9,366 participants across studies. At baseline, the participants' mean age ranged from 3.95 to 16.66 years $(M=$ 12.48 years, $S D=2.55)$. On average, the length of the longitudinal follow-up assessment 
PEER INFLUENCE IN CHILDHOOD AND ADOLESCENCE

between consecutive waves was 13.49 months $(S D=12.01, M d n=12$ months, range $=3-96$ months), with the vast majority of the studies (80\%) examining peer influence effects across a period of 6 or 12 months ( $22.9 \%$ and $57 \%$, respectively). Ultimately, this allowed us to calculate effect sizes across a developmental period spanning from the age of 3.95 to 22 years.

Across studies, externalizing behaviors were most often examined as outcomes of peer influence effects, including problem behavior, substance use (e.g., alcohol, tobacco, and marijuana use), and aggression, followed by internalizing and academic behaviors (see Figure 2). A minority of studies examined different types of outcomes, such as prosocial behaviors $(n=3)$, sexual behaviors $(n=2)$, and weight-related behaviors $(n=2)$. Notably, the 43 studies excluded due to insufficient information to calculate effect sizes examined similar outcomes to the ones examined in this meta-analysis, that is, externalizing behaviors, especially substance use, followed by academic and internalizing outcomes. Table 1 summarizes the main descriptive characteristics of the studies included in this meta-analytic review.

\section{Average and Heterogeneity Peer Influence Effect Size}

Figure $3 \mathrm{~A}$ presents all the extracted 233 effect sizes. The observed cross-lagged effects (i.e., the effect of peers' behavior on subsequent target youths' behavior, controlling for initial similarity in behavior and stability over time) ranged from -0.21 to 0.29 across studies. The unconditional multilevel meta-regression model yielded a weighted mean cross-lagged regression coefficient, $\dot{\beta}=0.08(S E=0.01, p<.001,95 \%$ CI $[0.06 ; 0.09])$. This effect indicates that youths whose peers reported higher levels (or lower levels) of a certain behavior $X$ at baseline reported increases (or decreases) in their own behavior $X$ from baseline to a later time point. 


\section{PEER INFLUENCE IN CHILDHOOD AND ADOLESCENCE}

When examining heterogeneity in the effect sizes, we found significant variation at all levels. Specifically, the median sampling variance was 0.002 and represented $31.77 \%$ of the total variance. The Level 2 variance $\left(0.002, \chi^{2}(1)=70.64, p<.001\right)$ represented $27.17 \%$ of the total variance, suggesting that differences in effect sizes reported within the same wave of a given study were larger than expected based on sampling variance alone. The Level 3 variance $(0.001$, $\left.\chi^{2}(1)=10.76, p=.001\right)$ and the Level 4 variance $\left(0.001, \chi^{2}(1)=31.30, p<.001\right)$ represented $19.68 \%$ and $21.38 \%$ of the total variance, respectively, indicating that there were systematic differences in effect sizes between different measurement waves within the same study as well as between different studies.

As shown in Figure 3B, effect sizes computed using only consecutive waves $(k=155)$ ranged from -0.16 to 0.29 and the unconditional model yielded a mean cross-lagged regression coefficient highly similar to the one estimated based on all the effect sizes, $\dot{\beta}=0.08, S E=0.01$, $p<.001,95 \%$ CI $[0.07 ; 0.09]$.

\section{Moderators of Peer Influence Effects}

Type of behavior. Two approaches were used to examine the moderating role of type of behavior on peer influence effects. First, the primary analyses were conducted comparing peer influence effects across three macro-level behavioral domains, that is, externalizing, internalizing, and academic behaviors. This approach was chosen because, as shown in Figure 2, most studies examined peer influence effects in relation to behaviors that belonged to one of these three domains. Because only a minority of studies examined behaviors that did not fit in any of those domains (e.g., prosocial behaviors, weight-related behaviors), and because these other behaviors were too diverse to be combined in an additional macro-category and too few to be examined separately, those effect sizes were not included in these moderation analyses. These 


\section{PEER INFLUENCE IN CHILDHOOD AND ADOLESCENCE}

moderation analyses indicated that the cross-lagged regression coefficients did not differ across type of behavior, indicating that the magnitude of peer influence effects was similar for externalizing, internalizing, and academic behaviors (see Table 2).

Subsequently, secondary analyses were conducted to estimate effect sizes for more finegrained behavioral domains within each of the three macro-level domains separately. No moderation effect of behavior was found within any of the three domains. Specifically, no moderation effect was found within the externalizing domain, $F(2,138)=1.29, p=.279$, indicating no differences in peer influence effects related to substance use $(k=54, \dot{\beta}=0.09, S E=$ $0.01,95 \% \mathrm{CI}=[0.06,0.12], p<.001)$, problem behavior $(k=31, \dot{\beta}=0.07, S E=0.01,95 \% \mathrm{CI}=$ $[0.04,0.10], p<.001)$, and aggression $(k=56, \dot{\beta}=0.07, S E=0.01,95 \% \mathrm{CI}=[0.03,0.10], p$ $=.002)$. Additionally, within the internalizing domain, no moderation effect was found, $F(1,21)$ $=0.06, p=.811$, when comparing depression $(k=14, \dot{\beta}=0.09, S E=0.02,95 \% \mathrm{CI}=[0.04$, 0.15], $p=.005)$ to other internalizing problems, such as nonsuicidal self-injury and anxiety $(k=$ $9, \dot{\beta}=0.08, S E=0.03,95 \% \mathrm{CI}=[0.01,0.15], p=.028)$. Finally, no moderation was revealed within the academic domain, $F(1,29)=0.46, p=.503$, indicating similar peer influence effects for academic achievement (e.g., GPA; $k=25, \dot{\beta}=0.05, S E=0.02,95 \% \mathrm{CI}=[0.01,0.09], p$ $=.025)$ and academic engagement/motivation $(k=6, \dot{\beta}=0.07, S E=0.02,95 \% \mathrm{CI}=[-0.001$, $0.14], p=.052)$.

Analyses conducted using only effect sizes between consecutive assessments yielded highly similar results to those found using all effect sizes. In sum, the type of behavior examined did not moderate peer influence effects, which emerged to be significant, and similar in size, across all behaviors. 


\section{PEER INFLUENCE IN CHILDHOOD AND ADOLESCENCE}

Peer relationship type. We examined whether the type of peer relationship moderated peer influence effects by comparing effect sizes reflecting the influence of one close friend to those reflecting the influence of multiple friends. No moderation of peer relationship type was revealed, neither with all effect sizes nor with effect sizes computed between consecutive assessments only, indicating that youth were equally influenced by their close friend as by multiple friends ${ }^{5}$ (see Table 2).

Peer context. The moderating effect of peer context was first examined with the classroom context as reference category. An overall significant test was revealed (see Table 2). Post hoc comparisons indicated that peer influence effects were weaker when peer affiliations were restricted to the classroom context, as compared to each of the other contexts (i.e., grade vs. class: $\beta=0.05, S E=0.02,95 \% \mathrm{CI}=[0.01,0.09], p=.022$; school vs. class: $\beta=0.06, S E=0.02$, $95 \% \mathrm{CI}=[0.02,0.10], p=.010$; not limited to school vs. class: $\beta=0.05, S E=0.02,95 \% \mathrm{CI}=$ $[0.01,0.09], p=.016$; see Table 2 for average effect size of each peer context). No differences in the strength of peer influence were found when comparing the other three peer contexts. The same pattern of results emerged when examining only effect sizes computed between consecutive assessments.

Mean age. Two models were conducted to examine the moderating role of participants' age. First, a linear effect of age was examined; this analysis revealed no moderating effect of age (see Table 2 and Figure 4). Furthermore, given the hypothesis that peer influence may peak during early adolescence, a quadratic effect of age was also examined. No quadratic effect of age

\footnotetext{
${ }^{5}$ We also investigated the extent to which studies that used the Social Cognitive Map (SCM; Cairns et al., 1985) method to identify peer affiliations (see point 6 in Method section on inclusion and exclusion criteria) affected our results. With SCM, youth are asked to identify peer groups, including those of which they are not part. Thus, this method may lead to the identification of different peer relationship types (e.g., including also less close and intimate peers), which in turn may result in weaker peer influence effects. However, excluding SCM studies $(n=4 ; k=9)$ from the main analyses yielded an identical cross-lagged regression coefficient, $\beta^{-}=0.07(S E=0.01, p<.001,95 \%$ CI $[0.06 ; 0.09])$ and did not meaningfully modify any of the moderation analyses.
} 
PEER INFLUENCE IN CHILDHOOD AND ADOLESCENCE

was found $(\beta=-0.0002, S E=0.0007,95 \% \mathrm{CI}=[-0.0018,0.0015], p=.808)$. Analyses including only effect sizes computed between consecutive assessments also yielded no significant effects of age. In sum, no evidence emerged supporting age differences in the magnitude of peer influence effects, indicating that the estimated peer influence effect did not differ as a function of age.

Time lag. We examined whether the time lag between assessments, measured in years, moderated peer influence effects. Following the Lag-as-Moderator Meta-Analysis framework (Card, 2019), we included both a linear and a quadratic term for time lag (centered $\left.{ }^{6}\right)$ to examine whether peer influence decreased with time lag (linear) as well as a potential maximum of influence at a particular time lag (quadratic). These analyses revealed a small but significant negative linear effect of time lag (see Table 2), indicating that the estimated cross-lagged regression coefficient decreased when assessments spanned a longer time period (see Figure 5). This finding suggests that peers were more influential when the follow-up assessments occurred within a shorter time frame. The quadratic term for time lag was not significant (see Table 2). Notably, the moderating role of time lag was not examined in the dataset including only effect sizes calculated between consecutive assessments, as the vast majority of these effect sizes (about $86 \%$ ) were computed over a period of 6 or 12 months, thus resulting in very limited variability.

Multivariate Moderation Model. Consistent with the univariate analyses, the multivariate moderation model, in which all five main moderators were simultaneously examined, revealed that only the linear effect of time lag $(\beta=-0.02 S E=0.01,95 \% \mathrm{CI}=[-0.04$, $0.002], p=.034$ ) and peer context (grade vs. class: $\beta=0.05, S E=0.02,95 \% \mathrm{CI}=[0.01,0.08], p$

\footnotetext{
${ }^{6}$ The quadratic term was computed by first centering time lag using the mean time lag weighted by the inverse sampling variance, consistent with the Lag-as-Moderator Meta-Analysis framework (Card, 2019).
} 
PEER INFLUENCE IN CHILDHOOD AND ADOLESCENCE

$=.014$; school vs. class: $\beta=0.05 S E=0.02,95 \% \mathrm{CI}=[0.009,0.09], p=.025$; not limited to

school vs. class: $\beta=0.03, S E=0.02,95 \% \mathrm{CI}=[-0.01,0.08], p=.118)$ significantly predicted the strength of peer influence effects.

Other Moderators. Results from models examining the other moderators are reported in Table 2. These analyses, as well as those conducted using only effect sizes between consecutive assessments, all revealed that none of the additional moderators significantly predicted peer influence effects. Thus, the magnitude of peer influence effects was similar across studies, irrespectively of publication type, publication year, sample characteristics (i.e., country, gender, and ethnicity), and report type of the behavior.

\section{Publication Bias}

Two funnel plots were created and visually inspected, that is, one including all effect sizes and one including only effect sizes computed between consecutive assessments (see Figure 6). Both funnel plots showed approximately a symmetric funnel shape, suggesting no clear signs of publication bias. Testing the moderating effect of the inverse sampling variance yielded nonsignificant results, both when examining all effect sizes together $(\beta=-0.000007, S E=0.000003$, $95 \% \mathrm{CI}=[-0.00003,0.00002], p=.216)$, as well as for effect sizes between consecutive assessments $(\beta=-0.000007, S E=0.000002,95 \% \mathrm{CI}=[-0.00002,0.00001], p=.145)$. The same results emerged in sensitivity analyses that excluded the two effect sizes from the extremely large sample $(N>9,000)$, which could have been overly influential. Finally, effect sizes did not significantly differ according to their publication type, $F(1,231)=0.003, p=.954$, for all effect sizes, and $F(1,153)=0.07, p=.799$, for effect sizes computed between consecutive assessments only. In sum, there was no evidence of publication bias across all three tests, suggesting that 


\section{PEER INFLUENCE IN CHILDHOOD AND ADOLESCENCE}

publication bias in this area of research has no impact on estimates and conclusions reported here.

\section{Discussion}

Popular media, undergraduate textbooks, and empirical reports frequently discuss childhood and adolescence as developmental periods characterized by susceptibility to peer influence, often citing peer influence as a powerful and perhaps ubiquitous process that can substantially alter adaptation and behavioral trajectories. Yet, remarkably no prior study has offered a comprehensive meta-analysis of the peer influence literature among youth. Thus, it has been unknown how peer influence effects compare in strength to other psychological processes that are relevant to child and adolescent development. The purpose of this meta-analysis was to review a large literature that has accumulated for the past half-century to quantify the magnitude of peer influence effects among youth based on the best available methodological designs used in observational research to date. This meta-analytic review offers an important contribution to the literature first by examining the strength of peer influence effects across a wide range of attitudinal and behavioral outcomes, using a rigorous multilevel meta-analytic approach that allowed the inclusion of multiple dependent effect sizes from the same study. Moreover, the effect of potential moderators was examined, focusing particularly on the time lag between measurements in peer influence studies, youths' developmental stage, peer relationship type and context, and a myriad of outcomes that have been examined in prior work. We found a small but significant peer influence effect, which was consistent across a broad range of behaviors. Results provide the most comprehensive and thorough assessment of peer influence among youth to date. 
PEER INFLUENCE IN CHILDHOOD AND ADOLESCENCE

\section{Estimating the Magnitude of Peer Influence Effects}

A primary goal of this study was the use of meta-analytic methods to obtain an omnibus estimate of the magnitude of peer influence effects in youth. Results from 60 independent studies (reported in 71 studies) yielding 233 effect sizes revealed a significant, positive effect $(\dot{\beta}=0.08)$, indicating that youth who have friends endorsing specific attitudes or engaging in specific behaviors are significantly more likely to report increases in these same attitudes and behaviors over time. Importantly, this finding also implies that youth whose friends reported lower endorsement of a behavior/attitude are more likely to report decreases in this behavior/attitude over time (see also Allen et al., 2020). Overall, data revealed no evidence for publication bias in this effect size based on the publication status of each study (e.g., peer-reviewed versus dissertations), funnel plots inspection, and analyses regressing effect sizes on study weights (inverse variances).

These findings are notable because they confirm that even when using rigorous methodological approaches, including longitudinal designs, "external" informants (i.e., other than youths' report of their peers' behavior) to measure peers' behaviors, and statistical procedures that control for youths' own baseline behaviors, significant influence effects are revealed. This significant effect was found to be robust across many types of behavior (e.g., externalizing, internalizing, academic); yet, importantly, despite this effect's broad nature, its magnitude was small and significant heterogeneity emerged in the observed effect sizes. It is hard to compare our estimate to previous longitudinal meta-analytic estimates of peer influence because this is the first comprehensive meta-analysis on this topic, and prior work examined peer influence related to specific outcomes and using different approaches. Yet, it may not be surprising that the peer influence effect that emerged in our work is smaller in magnitude than 


\section{PEER INFLUENCE IN CHILDHOOD AND ADOLESCENCE}

the one revealed in Liu and colleagues' (2017) meta-analysis on adolescents' smoking behavior, given that they examined both actual (i.e., as reported by the peers themselves) and perceived peers' behavior (i.e., target adolescents' reports of their perceptions of peers' behavior). Studies examining prospective associations between youths' self-reported estimations of their peers' behavior and youths' own outcomes have important value within the literature, but they may best be characterized not as a test of peer influence hypotheses, but as a study of social-cognitive processes including youths' perceptions of peers. Our effect size, however, is comparable to the one found in Gallupe and colleagues' (2019) meta-analysis on offending behavior, which revealed a small peer influence effect in studies that used stochastic actor-based models to examine only actual peers' behavior.

Overall, this finding seems to suggest that although peers influence youth engagement in a wide array of behaviors and attitudes (see moderators section), perhaps peer influence effects may not be as powerful as researchers have often assumed. To fully understand the impact and implications of this finding, several considerations should be noted. First, the small effect size may, at least in part, result from the rigorous and conservative approach used to infer peer influence effects. Indeed, prior meta-analyses using the same cross-lagged regression approach often revealed equally small estimates, even between psychological constructs which are assumed to be highly correlated, such as the cross-lagged effect of attachment on substance use (Fairbairn et al., 2018), of positive emotionality on depression (Khazanov et al., 2016), of social anxiety on loneliness (Maes et al., 2019), or of depression on self-esteem (Sowislo \& Orth, 2013). Some researchers have also noted that a cross-lagged approach may be excessively conservative to estimate peer influence effects, as in these models the stability path of youths' behavior over time (i.e., correlation between the youth's behavior at an earlier and later time 


\section{PEER INFLUENCE IN CHILDHOOD AND ADOLESCENCE}

point) tends to be overestimated, thus reducing the possible effect of the peer behavior (Haynie \& Osgood, 2005; McGloin \& Thomas, 2019). Furthermore, it is possible that the stability path itself may in part be the result of peer influence processes; ceiling effects may prevent alreadysimilar friends from becoming more similar over time, such that, eventually, stability in similarity may be a clear marker of continued peer influence (Laursen, 2018). Of note, however, a cross-lagged approach has also been the most commonly used in the peer influence literature to date, and because cross-lagged estimates could be computed from bivariate correlations, this approach allowed us to compare many peer influence studies in which other methodological approaches were utilized.

Second, the conservative effect size estimate may be due to the unique nature of the longitudinal studies included in this literature. For instance, most studies reviewed included long lags (i.e., 6 to 12 months) between the measurement of peers' and youths' own outcomes (see Figure 5), which is significant for several reasons. First, many theories posit peer influence mechanisms that involve dynamic social interaction processes (e.g., imitation, deviancy training, emotional contagion; see Dishion \& Tipsord, 2011) that evolve over very short time frames, suggesting that exposure to peers may have more immediate effects. Second, research indicates that many youth friendships change within a one-year period (see Poulin \& Chan, 2010), suggesting possible differences in the sources of potential friend influence that were unmeasured in these studies. Each of these issues suggests that more fine-grained or perhaps ecologicalmomentary assessment approaches would be useful in future works (Prinstein \& Giletta, 2020; Weerman et al., 2018). Furthermore, while all studies included in this meta-analysis controlled for baseline levels of youths' behavior to account for the extent to which peers' behavior was associated with youths" own behavior over time, the "baseline" assessment most often does not 


\section{PEER INFLUENCE IN CHILDHOOD AND ADOLESCENCE}

reflect a true beginning point for the friendship. As noted above, it is possible that peer influence within these friendships had already occurred prior to the baseline assessment, and youth and their peers were already highly similar at the beginning of the study, thus leaving little room to identify further changes due to influence processes. For example, if a friend influences an adolescent to increase their drinking during middle school, but the study baseline measures this dyad's alcohol use starting in high school, the study may reveal nonsignificant or small peer influence effects for this dyad in which peer influence had previously occurred.

Third, it is possible that whereas some youth influence one another to increase specific risk behaviors or attitudes over time, others could influence one another more positively and lead to decreases in those behaviors or attitudes (e.g., a peer influences their friend to smoke less over time), resulting in an overall "washing out" and reduction in the magnitude of the average effect across youth. Other youth may influence one another in indirect ways that would not be captured through assessing the same behaviors/attitudes over time (e.g., an adolescent whose friends engage in disordered food-related behaviors may begin to exercise excessively). And of course, there are likely a plethora of potential characteristics of individual youth and friendships that affect the magnitude of influence, but which were not assessed with enough frequency across studies to meta-analyze (e.g., each youth's susceptibility to peer influence, differences within the dyad in level of popularity, reciprocated vs. unreciprocated friendships; Bot et al., 2005; Hiatt et al., 2017; Laursen et al., 2012). Indeed, it is possible that within dyads and across dyads, some peers influence their friends more strongly than others. These ideas are consistent with the substantial heterogeneity in the effect sizes observed both within as well as between studies, suggesting that different unexamined methodological, individual and contextual features are 


\section{PEER INFLUENCE IN CHILDHOOD AND ADOLESCENCE}

likely to play a critical role in modifying the extent to which youth are influenced by their peers' behavior.

Finally, we focused on assessing peers' behaviors and attitudes using "external" informants (i.e., other than youths' report of their peers' behavior) as predictors of youths' own behaviors and attitudes, due to evidence that youth often misreport their peers' behavior (e.g., overestimate peers' risk behaviors; Prinstein \& Wang, 2005). Nevertheless, some youths may be more strongly influenced by how they perceive their peers to behave, even if this does not necessarily reflect the actual peer behavior, suggesting more complex modeling of peer influence may be needed in future work. For instance, it may be necessary for investigators to measure both peers' (externally-reported) behavior and adolescents' cognitive awareness of their peers' behavior to adequately reach conclusions regarding peer influence processes.

In summary, we found a small but significant peer influence effect when examining hundreds of effect sizes that included a broad range of behaviors and assessed periods of time that may or may not capture the window of peer influence effects. Given these factors and others, it is likely that our estimate of peer influence effects was a conservative one, which may have resulted in an underestimation of peer influence effects, further increasing our confidence that peers indeed influence one another's behaviors and attitudes over time. Our next goal was to examine whether the size of the peer influence effect would differ across types of behaviors and a range of other moderators.

\section{Examining Peer Influence Moderators}

The examination of effect size moderators revealed surprisingly few statistically significant differences across peer influence effects. The first examined moderator allowed for a consideration of peer influence effects across a range of disparate types of behaviors. Based on 
PEER INFLUENCE IN CHILDHOOD AND ADOLESCENCE

available effect sizes within the literature, it was possible to categorize prior studies into three macro-categories including externalizing behavior (i.e., aggression, problem behavior, substance use), academic outcomes (i.e., motivation, scholastic performance), and internalizing behavior (i.e., depression, self-injury), yet prior work yielded equivocal predictions regarding the relative strength of peer influence effects for each outcome. Interestingly, results from this study revealed no significant differences; significant peer influence effects were observed for all three behavioral outcomes, and effect sizes were remarkably similar. Results are intriguing for several reasons.

First, findings suggest that the process of influence may be more broadly relevant than previously realized. The most commonly studied outcomes in the current set of studies were related to externalizing behaviors, such as aggression, substance use, and deviant behaviors, likely due to characteristics of these behaviors (e.g., visibility, social reward) that, as highlighted in theoretical work, may facilitate influence processes among peers, particularly during adolescence (e.g., Bandura 1971, 1973). Yet our findings revealed that peer influence effects were equally strong across a broad range of behaviors and attitudes, suggesting that youth may be attuned to social processes non-specifically, perhaps attending to social norms or their peers' perspectives in a broader way than previously assumed (e.g., even in the absence of [explicit] social rewards). This idea is consistent with recent neuroscience research suggesting that influence and decision-making in social contexts may be associated not only with neural activity reflecting social rewards processes (e.g., activation of the ventral striatum; Nook et al., 2015; Telzer et al., 2020) but also with the recruitment of social brain regions (e.g., dorsomedial prefrontal cortex; temporoparietal junction). For instance, regions involved in mentalizing 
PEER INFLUENCE IN CHILDHOOD AND ADOLESCENCE

indicate a general orientation and attunement to others (Telzer et al., 2018; van Hoorn et al., 2019).

Moreover, the current findings offer a compelling argument for a substantial expansion of peer influence theories to a much wider array of youth adjustment and adaptation indices. The studies included in our meta-analysis disproportionately focused on externalizing outcomes (e.g., aggression, substance use), with less attention to other critical outcomes that are known to be affected by influence processes (e.g., depressive symptoms), and very little attention to other high-priority risk behaviors, such as weight-related behaviors, sexual-risk behaviors, or safety behaviors (e.g., safe driving, healthy exercise, use of sun protection) that each may be deeply entrenched in youths' interactions with peers. Consideration of a broader range of behaviors and attitudes could be useful not only to fully understand the scope of peer influences but also to help elucidate what mechanisms may be common or discrete to explain why individuals conform. Indeed, far more research has been conducted to understand whether, rather than why peer influence occurs (Brechwald \& Prinstein, 2011). The study of additional outcomes may begin to reveal whether influence processes are relevant only to observable, socially sanctioned, explicitly communicated, or consciously encoded behaviors, or whether far more elusive processes of influence may guide our behavior more strongly than previously realized (Pronin et al., 2007). Similarly, further research may reveal that peer influence processes may be far more complex than previously considered, with some youth engaging in behaviors opposite to those of an exemplar (i.e., anti-conformity), and others influenced to engage in behaviors that are related, but not identical to their peers' (e.g., use of alcohol following exposure to a peer's use of marijuana, referred to as "indirect influence"; Giletta et al., 2013; Gremmen et al., 2019; Sijtsema et al., 2014). Questions such as these are preliminary, requiring far more examination, but may be 
PEER INFLUENCE IN CHILDHOOD AND ADOLESCENCE

prompted by findings from this study suggesting a more consistently strong peer influence effect across a broader range of outcomes than has previously been examined.

Moderator analyses also considered differences in the magnitude of peer influence based on peer relationship type, yet no significant effects were revealed. In other words, youth were equally influenced by their close friend as by multiple friends, despite known differences in intimacy and disclosure that characterize such closer friendships (Bagwell \& Bukowski, 2018). This finding may reflect a phenomenon related to the power of peers more generally (i.e., regardless of closeness in peer relationships) or at least three methodological artifacts in the literature regarding the operationalization and identification of friendships. First, it is common for studies examining the influence of multiple friends to include youths' closest or best friend within this influencer group, which obscures comparisons across studies. Second, close friends were operationalized in a broad range of ways across the studies included in our meta-analysis, including as one's "closest friend," "best friend," or "very best friend." Studies also differed in whether they provided participants with specific definitions of friends or allowed participants to self-define the terms. Finally, studies aiming to capture youths' closest friendships may or may not succeed in identifying the "true best friend," which requires that one's closest friend is available in the nomination pool, and also is an active participant in the study (see Giletta et al., 2011). These findings offer important implications for consistency in future work on peer influence.

Significant moderation effects were revealed for the peer context as a moderator of peer influence effects. Specifically, effects were weaker when peer affiliations were restricted to the classroom context, as compared to studies that allowed for broader nomination contexts (gradewide, school-wide, and not limited to school). This finding was partially consistent with our 


\section{PEER INFLUENCE IN CHILDHOOD AND ADOLESCENCE}

general expectation that peer influence effects would be stronger when peer affiliations were permitted across a broader range of contexts; naturally, the chances of identifying youths' most intimate and influential friends will increase if youth are less restricted in whom they can nominate. But we did not find evidence for our specific hypothesis that peer influence effects would be stronger in studies that allowed for peer affiliations beyond the school context when compared to studies using school-wide and grade-wide nominations. These findings, however, should be interpreted in light of several methodological issues that characterize the study of peer contexts. First, only nine studies included out-of-school nominations; over $85 \%$ of studies examined within-school friendships, likely due to sampling convenience. Second, when these within-school studies allowed for nominations across the full school context, they likely included a large proportion of within-grade nominations, given homophily processes in which children and adolescents tend to befriend peers within their grade (e.g., Schaefer et al., 2011). It is possible that the lack of differences among the beyond-school, school-wide, and grade-wide nomination contexts was partially due to these methodological factors. Future peer influence studies should continue to explore broader contexts, although such studies present the challenge of recruiting and retaining youth and their friends over time without the convenience of schoolbased data collection.

A fourth moderator examined within this study captured potential differences in the developmental stage of youth when peer influence processes were measured. Based on prior work, we had hypothesized that we would observe an effect of age, evident in either an increase in the strength of peer influence effects from childhood to adolescence (i.e., linear effect), or with early adolescence emerging as the peak period of peer influence effects (i.e., curvilinear pattern). Yet our results revealed no linear or curvilinear effects of age on the peer influence 
PEER INFLUENCE IN CHILDHOOD AND ADOLESCENCE

effect sizes, providing no evidence in support of age differences in the magnitude of peer influence effects. This lack of age finding was surprising given developmental empirical evidence showing that (early) adolescents are particularly sensitive to peer cues, more so than both children and adults, have increased social motivation toward their peers, and tend to value and conform to peers' behavior more than to adults' behavior (e.g., Knoll et al., 2015; Somerville et al., 2013). The increased orientation and sensitivity to peers have been related to neurobiological changes that characterize the transition to adolescence (e.g., pubertal maturation; Dahl et al., 2018), and are assumed to adaptively prepare adolescents to form and maintain positive relationships with their peers (Blakemore \& Mills, 2014). For instance, neuroscience models and research suggest that during adolescence, profound structural and functional developments are observed in the social brain network (e.g., temporoparietal junction, superior temporal sulcus), which are posited to underlie adolescents' increased susceptibility to their peers (Blakemore \& Mills, 2014). Other models (e.g., imbalance model; Casey, 2015) emphasize adolescents' heightened reward sensitivity, evident in increased activation of the limbic regions of the brain (e.g., ventral striatum), which in combination with still-developing cognitive control regions, may explain adolescents' engagement in risk-taking behavior, especially when exposed to peers. The fact that evidence from the current meta-analysis is not consistent with this research should, however, be interpreted cautiously and certainly not as a definitive way to reject the possibility of age differences. Indeed, this finding may be due to limited variability in the age range examined in our study (see Figure 4). Unfortunately, few studies meeting our inclusion criteria examined peer influence among pre-pubertal youth (in seven studies, including 17 effect sizes, participants' mean age was below 10 years, which typically delineates the onset of puberty among girls; see Figure 4) and only one study (i.e., one effect size) included participants who at 


\section{PEER INFLUENCE IN CHILDHOOD AND ADOLESCENCE}

baseline were older than 17 years on average, thereby limiting as comprehensive an analysis of developmental effects as is needed. Further consideration of age differences in peer influence effects is an important area for future research.

Last, analysis of moderators supported the hypothesis that the magnitude of effect sizes was greater for studies with a shorter duration between assessment waves. On the one hand, this result indicates that over the course of several years, the influence of peers may fade (see Figure 5), a finding that may not be surprising in light of the considerations discussed above, including the multiple sources of peer influence that youth are likely to encounter and the dynamic nature of peer affiliations. On the other hand, this finding may also suggest that many peer influence processes may be better captured using shorter-term designs. While the shortest time included in our meta-analysis was 3 months, in some cases peer influence may occur within a few weeks, days, or perhaps even minutes following peer exposure.

In future research, it will be critical to determine whether the assessment of shorter time lags in peer influence research may yield stronger effect sizes as well as greater insight into the processes that drive peer influence effects. For instance, results regarding the short-term power of peers also may suggest that youths' behavior is more likely affected by psychological states, rather than traits that are influenced by peer exposure. This idea is consistent with Dishion and colleagues' work on deviancy training (e.g., Dishion et al., 1996; Poulin et al., 1999), revealing that brief interactional patterns, and associated affective states — such as those resulting from behavioral reinforcement following deviant utterances among friends - may be more powerful determinants of peer influence than enduring relationship qualities among peers. Furthermore, peer influence effects may often occur as a result of specific situational circumstances (e.g., emulating peers' behavior to avoid being ridiculed) or opportunities (e.g., absence of adults; see 
PEER INFLUENCE IN CHILDHOOD AND ADOLESCENCE

Weerman et al., 2018). Notably, similar peer influence effects and processes would likely be missed in long-term studies covering several months or years. Of course, in the absence of experimental methods or further research examining short- versus longer-time frames of peer influence, results should be interpreted cautiously, and implications for understanding the mechanisms of peer influence are speculative. This area would be a fruitful direction for future work, which could strongly benefit from technology innovations that allow for capturing these more immediate peer influence effects as they occur in real-time in youths" "real life." For example, with $95 \%$ of teens now having access to smart phones (Schaeffer, 2019), ecological momentary assessment (EMA) methods can be easily employed.

\section{Limitations and Future Directions}

Throughout this discussion, we have highlighted several limitations of the body of work we meta-analyzed, such as long time lags between data collection points, an over-emphasis on externalizing problems, inconsistent definitions of "friendships" that vary across in- and out-ofschool contexts, and a limited number of samples of pre-pubertal children. This review offered several critical directions for future work on peer influence processes discussed above, including the use of EMA data collection approaches that may capture more immediate peer influence effects, the expansion of research to a broader range of outcomes and ages, and a stronger consideration of designs that would allow for the study of mechanisms. Several additional limitations and future directions also are worth considering.

First, although this meta-analysis included only longitudinal studies to predict changes in behaviors over time, it relied solely on observational data; therefore, no causal inferences can be drawn. Although longitudinal observational studies allow the opportunity for improved external validity, the inclusion of behaviors that would be infeasible or unethical to study among youth in 
PEER INFLUENCE IN CHILDHOOD AND ADOLESCENCE

a lab setting (e.g., substance use, self-injury), and the observation of how behaviors develop over time, experimental studies remain fundamental to inferring causality as well as to providing essential information about peer influence processes (e.g., Chein et al., 2011; Cohen \& Prinstein, 2006; Gardner \& Steinberg, 2005; Gommans et al., 2017; Sherman et al., 2016).

Additionally, as some researchers have emphasized (Allen et al., 2020; Berndt and Murphy, 2002), most analytic techniques used to infer peer influence effects, including the crosslagged approach utilized in this meta-analysis, do not directly allow us to tease apart the direction of peer influence effects. Rather, these effects indicate whether peers' behavior is associated with changes over time in youth behavior (or that youths become more similar to one other over time) - but does not necessarily mean increases in behavior. Future observational studies of peer influence in naturalistic settings should attempt to address this issue, for instance, by utilizing analytic techniques that allow the modeling of intra-individual changes over multiple time points.

Furthermore, it is important to note that our stringent inclusion criteria required the computation of unadjusted effects (i.e., without the influence of covariates). This methodological decision was necessary to ensure the precise estimation of peer influence effects and to allow the comparisons of effect sizes across studies. This decision resulted in the inclusion of fewer studies, and, more importantly, it remains unknown to what extent peer influence effects hold when accounting for other relevant third factors.

Moreover, many of the correlations and estimates used to compute the cross-lagged effects were likely based on interdependent data, thus violating the independence assumption required by traditional techniques, including the cross-lagged regression approach used in this meta-analysis. This problem is common in peer influence research; within close social 
PEER INFLUENCE IN CHILDHOOD AND ADOLESCENCE

relationships, such as friendships, observations are inherently interdependent because in these relationships, individuals reciprocally influence each other's behavior (Laursen, 2005). Although ignoring data dependency is unlikely to affect the size of the estimates, it may result in a bias in significance testing (Kenny, 1995). Specifically, because youths' and their friends' behavior tend to be positively correlated, such bias may yield an inflated Type II error, thus resulting in a more conservative significance test (Kenny, 1995). The use of the RVE method to correct the standard errors a posteriori (Fernández-Castilla et al., 2020; Tipton et al., 2019) likely limited this problem in the current meta-analyses. But a more substantial issue is that by neglecting, or attempting to overcome interdependence, peer influence processes are often overly simplified as being unidirectional processes. For instance, by considering the individual as the unit of analyses, some participants are randomly assigned to be the target of influence and others (i.e., their peers) the sources of influence, failing to capture the reciprocal nature of peer influence processes. Thus, it should be acknowledged that, whenever possible, future peer influence studies should prioritize the use of analytic approaches that allow the modeling of interdependent data, such as longitudinal APIM (for dyadic analyses; Cook \& Kenny, 2005) and stochastic actor-based modeling (for social network analyses; Snijders et al., 2010).

Related to this point, studies that used stochastic actor-based modeling could not be included, as discussed in the method section. In the last decade, these models have been widely employed to examine peer influence (e.g., Veenstra et al., 2013), as they offer a sophisticated approach to estimate influence effects within the entire social network by modeling the coevolution of network dynamics (e.g., friendship relationships) and behavioral dynamics (e.g., youths' behavior) over time. Not only do stochastic actor-based models allow the modeling of interdependent data, but they also offer several other important advantages; for instance, this 


\section{PEER INFLUENCE IN CHILDHOOD AND ADOLESCENCE}

approach allows the estimation of peer influence effects while accounting for possible selection and structural network effects (e.g., reciprocity, transitivity). Unfortunately, this approach also presents limitations; in most prior work utilizing stochastic actor-based models, estimates across time points are collapsed, outcomes must be categorized as ordinal discrete variables (see Snijders et al., 2010), and effect sizes that are comparable to other analytic approaches cannot be extracted, as discussed in the method section. Nevertheless, the exclusion of these studies resulted in the omission of an important part of the peer influence literature. It is encouraging to note similarities between findings from this meta-analysis and prior meta-analytic work on stochastic actor-based models (Gallupe et al., 2019), suggesting that this work did not result in a biased peer influence estimate. Moreover, although stochastic actor-based models have been suggested to offer a more conservative way to estimate peer influence effects, recent work suggests that traditional analytic techniques do not seem to yield more biased peer influence estimates than stochastic actor-based models do (Ragan et al., 2019).

Additionally, as with many topics in psychological science, our review of the literature revealed a relatively limited number of investigations in non-Western countries and with nonWhite populations. Future work may benefit by diversifying the populations examined, as, for example, the study of cultural differences, perhaps particularly within collectivistic societies (Liu et al., 2017), may yield important insights regarding how conformity and social norms processes occur.

Finally, with an increasing number of peer interactions now occurring online, it is critically important to understand how peer influence occurs through social media (see ChoukasBradley \& Nesi, 2020 for a review). Preliminary work has highlighted the potential for peer 
PEER INFLUENCE IN CHILDHOOD AND ADOLESCENCE

influence to occur via social media (Nesi et al., 2017; Sherman et al., 2016) in exciting and compelling ways, yet this field of research is in its infancy.

\section{Practical Implications and Conclusions}

Findings from this meta-analysis have several practical implications. Perhaps most fundamentally, findings suggest that to understand youths' behavior, it is critical to consider and measure peers' behavior. This idea appears to be true across a wide range of behaviors and age groups, with important implications for peer relations researchers, educators, interventionists, and policymakers hoping to change behavior.

Yet, it may be shortsighted to infer from these results that peers solely introduce risk for adaptive youth development or that children and adolescents should be shielded from their peers. Indeed, peer conformity is a normative and developmentally adaptive process reflecting youths' ability to encode social norms, contribute to peer group values, and rapidly adapt their attitudes or behavior; note that these advantages have been cited within developmental, neurocognitive, and evolutionary literatures as attributes that promoted the success of the human species (Prinstein \& Giletta, 2020). Establishing autonomy from adults and demonstrating responsivity to social rewards (Blakemore, 2018; Ellis et al., 2012) also reflect developmental competencies. Understanding how to leverage these adaptive skills to promote healthy and prosocial behavior will be an important future direction for researchers interested in peer influence processes (see Chung et al., 2020).

Overall, findings from this study provide a comprehensive synthesis and meta-analysis of peer influence effects among youth, revealing a small but significant and robust effect for peer influence processes across a broad range of behaviors and attitudes. These findings offer an opportunity for investigators to move beyond examinations attempting to establish evidence of 
PEER INFLUENCE IN CHILDHOOD AND ADOLESCENCE

peer influence effects, and instead to more thoroughly explore when, for whom, and under what conditions peer influence may be most likely to occur. 
PEER INFLUENCE IN CHILDHOOD AND ADOLESCENCE

\section{References}

The references with an asterisk indicate studies included in the meta-analysis.

Abrams, D., \& Hogg, M. A. (1990). Social identity theory: Constructive and critical advances. London, UK: Harvester Wheatsheat.

*Adams, R. E., Bukowski, W. M., \& Bagwell, C. (2005). Stability of aggression during early adolescence as moderated by reciprocated friendship status and friend's aggression. International Journal of Behavioral Development, 29(2), 139-145. https://doi.org/10.1080/01650250444000397

Albert, D., Chein, J., \& Steinberg, L. (2013). The teenage brain: Peer influences on adolescent decision making. Current Directions in Psychological Science, 22(2), 114-120. https://doi.org/10.1177/0963721412471347

*Allen, J. P., Chango, J., \& Szwedo, D. (2014). The adolescent relational dialectic and the peer roots of adult social functioning. Child Development, 85(1), 192-204. https://doi.org/10.1111/cdev.12106

*Allen, J. P., Chango, J., Szwedo, D., Schad, M., \& Marston, E. (2012). Predictors of susceptibility to peer influence regarding substance use in adolescence. Child Development, 83(1), 337-350. https://doi.org/10.1111/j.1467-8624.2011.01682.x

Allen, J. P., Loeb, E. L., Kansky, J., \& Davis, A. A. (2020). Beyond susceptibility: Openness to peer influence is predicted by adaptive social relationships. International Journal of Behavioral Development. https://doi.org/10.1177/0165025420922616

Allen, J. P., Porter, M. R., \& McFarland, F. C. (2006). Leaders and followers in adolescent close friendships: Susceptibility to peer influence as a predictor of risky behavior, friendship 
PEER INFLUENCE IN CHILDHOOD AND ADOLESCENCE

instability, and depression. Development and Psychopathology, 18(1), 155-172.

https://doi.org/10.1017/S0954579406060093

Allen, J. P., Porter, M. R., McFarland, F. C., Marsh, P., \& McElhaney, K. B. (2005). The two faces of adolescents' success with peers: Adolescent popularity, social adaptation, and deviant behavior. Child Development, 76(3), 747-760. https://doi.org/10.1111/j.14678624.2005.00875.x

*Altermatt, E. R., \& Pomerantz, E. M. (2003). The development of competence-related and motivational beliefs: An investigation of similarity and influence among friends. Journal of Educational Psychology, 95(1), 111-123. https://doi.org/10.1037/0022-0663.95.1.111

Assink, M., \& Wibbelink, C. (2016). Fitting three-level meta-analytic models in R: A step-bystep tutorial. The Quantitative Methods for Psychology, 12(3), 154-174. https://doi.org/10.20982/tqmp.12.3.p154

Badaly, D. (2013). Peer similarity and influence for weight-related outcomes in adolescence: A meta-analytic review. Clinical Psychology Review, 33(8), 1218-1236. https://doi.org/10.1016/j.cpr.2013.09.003

Bagwell, C. L., \& Bukowski, W. M. (2018). Friendship in childhood and adolescence: Features, effects, and processes. In W. M. Bukowski, B. Laursen \& K. H. Rubin (Eds.), Handbook of peer interactions, relationships, and groups ( $2^{\text {nd }}$ ed.), pp. 371-390. The Guilford Press, New York, NY.

Bandura, A. (1971). Vicarious and self-reinforcement processes. In R. Glaser (Ed.), The nature of reinforcement (pp. 228-278). Academic Press.

Bandura, A. (1973). Aggression: A social learning analysis. Prentice-Hall. 
62

PEER INFLUENCE IN CHILDHOOD AND ADOLESCENCE

Bandura, A. (1977). Social learning theory. Prentice-Hall. https://doi.org/10.1177/105960117700200317

Beck, A. T., \& Beck, R. W. (1972). Screening depressed patients in family practice. Postgraduate Medicine, 52(6), 81-85. https://doi.org/10.1080/00325481.1972.11713319

Becker, B. J. (1992). Using results from replicated studies to estimate linear models. Journal of Educational Statistics, 17(4), 341-362. https://doi.org/10.3102/10769986017004341

Becker, B. J. (2009). Model-based meta-analysis. In H. Cooper, L. V. Hedges, \& J. C. Valente (Eds.), The handbook of research synthesis and meta-analysis (2nd ed., pp. 377-395). New York, NY: SAGE.

Berger, S., Christandl, F., Bitterlin, D., \& Wyss, A. M. (2019). The social insectivore: Peer and expert influence affect consumer evaluations of insects as food. Appetite, 141, 104338. https://doi.org/10.1016/j.appet.2019.104338

Berndt, T. J., \& Murphy, L. M. (2002). Influences of friends and friendships: Myths, truths, and research recommendations. In R. V. Kail (Ed.), Advances in child development and behavior (Vol. 30, pp. 275-310). Academic Press.

*Birkett, M., \& Espelage, D. L. (2015). Homophobic name-calling, peer-groups, and masculinity: The socialization of homophobic behavior in adolescents. Social Development, 24(1), 184-205. https://doi.org/10.1111/sode.12085

Blakemore, S.-J. (2018). Avoiding social risk in adolescence. Current Directions in Psychological Science, 27(2), 116-122. https://doi.org/10.1177/0963721417738144

Blakemore, S.-J., \& Mills, K. L. (2014). Is adolescence a sensitive period for sociocultural processing? Annual Review of Psychology, 65, 187-207. https://doi.org/10.1146/annurevpsych-010213-115202 
PEER INFLUENCE IN CHILDHOOD AND ADOLESCENCE

Blanton, H., Köblitz, A., \& McCaul, K. D. (2008). Misperceptions about norm misperceptions: Descriptive, injunctive, and affective 'social norming' efforts to change health behaviors. Social and Personality Psychology Compass, 2(3), 1379-1399.

https://doi.org/10.1111/j.1751-9004.2008.00107.x

Borghuis, J., Denissen, J., Oberski, D., Sijtsma, K., Meeus, W., Branje, S., \& Bleidorn, W. (2017). Big five personality stability, change, and codevelopment across adolescence and early adulthood. Journal of Personality and Social Psychology, 113(4), 641-657. https:// doi.org/10.1037/pspp0000138

Bot, S. M., Engels, R. C. M. E., Knibbe, R. A., \& Meeus, W. H. (2005). Friend's drinking behaviour and adolescent alcohol consumption: The moderating role of friendship characteristics. Addictive Behaviors, 30(5), 929-947.

https://doi.org/10.1016/j.addbeh.2004.09.012

Brechwald, W. A., \& Prinstein, M. J. (2011). Beyond homophily: A decade of advances in understanding peer influence processes. Journal of Research on Adolescence, 21(1), 166179. https://doi.org/10.1111/j.1532-7795.2010.00721.x

*Brendgen, M., Vitaro, F., \& Bukowski, W. M. (2000). Stability and variability of adolescents' affiliation with delinquent friends: Predictors and consequences. Social Development, 9(2), 205-225. https://doi.org/10.1111/1467-9507.00120

Brown, B. B., Bakken, J. P., Ameringer, S. W., \& Mahon, S. D. (2008). A comprehensive conceptualization of the peer influence process in adolescence. In M. J. Prinstein \& K. A. Dodge (Eds.), Understanding peer influence in children and adolescents. (pp. 17-44). The Guilford Press. 
PEER INFLUENCE IN CHILDHOOD AND ADOLESCENCE

Byrne, D. (1961). Interpersonal attraction and attitude similarity. The Journal of Abnormal and Social Psychology, 62(3), 713-715. https://doi.org/10.1037/h0044721

Cairns, R. B., Perrin, J. E., \& Cairns, B. D. (1985). Social structure and social cognition in early adolescence: Affiliative patterns. Journal of Early Adolescence, 5(3), 339-355. https://doi.org/10.1177/0272431685053007

Card, N. A. (2012). Applied meta-analysis for social science research. The Guilford Press.

Card, N. A. (2019). Lag as moderator meta-analysis: A methodological approach for synthesizing longitudinal data. International Journal of Behavioral Development, 43(1), 80-89. https://doi.org/10.1177/0165025418773461

Casey, B. J. (2015). Beyond simple models of self-control to circuit-based accounts of adolescent behavior. Annual Review of Psychology, 66, 295-319. https://doi.org/10.1146/ annurev-psych-010814-015156

Chein, J., Albert, D., O'Brien, L., Uckert, K., \& Steinberg, L. (2011). Peers increase adolescent risk taking by enhancing activity in the brain's reward circuitry. Developmental Science, 14(2), F1-10. https://doi.org/10.1111/j.1467-7687.2010.01035.x

Choukas-Bradley, S., \& Nesi, J. (2020). Applying developmental theory to adolescent peer influence processes in the social media context. In N. V. Zalk \& C. Monks (Eds.), Online peer engagement in adolescence: Positive and negative aspects of online social interaction. Routledge. https://doi.org/10.4324/9780429468360-9

Choukas-Bradley, S., Giletta, M., Cohen, G. L., \& Prinstein, M. J. (2015). Peer influence, peer status, and prosocial behavior: An experimental investigation of peer socialization of adolescents' intentions to volunteer. Journal of Youth Adolescence, 44(12), 2197-2210. https://doi.org/10.1007/s10964-015-0373-2 


\section{PEER INFLUENCE IN CHILDHOOD AND ADOLESCENCE}

Christakis, N. A., \& Fowler, J. H. (2007). The spread of obesity in a large social network over 32 years. New England Journal of Medicine, 357(4), 370-379. https://doi.org/10.1056/NEJMsa066082

Chung, D., Orloff, M. A., Lauharatanahirun, N., Chiu, P. H., \& King-Casas, B. (2020). Valuation of peers' safe choices is associated with substance-naïveté in adolescents. Proceedings of the National Academy of Sciences, 117(50), 31729-31737.

Cillessen, A. H. N., \& Bukowski, W. M. (2018). Sociometric perspectives. In W. M. Bukowski, B. Laursen, \& K. H. Rubin (Eds.), Handbook of peer interactions, relationships, and groups (2nd ed., pp. 64-83). The Guilford Press.

Cohen, G. L., \& Prinstein, M. J. (2006). Peer contagion of aggression and health risk behavior among adolescent males: An experimental investigation of effects on public conduct and private attitudes. Child Development, 77(4), 967-983. https://doi.org/10.1111/j.14678624.2006.00913.x

Cohen, J. (1977). Sources of peer group homogeneity. Sociology of Education, 50(4), 227-241. https://doi.org/10.2307/2112497

Colich, N. L., Rosen, M. L., Williams, E. S., \& McLaughlin, K. A. (2020). Biological aging in childhood and adolescence following experiences of threat and deprivation: A systematic review and meta-analysis. Psychological Bulletin, 146(9), 721-764.

*Conway, C. C., Rancourt, D., Adelman, C. B., Burk, W. J., \& Prinstein, M. J. (2011). Depression socialization within friendship groups at the transition to adolescence: The roles of gender and group centrality as moderators of peer influence. Journal of Abnormal Psychology, 120(4), 857-867. https://doi.org/10.1037/a0024779 


\section{PEER INFLUENCE IN CHILDHOOD AND ADOLESCENCE}

Cook, W. L., \& Kenny, D. A. (2005). The actor-partner interdependence model: A model of bidirectional effects in developmental studies. International Journal of Behavioral Development, 29(2), 101-109. https://doi.org/10.1080/01650250444000405

Coyne, J. C. (1976). Toward an interactional description of depression. Psychiatry, 39(1), 28-40. https://doi.org/10.1080/00332747.1976.11023874

Curran, P. J., \& Bauer, D. J. (2011). The disaggregation of within-person and between-person effects in longitudinal models of change. Annual Review of Psychology, 62, 583-619.

Dahl, R. E., Allen, N. B., Wilbrecht, L., \& Suleiman, A. B. (2018). Importance of investing in adolescence from a developmental science perspective. Nature, 554(7693), 441-450. https://doi.org/10.1038/nature25770

D'Amico, E., \& McCarthy, D. (2006). Escalation and initiation of younger adolescents' substance use: The impact of perceived peer use. Journal of Adolescent Health, 39(4), 481-487. https://doi.org/10.1016/j.jadohealth.2006.02.010

*Dawes, M. (2014). Peer influence in early adolescents' popularity goal (Publication No. 3623137) [Doctoral dissertation, Temple University]. ProQuest LLC.

*de Kemp, R. A. T., Scholte, R. H. J., Overbeek, G., \& Engels, R. C. M. E. (2006). Early adolescent delinquency: The role of parents and best friends. Criminal Justice and Behavior, 33(4), 488-510. https://doi.org/10.1177/0093854806286208

*DeLay, D., Laursen, B., Kiuru, N., Poikkeus, A. M., Aunola, K., \& Nurmi, J. E. (2015). Stable same-sex friendships with higher achieving partners promote mathematical reasoning in lower achieving primary school children. British Journal of Developmental Psychology, 33(4), 519-532. https://doi.org/10.1111/bjdp.12117 
PEER INFLUENCE IN CHILDHOOD AND ADOLESCENCE

*Deutsch, A. R., Chernyavskiy, P., Steinley, D., \& Slutske, W. S. (2015). Measuring peer socialization for adolescent substance use: A comparison of perceived and actual friends' substance use effects. Journal of Studies on Alcohol and Drugs, 76(2), 267-277. https://doi.org/10.15288/jsad.2015.76.267

Dishion, T. J., \& Tipsord, J. M. (2011). Peer contagion in child and adolescent social and emotional development. Annual Review of Psychology, 62, 189-214. https://doi.org/10.1146/annurev.psych.093008.100412

Dishion, T. J., Spracklen, K. M., Andrews, D. W., \& Patterson, G. R. (1996). Deviancy training in male adolescent friendships. Behavior Therapy, 27(3), 373-390. https://doi.org/10.1016/S0005-7894(96)80023-2

*Donohew, R. L., Hoyle, R. H., Clayton, R. R., Skinner, W. F., Colon, S. E., \& Rice, R. E. (1999). Sensation seeking and drug use by adolescents and their friends: Models for marijuana and alcohol. Journal of Studies on Alcohol, 60(5), 622631. https://doi.org/10.15288/jsa.1999.60.622

*Dulli, L. S. (2006). Primary socialization theory and bullying: The effects of primary sources of socialization on bullying behaviors among adolescents [Unpublished doctoral dissertation]. University of North Carolina at Chapel Hill.

Ellis, B. J., Del Giudice, M., Dishion, T. J., Figueredo, A. J., Gray, P., Griskevicius, V., Hawley, P. H., Jacobs, W. J., James, J., Volk, A. A., \& Wilson, D. S. (2012). The evolutionary basis of risky adolescent behavior: Implications for science, policy, and practice. Developmental Psychology, 48(3), 598-623. https://doi.org/10.1037/a0026220 


\section{PEER INFLUENCE IN CHILDHOOD AND ADOLESCENCE}

*Ellis, W. E., \& Zarbatany, L. (2007). Peer group status as a moderator of group influence on children's deviant, aggressive, and prosocial behavior. Child Development, 78(4), 1240 1254. https://doi.org/10.1111/j.1467-8624.2007.01063.x

Engels, R. C. M. E., Knibbe, R. A., Vries, H. D., Drop, M. J., \& van Breukelen, G. J. P. (1999). Influences of parental and best friends' smoking and drinking on adolescent use: A longitudinal study. Journal of Applied Social Psychology, 29(2), 337-361. https://doi.org/ 10.1111/j.1559-1816.1999.tb01390.x

Epple, D., \& Romano, R. E. (1998). Competition between private and public schools, vouchers, and peer-group effects. The American Economic Review, 88(1), 33-62. Retrieved from www.jstor.org/stable/116817

*Erickson, K. G., Crosnoe, R., \& Dornbusch, S. M. (2000). A social process model of adolescent deviance: Combining social control and differential association perspectives. Journal of Youth and Adolescence, 29(4), 395-425. https://doi.org/10.1023/A:1005163724952

Fairbairn, C. E., Briley, D. A., Kang, D., Fraley, R. C., Hankin, B. L., \& Ariss, T. (2018). A meta-analysis of longitudinal associations between substance use and interpersonal attachment security. Psychological Bulletin, 144(5), 532-555. https://doi.org/10.1037/bul0000141

Fernández-Castilla, B., Aloe, A. M., Declercq, L., Jamshidi, L., Beretvas, S. N., Onghena, P., \& Van den Noortgate, W. (2020). Estimating outcome-specific effects in meta-analyses of multiple outcomes: A simulation study. Behavior Research Methods, 1-16.

Fernández, B., Constantin, M. A., Giletta, M., \& Maes, M. (2020, November 11). Cross-Lagged Effects and Corresponding Sampling Variances. https://doi.org/10.17605/OSF.IO/XFWN5 


\section{PEER INFLUENCE IN CHILDHOOD AND ADOLESCENCE}

Festinger, L. (1954). A theory of social comparison processes. Human Relations, 7, 117 - 140.

*Fisher, L. A., \& Bauman, K. E. (1988). Influence and selection in the friend-adolescent relationship: Findings from studies of adolescent smoking and drinking. Journal of Applied Social Psychology, 18(4, Pt 2), 289-314. https://doi.org/10.1111/j.15591816.1988.tb00018.x

Fisher, Z., Tipton, E.,\& Zhipeng, H. (2017). Robumeta: Robust Variance Meta-Regression. R package version 2.0. https://CRAN.R-project.org/package=robumeta

*French, D. C., Purwono, U., \& Rodkin, P. (2014). Indonesian Muslim adolescents' use of tobacco and alcohol: Associations with use by friends and network affiliates. MerrillPalmer Quarterly, 60(4), 385-

402. https://doi.org/10.13110/merrpalmquar1982.60.4.0385

*French, D. C., Purwono, U., \& Triwahyuni, A. (2011). Friendship and the religiosity of Indonesian Muslim adolescents. Journal of Youth and Adolescence, 40(12), 1623-1633. https://doi.org/10.1007/s10964-011-9645-7

Gallupe, O., McLevey, J., \& Brown, S. (2019). Selection and influence: A meta-analysis of the association between peer and personal offending. Journal of Quantitative Criminology, 35, 313-335. https://doi.org/10.1007/s10940-018-9384-y

Gardner, M., \& Steinberg, L. (2005). Peer influence on risk taking, risk preference, and risky decision making in adolescence and adulthood: An experimental study. Developmental Psychology, 41(4), 625-635. doi:http://dx.doi.org/10.1037/0012-1649.41.4.625

Gibbons, F. X., Gerrard, M., \& Lane, D. J. (2003). A social reaction model of adolescent health risk. In J. M. Suls \& K. Wallson (Eds.), Social psychological foundations of health and illness (pp. 107-136). Oxford, UK: Blackwell. 


\section{PEER INFLUENCE IN CHILDHOOD AND ADOLESCENCE}

Gibbons, F. X., Helweg-Larsen, M., \& Gerrard, M. (1995). Prevalence estimates and adolescent risk behavior: Cross-cultural differences in social influence. Journal of Applied Psychology, 80(1), 107-121. https://doi.org/10.1037/0021-9010.80.1.107

Giletta, M., Burk, W. J., Scholte, R. H. J., Engels, R. C. M. E., \& Prinstein, M. J. (2013). Direct and indirect peer socialization of adolescent nonsuicidal self-injury. Journal of Research on Adolescence, 23(3), 450-463. https://doi.org/10.1111/jora.12036

*Giletta, M., Scholte, R. H. J., Burk, W. J., Engels, R. C. M. E., Larsen, J. K., Prinstein, M. J., \& Ciairano, S. (2011). Similarity in depressive symptoms in adolescents' friendship dyads: Selection or socialization? Developmental Psychology, 47(6), 1804-1814. https://doi.org/ $10.1037 / \mathrm{a} 0023872$

Gilleskie, D., \& Zhang, S. (2009). Friendship formation and smoking initiation among teens (Working Paper). Retrieved from http://citeseerx.ist.psu.edu/viewdoc/download? doi $=10.1 .1 .496 .7307 \&$ rep $=$ rep1\&type $=$ pdf

Gommans, R., Sandstrom, M. J., Stevens, G. W., ter Bogt, T. F., \& Cillessen, A. H. N. (2017). Popularity, likeability, and peer conformity: Four field experiments. Journal of Experimental Social Psychology, 73, 279-289. https://doi.org/10.1016/j.jesp.2017.10.001

*Goodwin, N. P., Mrug, S., Borch, C., \& Cillessen, A. H. N. (2012). Peer selection and socialization in adolescent depression: The role of school transitions. Journal of Youth and Adolescence, 41(3), 320-332. https://doi.org/10.1007/s10964-011-9723-x

Gottfredson, M., \& Hirschi, T. (1987). The methodological adequacy of longitudinal research on crime. Criminology, 25(3), 581-614. https://doi.org/10.1111/j.1745-9125.1987.tb00812.x

Gremmen, M. C., Berger, C., Ryan, A. M., Steglich, C. E. G., Veenstra, R., \& Dijkstra, J. K. (2019). Adolescents' friendships, academic achievement, and risk behaviors: Same- 


\section{PEER INFLUENCE IN CHILDHOOD AND ADOLESCENCE}

behavior and cross-behavior selection and influence processes. Child Development, 90(2), e192-e211. https://doi.org/10.1111/cdev.13045

*Güroğlu, B., Cillessen, A. H. N., Haselager, G. J. T., \& van Lieshout, C. F. M. (2012). “Tell me who your friends are and I'll tell you who your friends will be": Consistency and change in social competence in adolescent friendships across school transitions. Journal of Social and Personal Relationships, 29(7), 861-

\section{3. https://doi.org/10.1177/0265407512448272}

*Hall, J. A., \& Valente, T. W. (2007). Adolescent smoking networks: The effects of influence and selection on future smoking. Addictive Behaviors, 32(12), 3054-3059. https://doi.org/ 10.1016/j.addbeh.2007.04.008

*Halliday-Scher, K. (2000). A model of parent and friend relationship effects on adolescent substance use (Publication No. 9966143) [Doctoral dissertation, Wayne State University]. Bell \& Howell Information and Learning.

Harter, S., Stocker, C., \& Robinson, N. (1996). The perceived directionality of the link between approval and self-worth: The liabilities of a looking glass self-orientation among young adolescents. Journal of Research on Adolescence, 6(3), 285-308.

Haun, D. B., \& Tomasello, M. (2011). Conformity to peer pressure in preschool children. Child Development, 82(6), 1759-1767. https://doi.org/10.1111/j.1467-8624.2011.01666.x

Haynie, D. L. (2001). Delinquent peers revisited: Does network structure matter? American Journal of Sociology, 106(4), 1013-1057. https://doi.org/10.1086/320298

Haynie, D. L., \& Osgood, D. W. (2005). Reconsidering peers and delinquency: How do peers matter? Social Forces, 84(2), 1109-1130. https://doi.org/10.1353/sof.2006.0018 


\section{PEER INFLUENCE IN CHILDHOOD AND ADOLESCENCE}

Hedges, L. V., Tipton, E., \& Johnson, M. C. (2010). Robust variance estimation in metaregression with dependent effect size estimates. Research Synthesis Methods, 1(1), 39-65.

Helms, S. W., Choukas-Bradley, S., Widman, L., Giletta, M., Cohen, G. L., \& Prinstein, M. J. (2014). Adolescents misperceive and are influenced by high-status peers' health risk, deviant, and adaptive behavior. Developmental Psychology, 50, 2697-2714. doi:10.1037/ a0038178

Henneberger, A. K., Mushonga, D. R., \& Preston, A. M. (2020). Peer influence and adolescent substance use: A systematic review of dynamic social network research. Adolescent Research Review. https://doi.org/10.1007/s40894-019-00130-0

*Henry, D. B., Schoeny, M. E., Deptula, D. P., \& Slavick, J. T. (2007). Peer selection and socialization effects on adolescent intercourse without a condom and attitudes about the costs of sex. Child Development, 78(3), 825-838. Retrieved from www.jstor.org/stable/4620671

*Hiatt, C., Laursen, B., Stattin, H., \& Kerr, M. (2017). Best friend influence over adolescent problem behaviors: Socialized by the satisfied. Journal of Clinical Child and Adolescent Psychology, 46(5), 695-708. https://doi.org/10.1080/15374416.2015.1050723

*Hogue, A., \& Steinberg, L. (1995). Homophily of internalized distress in adolescent peer groups. Developmental Psychology, 31(6), 897-906.

Hox, J. J., Moerbeek, M., \& van de Schoot, R. (2002). Multilevel analysis: Techniques and applications. Routledge. https://doi.org/10.4324/9781410604118

Hoxby, C. (2000). Peer effects in the classroom: Learning from gender and race variation. (NBER Working Paper 7867). National Bureau of Economic Research. https://doi.org/10.3386/w7867 


\section{PEER INFLUENCE IN CHILDHOOD AND ADOLESCENCE}

Joiner, T. E., Jr. \& Katz, J. (1999). Contagion of depressive symptoms and mood: Meta-analytic review and explanations from cognitive, behavioral, and interpersonal viewpoints. Clinical Psychology: Science and Practice, 6(2), 149-164. https://doi.org/10.1093/clipsy.6.2.149

Joiner, T. E., Jr. (1994). Contagious depression: Existence, specificity to depressed symptoms, and the role of reassurance seeking. Journal of Personality and Social Psychology, 67(2), 287-296. https://doi.org/10.1037/0022-3514.67.2.287

Juvonen, J., \& Murdock, T. B. (1995). Grade-level differences in the social value of effort: Implications for self-presentation tactics of early adolescents. Child Development, 66(6), 1694-1705. https://doi.org/10.1111/j.1467-8624.1995.tb00959.x

*Kamper-DeMarco, K. E. (2016). The influence of friendships on aggressive behavior in early childhood: Examining the interdependence of aggression (Publication No. 10163760) [Doctoral dissertation, University at Buffalo]. ProQuest LLC.

*Kandel, D. B. (1978). Homophily, selection, and socialization in adolescent friendships. American Journal of Sociology, 84(2), 427-436. Retrieved from www.jstor.org/stable/2777857

Kandel, D. B., Kessler, R. C., \& Margulies, R. Z. (1978). Antecedents of adolescent initiation into stages of drug use: A developmental analysis. Journal of Youth and Adolescence, 7(1), 13-40. https://doi.org/10.1007/BF01538684

Kao, G., \& Joyner, K. (2004). Do race and ethnicity matter among friends? Activities among interracial, interethnic, and intraethnic adolescent friends. The Sociological Quarterly, 45(3), 557-573. www.jstor.org/stable/4120863 
PEER INFLUENCE IN CHILDHOOD AND ADOLESCENCE

*Keijsers, L., Branje, S., Hawk, S. T., Schwartz, S. J., Frijns, T., Koot, H. M., van Lier, P., \& Meeus, W. (2012). Forbidden friends as forbidden fruit: Parental supervision of friendships, contact with deviant peers, and adolescent delinquency. Child Development, 83(2), 651-666. https://doi.org/10.1111/j.1467-8624.2011.01701.x

Kenny, D. A. (1995). The effect of nonindependence on significance testing in dyadic research. Personal Relationships, 2(1), 67-75. https://doi.org/10.1111/j.1475-6811.1995.tb00078.x

Khazanov, G. K., \& Ruscio, A. M. (2016). Is low positive emotionality a specific risk factor for depression? A meta-analysis of longitudinal studies. Psychological Bulletin, 142(9), 9911015. https://doi.org/10.1037/bul0000059

*Kiesner, J., Cadinu, M., Poulin, F., \& Bucci, M. (2002). Group identification in early adolescence: Its relation with peer adjustment and its moderator effect on peer influence. Child Development, 73, 196-208. https://doi.org/10.1111/1467-8624.00400

Kilford, E. J., Garrett, E., \& Blakemore, S.-J. (2016). The development of social cognition in adolescence: An integrated perspective. Neuroscience and Biobehavioral Reviews, 70, 106-120. https://doi.org/10.1016/j.neubiorev.2016.08.016

*Kindermann, T. A. (1993). Natural peer groups as contexts for individual development: The case of children's motivation in school. Developmental Psychology, 29(6), 970-977. https://doi.org/10.1037/0012-1649.29.6.970

Kindermann, T. A., \& Vollet, J. (2014). Social networks within classroom ecologies: Peer effects on students' engagement in the context of relationships with teachers and parents. Zeitschrift für Erziehungswissenschaft, 17(S5), 135-151. https://doi.org/10.1007/s11618014-0555-9 


\section{PEER INFLUENCE IN CHILDHOOD AND ADOLESCENCE}

Knoll, L. J., Magis-Weinberg, L., Speekenbrink, M., \& Blakemore, S.-J. (2015). Social influence on risk perception during adolescence. Psychological Science, 26(5), 583-592. https://doi.org/10.1177/0956797615569578

Kovacs, M. (1992). Children's depression inventory: Manual. Multi-Health Systems.

Lam, C. B., McHale, S. M., \& Crouter, A. C. (2014). Time with peers from middle childhood to late adolescence: Developmental course and adjustment correlates. Child Development, 85(4), 1677-1693. https://doi.org/10.1111/cdev.12235

*Larsen, H., Overbeek, G., Vermulst, A. A., Granic, I., \& Engels, R. C. M. E. (2010). Initiation and continuation of best friends and adolescents' alcohol consumption: Do self-esteem and self-control function as moderators? International Journal of Behavioral Development, 34(5), 406-416. https://doi.org/10.1177/0165025409350363

Laursen, B. (2005). Dyadic and group perspectives on close relationships. International Journal of Behavioral Development, 29(2), 97-100. https://doi.org/10.1080/01650250444000450

Laursen, B. (2018). Peer influence. In W. M. Bukowski, B. Laursen, \& K. H. Rubin (Eds.), Handbook of peer interactions, relationships, and groups (2nd ed., pp. 447-469). The Guilford Press.

Laursen, B., Hafen, C. A., Kerr, M., \& Stattin, H. (2012). Friend influence over adolescent problem behaviors as a function of relative peer acceptance: To be liked is to be emulated. Journal of Abnormal Psychology, 121(1), 88-94. https://doi.org/10.1037/a0024707

Leung, R. K., Toumbourou, J. W., \& Hemphill, S. A. (2014). The effect of peer influence and selection processes on adolescent alcohol use: A systematic review of longitudinal 
PEER INFLUENCE IN CHILDHOOD AND ADOLESCENCE

studies. Health Psychology Review, 8(4), 426-457.

https://doi.org/10.1080/17437199.2011.587961

*Li, L., Lu, T., Niu, L., Feng, Y., Jin, S., \& French, D. C. (2017). Tobacco use by middle and high school Chinese adolescents and their friends. Journal of Youth and Adolescence, 46(6), 1262-1274. https://doi.org/10.1007/s10964-016-0563-6

Liu, J., Zhao, S., Chen, X., Falk, E., \& Albarracin, D. (2017). The influence of peer behavior as a function of social and cultural closeness: A meta-analysis of normative influence on adolescent smoking initiation and continuation. Psychological Bulletin, 143(10), 10821115. https://doi.org/10.1037/bul0000113

*Luo, Q. (2001). Parenting and friend affiliation in adolescent development: A cross-cultural comparison [Unpublished doctoral dissertation]. Wayne State University.

Maes, M., Nelemans, S. A., Danneel, S., Fernández-Castilla, B., Van den Noortgate, W., Goossens, L., \& Vanhalst, J. (2019). Loneliness and social anxiety across childhood and adolescence: Multilevel meta-analyses of cross-sectional and longitudinal associations. Developmental Psychology, 55(7), 1548-1565. https://doi.org/10.1037/dev0000719

Marcos, Y. Q., Sebastián, M. J. Q., Aubalat, L. P., Ausina, J. B., \& Treasure, J. (2013). Peer and family influence in eating disorders: A meta-analysis. European Psychiatry, 28(4), 199206. https://doi.org/10.1016/j.eurpsy.2012.03.005

*Marion, D., Laursen, B., Kiuru, N., Nurmi, J. E., \& Salmela-Aro, K. (2014). Maternal affection moderates friend influence on schoolwork engagement. Developmental Psychology, 50(3), 766-771. https://doi.org/10.1037/a0034295 
PEER INFLUENCE IN CHILDHOOD AND ADOLESCENCE

Marks, G., \& Miller, N. (1987). Ten years of research on the false-consensus effect: An empirical and theoretical review. 102(1), 72-90. https://doi.org/10.1037/00332909.102.1.72

*Marks, P. E. L., Cillessen, A. H. N., \& Crick, N. R. (2012). Popularity contagion among adolescents. Social Development, 21(3), 501-521. https://doi.org/10.1111/j.1467$\underline{9507.2011 .00647 . x}$

Martin, C. L., Kornienko, O., Schaefer, D. R., Hanish, L. D., Fabes, R. A., \& Goble, P. (2013). The role of sex of peers and gender-typed activities in young children's peer affiliative networks: A longitudinal analysis of selection and influence. Child Development, 84(3), 921-937. https://doi.org/10.1111/cdev.12032

Mayeux, L., Sandstrom, M. J., \& Cillessen, A. H. N. (2008). Is being popular a risky proposition? Journal of Research on Adolescence, 18(1), 49-74. https://doi.org/10.1111/j.1532-7795.2008.00550.x

McGloin, J. M., \& Thomas, K. J. (2019). Peer influence and delinquency. Annual Review of Criminology, 2(1), 241-264. https://doi.org/10.1146/annurev-criminol-011518-024551

McLeod, B. D., \& Weisz, J. R. (2004). Using dissertations to examine potential bias in child and adolescent clinical trials. 72(2), 235-251. https://doi.org/10.1037/0022-006X.72.2.235

*Medler, S. M. (2000). Adolescent smoking behavior: The dynamics of parental and peer influence, attitude, and the active role of the adolescent (Publication No. 9992242) [Doctoral dissertation, Wayne State University]. Bell \& Howell Information and Learning.

*Mercken, L., Candel, M., Willems, P., \& de Vries, H. (2007). Disentangling social selection and social influence effects on adolescent smoking: The importance of reciprocity in 
PEER INFLUENCE IN CHILDHOOD AND ADOLESCENCE

friendships. Addiction, 102(9), 1483-1492. https://doi.org/10.1111/j.1360$\underline{0443.2007 .01905 . x}$

Mercken, L., Steglich, C., Sinclair, P., Holliday, J., \& Moore, L. (2012). A longitudinal social network analysis of peer influence, peer selection, and smoking behavior among adolescents in British schools. Health Psychology, 31(4), 450-459. https://doi.org/10.1037/a0026876

Meter, D. J., \& Card, N. A. (2016). Stability of children's and adolescents' friendships: A metaanalytic review. Merrill-Palmer Quarterly, 62, 252. https://doi.org/10.13110/merrpalmquar1982.62.3.0252

*Meter, D. J., Casper, D. M., \& Card, N. A. (2015). Perceptions of intimacy and friendship reciprocity moderate peer influence on aggression. Aggressive Behavior, 41(5), 432-442. https://doi.org/10.1002/ab.21577

*Miklikowska, M. (2017). Development of anti-immigrant attitudes in adolescence: The role of parents, peers, intergroup friendships, and empathy. British Journal of Psychology, 108(3), 626-648. https://doi.org/10.1111/bjop.12236

Moher, D., Liberati, A., Tetzlaff, J., Altman, D. G., \& The PRISMA Group (2009). Preferred reporting items for systematic reviews and meta-analyses: The PRISMA statement. PLoS Medicine, 6(7), e1000097. https://doi.org/10.1371/journal.pmed.1000097

*Molloy, L. E., Gest, S. D., \& Rulison, K. L. (2011). Peer influences on academic motivation: Exploring multiple methods of assessing youths' most "influential" peer relationships. The Journal of Early Adolescence, 31(1), 13-40. https://doi.org/10.1177/0272431610384487 


\section{PEER INFLUENCE IN CHILDHOOD AND ADOLESCENCE}

*Moriarty, J., McVicar, D., \& Higgins, K. (2016). Cross-section and panel estimates of peer effects in early adolescent cannabis use: With a little help from my 'friends once removed'. Social Science and Medicine, 163, 37-44.

https://doi.org/10.1016/j.socscimed.2016.06.032

*Mounts, N. S. (2002). Parental management of adolescent peer relationships in context: The role of parenting style. Journal of Family Psychology, 16(1), 58-69. https://doi.org/10.1037//0893-3200.16.1.58

*Mrug, S., Borch, C., \& Cillessen, A. H. N. (2011). Other-sex friendships in late adolescence: Risky associations for substance use and sexual debut? Journal of Youth and Adolescence, 40(7), 875-888. https://doi.org/10.1007/s10964-010-9605-7

Nelson, E. E., Jarcho, J. M., \& Guyer, A. E. (2016). Social re-orientation and brain development: An expanded and updated view. Developmental Cognitive Neuroscience, 17, 118-127. https://doi.org/doi.org/10.1016/j.den.2015.12.008

Nesi, J., Choukas-Bradley, S., \& Prinstein, M. J. (2018a). Transformation of adolescent peer relations in the social media context: Part $1-\mathrm{A}$ theoretical framework and application to dyadic peer relationships. Clinical Child and Family Psychological Review, 21, 267-294. https://doi.org/10.1007/s10567-018-0261-x

Nesi, J., Choukas-Bradley, S., \& Prinstein, M. J. (2018b). Transformation of adolescent peer relations in the social media context: Part 2-Application to peer group processes and future directions for research. Clinical Child and Family Psychology Review, 21, 295319. https://doi.org/10.1007/s10567-018-0262-9

Nesi, J., Rothenberg, W. A., Hussong, A. M., \& Jackson, K. M. (2017). Friends' alcohol-related social networking site activity predicts escalations in adolescent drinking: Mediation by 


\section{PEER INFLUENCE IN CHILDHOOD AND ADOLESCENCE}

peer norms. Journal of Adolescent Health, 60(6), 641-647.

https://doi.org/10.1016/j.jadohealth.2017.01.009

Newcomb, T. M. (1950). Change and persistence of attitudes. In T. M. Newcomb \& J. W. W. Charters (Eds.), Social psychology (pp. 194-232). Dryden Press. https://doi.org/10.1037/11275-006

*Nijhof, K. S., Scholte, R. H. J., Overbeek, G., \& Engels, R. C. M. E. (2010). Friends' and adolescents' delinquency: The moderating role of social status and reciprocity of friendships. Criminal Justice and Behavior, 37(3), 289-305. https://doi.org/10.1177/0093854809355776

Nook, E., Lindquist, K., \& Zaki, J. (2015). A new look at emotion perception: Concepts speed and shape facial emotion recognition. Emotion. https://doi.org/10.1037/a0039166

Obsuth, I., Sutherland, A., Cope, A., Pilbeam, L., Murray, A. L., \& Eisner, M. (2017). London Education and Inclusion Project (LEIP): Results from a cluster-randomized controlled trial of an intervention to reduce school exclusion and antisocial behavior. Journal of Youth and Adolescence, 46(3), 538-557. https://doi.org/10.1007/s10964-016-0468-4

*Payne, M. R. (2004). Making their mark: The impact of families, schools, neighborhoods and friends on early adolescent achievement [Unpublished doctoral dissertation]. Northwestern University.

*Pilgrim, C. (1998). Close friend's drug use, authoritative parenting and sensation seeking effects on drug use among European-American and African-American adolescents (Publication No. 9815360) [Doctoral dissertation, Wayne State University]. Bell \& Howell Information and Learning. 


\section{PEER INFLUENCE IN CHILDHOOD AND ADOLESCENCE}

*Platje, E., Vermeiren, R. R. J. M., Raine, A., Doreleijers, T. A. H., Keijsers, L. G. M. T., Branje, S. J. T., Popma, A., van Lier, P. A. C., Koot, H. M., Meeus, W. H. J., \& Jansen, L. M. C. (2013). A longitudinal biosocial study of cortisol and peer influence on the development of adolescent antisocial behavior. Psychoneuroendocrinology, 38(11), 2770-2779. https://doi.org/10.1016/j.psyneuen.2013.07.006

Poulin, F., \& Chan, A. (2010). Friendship stability and change in childhood and adolescence. Developmental Review 30(3), 257-272. https://doi.org/10.1016/j.dr.2009.01.001

*Poulin, F., Dishion, T. J., \& Haas, E. (1999). The peer influence paradox: Friendship quality and deviancy training within male adolescent friendships. Merrill-Palmer Quarterly, $45(1), 42-61$.

Prentice, D. A., \& Miller, D. T. (1993). Pluralistic ignorance and alcohol use on campus: Some consequences of misperceiving the social norm. Journal of Personality and Social Psychology, 243-256. https://doi.org/10.1037/0022-3514.64.2.243

*Prinstein, M. J. (2007). Moderators of peer contagion: A longitudinal examination of depression socialization between adolescents and their best friends. Journal of Clinical Child and Adolescent Psychology, 36(2), 159-170. https://doi.org/10.1080/15374410701274934

Prinstein, M. J., \& Dodge, K. A. (Eds.). (2008). Understanding peer influence in children and adolescents. The Guilford Press.

Prinstein, M. J., \& Giletta, M. (2020). Future directions in peer relations research. Journal of Clinical Child \& Adolescent Psychology, 49(4), 556-572. https://doi.org/10.1080/15374416.2020.1756299

Prinstein, M. J., \& Wang, S. S. (2005). False consensus and adolescent peer contagion: Examining discrepancies between perceptions and actual reported levels of friends' 
82

PEER INFLUENCE IN CHILDHOOD AND ADOLESCENCE

deviant and health risk behaviors. Journal of Abnormal Child Psychology, 33(3), 293306. https://doi.org/10.1007/s10802-005-3566-4

*Prinstein, M. J., Heilbron, N., Guerry, J. D., Franklin, J. C., Rancourt, D., Simon, V., \& Spirito, A. (2010). Peer influence and nonsuicidal self injury: Longitudinal results in community and clinically-referred adolescent samples. Journal of Abnormal Child Psychology, 38(5), 669-682. https://doi.org/10.1007/s10802-010-9423-0

Pronin, E., Berger, J., \& Molouki, S. (2007). Alone in a crowd of sheep: Asymmetric perceptions of conformity and their roots in an introspection illusion. Journal of Personality and Social Psychology, 92(4), 585-595. https://doi.org/10.1037/0022-3514.92.4.585

Pustejovsky, J. (2018). ClubSandwich: Cluster-Robust (Sandwich) Variance Estimators with Small-Sample Corrections. R package version 0.3.2. https://CRAN.R-project.org/package=clubSandwich

R Core Team (2020). R: A language and environment for statistical computing [Computer software; Version 3.6.3]. Vienna, Austria: R Foundation for Statistical Computing. Retrieved from http://www.Rproject.org/

Ragan, D. T., Osgood, D. W., Ramirez, N. G., Moody, J., \& Gest, S. D. (2019). A comparison of peer influence estimates from SIENA stochastic actor-based models and from conventional regression approaches. Sociological Methods \& Research. https://doi.org/10.1177/0049124119852369

*Rancourt, D., Conway, C. C., Burk, W. J., \& Prinstein, M. J. (2013). Gender composition of preadolescents' friendship groups moderates peer socialization of body change behaviors. Health Psychology, 32(3), 283-292. https://doi.org/10.1037/a0027980 


\section{PEER INFLUENCE IN CHILDHOOD AND ADOLESCENCE}

*Reitz, E., Deković, M., Meijer, A. M., \& Engels, R. C. M. E. (2006). Longitudinal relations among parenting, best friends, and early adolescent problem behavior. The Journal of Early Adolescence, 26(3), 272-295. https://doi.org/10.1177/0272431606288591

*Reynolds, A. D., \& Crea, T. M. (2015). Peer influence processes for youth delinquency and depression. Journal of Adolescence, 43, 83-95. https://doi.org/10.1016/j.adolescence.2015.05.013

Ross, L., Greene, D., \& House, P. (1977). The "false consensus effect": An egocentric bias in social perception and attribution processes. Journal of Experimental Social Psychology, 13(3), 279-301. https://doi.org/10.1016/0022-1031(77)90049-X

Ryan, A. (2000). Peer groups as a context for the socialization of adolescents' motivation, engagement, and achievement in school. Educational Psychologist, 35(2), 101-111. https://doi.org/10.1207/S15326985EP3502_4

*Salvas, M.-C., Vitaro, F., Brendgen, M., Lacourse, É., Boivin, M., \& Tremblay, R. E. (2011). Interplay between friends' aggression and friendship quality in the development of child aggression during the early school years. Social Development, 20(4), 645-663. https://doi.org/10.1111/j.1467-9507.2010.00592.x

Schaefer, D. R., Simpkins, S. D., Vest, A. E., \& Price, C. D. (2011). The contribution of extracurricular activities to adolescent friendships: new insights through social network analysis. Developmental Psychology, 47(4), 1141-1152.

Schaeffer, K. (2019, August 23). Most U.S. teens who use cellphones do it to pass time, connect with others, learn new things. Pew Research Center. https://www.pewresearch.org/fact$\operatorname{tank} / 2019 / 08 / 23 /$ most-u-s-teens-who-use-cellphones-do-it-to-pass-time-connect-withothers-learn-new-things/ 
PEER INFLUENCE IN CHILDHOOD AND ADOLESCENCE

Scholte, R. H. J., Engels, R. C. M. E., Sentse, M., \& Overbeek, G. (2012). Alcohol use and social adjustment in adolescence: A longitudinal, multilevel study. Substance Use and Misuse, 47(7), 821-826. https://doi.org/10.3109/10826084.2012.672278

*Schwartz-Mette, R. A., \& Rose, A. J. (2012). Co-rumination mediates contagion of internalizing symptoms within youths' friendships. Developmental Psychology, 48(5), 1355-1365. https://doi.org/10.1037/a0027484

Seguin, M. M. (1973). Opportunity for peer socialization in a retirement community. The Gerontologist, 13(2), 208-214. https://doi.org/10.1093/geront/13.2.208

Sherman, L. E., Payton, A. A., Hernandez, L. M., Greenfield, P. M., \& Dapretto, M. (2016). The power of the like in adolescence: Effects of peer influence on neural and behavioral responses to social media. Psychological Science, 27(7), 1027-1035. https://doi.org/10.1177/0956797616645673

*Shi, B., \& Xie, H. (2012). Socialization of physical and social aggression in early adolescents' peer groups: High-status peers, individual status, and gender. Social Development, 21(1), 170-194. https://doi.org/10.1111/j.1467-9507.2011.00621.x

Sijtsema, J. J., \& Lindenberg, S. M. (2018). Peer influence in the development of adolescent antisocial behavior: Advances from dynamic social network studies. Developmental Review, 50(Part B), 140-154. https://doi.org/10.1016/j.dr.2018.08.002

Sijtsema, J. J., Rambaran, J. A., Caravita, S. C., \& Gini, G. (2014). Friendship selection and influence in bullying and defending: Effects of moral disengagement. Developmental Psychology, 50(8), 2093-2104. https://doi.org/10.1037/a0037145 


\section{PEER INFLUENCE IN CHILDHOOD AND ADOLESCENCE}

Simon, V., Wargo Aikins, J., \& Prinstein, M. (2008). Romantic partner selection and socialization during early adolescence. Child Development, 79, 1676-1692. https://doi.org/10.1111/j.1467-8624.2008.01218.x

*Slagt, M., Dubas, J. S., Deković, M., Haselager, G. J. T., \& van Aken, M. A. G. (2015). Longitudinal associations between delinquent behaviour of friends and delinquent behaviour of adolescents: Moderation by adolescent personality traits. European Journal of Personality, 29(4), 468-477. https://doi.org/10.1002/per.2001

Smirnov, I., \& Thurner, S. (2017). Formation of homophily in academic performance: Students change their friends rather than performance. PLoS ONE, 12(8), e0183473. https://doi.org/10.1371/journal.pone.0183473

Snijders, T. A. B., van de Bunt, G. G., \& Steglich, C. E. G. (2010). Introduction to stochastic actor-based models for network dynamics. Social Networks, 32(1), 44-60. https://doi.org/ 10.1016/j.socnet.2009.02.004

Somerville, L. H., Jones, R. M., Ruberry, E. J., Dyke, J. P., Glover, G., \& Casey, B. J. (2013). The medial prefrontal cortex and the emergence of self-conscious emotion in adolescence. Psychological Science, 24(8), 1554-1562. https://doi.org/10.1177/0956797613475633

Sowislo, J. F., \& Orth, U. (2013). Does low self-esteem predict depression and anxiety? A metaanalysis of longitudinal studies. Psychological Bulletin, 139(1), 213-240. https://doi.org/10.1037/a0028931

Steglich, C., Snijders, T. A. B., \& Pearson, M. (2010). Dynamic networks and behavior: Separating selection from influence. Sociological Methodology, 40(1), 329-393. https://doi.org/10.1111/j.1467-9531.2010.01225.x 


\section{PEER INFLUENCE IN CHILDHOOD AND ADOLESCENCE}

Steinberg, L., \& Silverberg, S. B. (1986). The vicissitudes of autonomy in early adolescence. Child Development, 57(4), 841-851. https://doi.org/10.2307/1130361

Sterne, J., Becker, B. J., \& Egger, M. (2005). The funnel plot. In H. R. Rothstein, A. J. Sutton, \& M. Borenstein (Eds.), Publication bias in meta-analysis: Prevention, assessment and adjustments (pp. 75-98). Wiley.

*Stevens, E. A., \& Prinstein, M. J. (2005). Peer contagion of depressogenic attributional styles among adolescents: A longitudinal study. Journal of Abnormal Child Psychology, 33(1), 25-37. https://doi.org/10.1007/s10802-005-0931-2

Stevenson, M. (2017). Breaking bad: Mechanisms of social influence and the path to criminality in juvenile jails. The Review of Economics and Statistics, 99(5), 824-838. https://doi.org/10.1162/REST_a_00685

Suleiman, A. B., \& Deardorff, J. (2015). Multiple dimensions of peer influence in adolescent romantic and sexual relationships: A descriptive, qualitative perspective. Archives of Sexual Behavior, 44(3), 765-775. https://doi.org/10.1007/s10508-014-0394-z

Telzer, E. H., Jorgensen, N. A., Prinstein, M. J., \& Lindquist, K. A. (2020). Neurobiological sensitivity to social rewards and punishments moderates link between peer norms and adolescent risk taking. Child Development, doi:http://dx.doi.org/10.1111/cdev.13466

Telzer, E. H., van Hoorn, J., Rogers, C. R., \& Do, K. T. (2018). Social influence on positive youth development: a developmental neuroscience perspective. In Advances in Child Development and Behavior (Vol. 54, pp. 215-258). JAI.

Tipton, E. (2015). Small sample adjustments for robust variance estimation with metaregression. Psychological Methods, 20(3), 375-393. 
PEER INFLUENCE IN CHILDHOOD AND ADOLESCENCE

Tipton, E., Pustejovsky, J. E., \& Ahmadi, H. (2019). A history of meta-regression: Technical, conceptual, and practical developments between 1974 and 2018. Research Synthesis Methods, 10(2), 161-179.

Valente, T. W., Ritt-Olson, A., Stacy, A., Unger, J., Okamoto, J., \& Sussman, S. (2007). Peer acceleration: Effects of a social network tailored substance abuse prevention program among high-risk adolescents. Addiction, 102, 1804-1815. https://doi.org/10.1111/j.13600443.2007.01992.x

van den Noortgate, W., López-López, J. A., Marín-Martínez, F., \& Sánchez-Meca, J. (2015). Meta-analysis of multiple outcomes: A multilevel approach. Behavior Research Methods, 47(4), 1274-1294. https://doi.org/10.3758/s13428-014-0527-2

van Eldik, W. M., de Haan, A. D., Parry, L. Q., Davies, P. T., Luijk, M. P., Arends, L. R., \& Prinzie, P. (2020). The interparental relationship: Meta-analytic associations with children's maladjustment and responses to interparental conflict. Psychological Bulletin, 146(7), 553-594.

van Hoorn, J., Shablack, H., Lindquist, K. A., \& Telzer, E. H. (2019). Incorporating the social context into neurocognitive models of adolescent decision-making: a neuroimaging metaanalysis. Neuroscience \& Biobehavioral Reviews, 101, 129-142.

van Hoorn, J., van Dijk, E., Guroglu, B., \& Crone, E. A. (2016). Neural correlates of prosocial peer influence on public goods game donations during adolescence. Social Cognitive and Affective Neuroscience, 11(6), 923-933. https://doi.org/10.1093/scan/nsw013

van Hoorn, J., van Dijk, E., Meuwese, R., Rieffe, C., \& Crone, E. A. (2016). Peer influence on prosocial behavior in adolescence. Journal of Research on Adolescence, 26(1), 90-100. https://doi.org/10.1111/jora.12173 


\section{PEER INFLUENCE IN CHILDHOOD AND ADOLESCENCE}

Vandell, D. L., Pierce, K. M., \& Dadisman, K. (2005). Out-of-school settings as a developmental context for children and youth. In R. V. Kail (Ed.), Advances in child development and behavior (vol. 33); (pp. 43-77). Elsevier Academic Press, San Diego, CA.

*Veed, G. E. (2009). The role of the peer group in adolescence: Effects on internalizing and externalizing symptoms (Publication No. 3365758) [Doctoral dissertation, University of Nebraska]. ProQuest LLC.

Veenstra, R., Dijkstra, J. K., Steglich, C., \& Van Zalk, M. H. W. (2013). Network-behavior dynamics. Journal of Research on Adolescence, 23(3), 399-412. https://doi.org/10.1111/jora.12070

*Véronneau, M. H., \& Dishion, T. J. (2010). Predicting change in early adolescent problem behavior in the middle school years: A mesosystemic perspective on parenting and peer experiences. Journal of Abnormal Child Psychology, 38(8), 1125-1137. https://doi.org/10.1007/s10802-010-9431-0

*Véronneau, M. H., \& Dishion, T. J. (2011). Middle school friendships and academic achievement in early adolescence: A longitudinal analysis. The Journal of Early Adolescence, 31(1), 99-124. https://doi.org/10.1177/0272431610384485

*Véronneau, M. H., Vitaro, F., Brendgen, M., Dishion, T. J., \& Tremblay, R. E. (2010). Transactional analysis of the reciprocal links between peer experiences and academic achievement from middle childhood to early adolescence. Developmental Psychology, 46(4), 773-790. https://doi.org/10.1037/a0019816

Viechtbauer, W. (2010). Conducting meta-analyses in R with the metafor package. Journal of Statistical Software, 36(3)1-48. https://doi.org/10.18637/jss.v036.i03 


\section{PEER INFLUENCE IN CHILDHOOD AND ADOLESCENCE}

Vitaro, F., Brendgen, M., \& Tremblay, R. E. (2000). Influence of deviant friends on delinquency: Searching for moderator variables. Journal of Abnormal Child Psychology, 28(4), 313325. https://doi.org/10.1023/A:1005188108461

*Vitaro, F., Brendgen, M., Boivin, M., Cantin, S., Dionne, G., Tremblay, R. E., Girard, A., \& Perusse, D. (2011). A monozygotic twin difference study of friends' aggression and children's adjustment problems. Child Development, 82(2), 617-632. https://doi.org/10.1111/j.1467-8624.2010.01570.x

*Vitaro, F., Pedersen, S., \& Brendgen, M. (2007). Children's disruptiveness, peer rejection, friends' deviancy, and delinquent behaviors: A process-oriented approach. Development and Psychopathology, 19(2), 433-453. https://doi.org/10.1017/S0954579407070216

*Vollet, J. W., Kindermann, T. A., \& Skinner, E. A. (2017). In peer matters, teachers matter: Peer group influences on students' engagement depend on teacher involvement. Journal of Educational Psychology, 109(5), 635-652. https://doi.org/10.1037/edu0000172

Weerman, F. M., Wilcox, P., \& Sullivan, C. J. (2018). The short-term dynamics of peers and delinquent behavior: An analysis of bi-weekly changes within a high school student network. Journal of Quantitative Criminology, 34(2), 431-463. https://doi.org/10.1007/s10940-017-9340-2

*Wentzel, K. R., Barry, C. M., \& Caldwell, K. A. (2004). Friendships in middle school: Influences on motivation and school adjustment. Journal of Educational Psychology, 96(2), 195-203. https://doi.org/10.1037/0022-0663.96.2.195

*Werner, N. E., \& Crick, N. R. (2004). Maladaptive peer relationships and the development of relational and physical aggression during middle childhood. Social Development, 13(4), 495-514. https://doi.org/10.1111/j.1467-9507.2004.00280.x 
PEER INFLUENCE IN CHILDHOOD AND ADOLESCENCE

*Woelders, L. C., Larsen, J. K., Scholte, R. H. J., Cillessen, A. H. N., \& Engels, R. C. M. E. (2010). Friendship group influences on body dissatisfaction and dieting among adolescent girls: A prospective study. Journal of Adolescent Health, 47(5), 456-462. https://doi.org/10.1016/j.jadohealth.2010.03.006

*You, J., Lin, M. P., Fu, K., \& Leung, F. (2013). The best friend and friendship group influence on adolescent nonsuicidal self-injury. Journal of Abnormal Child Psychology, 41(6), 9931004. https://doi.org/10.1007/s10802-013-9734-z

*Young, J. T. N., \& Weerman, F. M. (2013). Delinquency as a consequence of misperception: Overestimation of friends' delinquent behavior and mechanisms of social influence. Social Problems, 60(3), 334-356. https://doi.org/10.1525/sp.2013.60.3.334 


\section{PEER INFLUENCE IN CHILDHOOD AND ADOLESCENCE}

Table 1

Descriptive Characteristics of the Studies Included in the Meta-analytic Review

\begin{tabular}{|c|c|c|c|c|c|c|c|c|c|c|}
\hline Study & $N$ & $\begin{array}{c}N \\
\text { effect } \\
\text { sizes }\end{array}$ & Country & $\begin{array}{c}\% \\
\text { Girls } \\
\end{array}$ & $\begin{array}{c}\text { Age } \\
\text { baseline } \\
\text { (years) }\end{array}$ & $\begin{array}{c}N \\
\text { waves }\end{array}$ & $\begin{array}{c}\text { Time lag } \\
\text { (months } \\
\text { ) }\end{array}$ & $\begin{array}{l}\text { Peer rel. } \\
\text { type }\end{array}$ & $\begin{array}{c}\text { Peer } \\
\text { context }\end{array}$ & Behavior \\
\hline $\begin{array}{l}\text { Adams, Bukowski, \& } \\
\text { Bagwell, 2005* }\end{array}$ & 153 & 1 & USA & 48 & 11.5 & 2 & 6 & $\begin{array}{l}\text { Close } \\
\text { friend }\end{array}$ & Classroom & Aggression \\
\hline $\begin{array}{l}\text { Allen, Chango, \& } \\
\text { Szwedo, 2014 }\end{array}$ & 179 & 1 & USA & 53 & 14.3 & 2 & 96 & $\begin{array}{l}\text { Close } \\
\text { friend }\end{array}$ & Grade & Alcohol use \\
\hline $\begin{array}{l}\text { Allen, Chango, Szwedo, } \\
\text { Schad, \& Marston, } \\
2012^{\mathrm{a}}\end{array}$ & 147 & 1 & USA & 53 & 15.2 & 2 & 12 & $\begin{array}{l}\text { Close } \\
\text { friend }\end{array}$ & Grade & Comp. substance use \\
\hline $\begin{array}{l}\text { Altermatt \& Pomerantz, } \\
2003 *\end{array}$ & 726 & 3 & USA & 50 & 10.2 & 3 & 6 & $\begin{array}{l}\text { Close } \\
\text { friend }\end{array}$ & Classroom & Academic achievement \\
\hline $\begin{array}{l}\text { Birkett \& Espelage, } \\
2015^{*}\end{array}$ & 212 & 1 & USA & 51 & 12.4 & 2 & 6 & $\begin{array}{l}\text { Multiple } \\
\text { friends }\end{array}$ & Grade & Aggression \\
\hline $\begin{array}{l}\text { Brendgen, Vitaro, \& } \\
\text { Bukowski, 2000* }\end{array}$ & 152 & 1 & Canada & 51 & 12.1 & 2 & 12 & $\begin{array}{l}\text { Multiple } \\
\text { friends }\end{array}$ & Classroom & Problem behavior \\
\hline $\begin{array}{l}\text { Conway, Rancourt, } \\
\text { Adelman, Burk, \& } \\
\text { Prinstein, } 2011^{\text {b }}\end{array}$ & 579 & 2 & USA & 49 & 12.4 & 2 & 12 & $\begin{array}{l}\text { Multiple } \\
\text { friends }\end{array}$ & Grade & $\begin{array}{c}\text { Depressive symptoms, } \\
\text { Sad affect (sociometric } \\
\text { nominations) }\end{array}$ \\
\hline Dawes, 2014 & 232 & 1 & USA & 54 & 12.0 & 2 & 6 & $\begin{array}{l}\text { Multiple } \\
\text { friends }\end{array}$ & Grade & Popularity goals \\
\hline $\begin{array}{l}\text { de Kemp, Scholte, } \\
\text { Overbeek, \& Engels, } \\
2006^{\text {c* }}\end{array}$ & 433 & 3 & $\begin{array}{l}\text { Netherland } \\
\qquad \mathrm{s}\end{array}$ & 55 & 12.3 & 3 & 6 & $\begin{array}{l}\text { Close } \\
\text { friend }\end{array}$ & Grade & Problem behavior \\
\hline $\begin{array}{l}\text { DeLay, Laursen, Kiuru, } \\
\text { Poikkeus, Aunola, \& }\end{array}$ & 397 & 1 & Finland & 52 & 9.7 & 2 & 12 & $\begin{array}{l}\text { Close } \\
\text { friend }\end{array}$ & Classroom & Academic achievement \\
\hline
\end{tabular}




\begin{tabular}{|c|c|c|c|c|c|c|c|c|c|c|}
\hline Study & $N$ & $\begin{array}{c}N \\
\text { effect } \\
\text { sizes }\end{array}$ & Country & $\begin{array}{c}\% \\
\text { Girls } \\
\end{array}$ & $\begin{array}{c}\text { Age } \\
\text { baseline } \\
\text { (years) }\end{array}$ & $\begin{array}{c}N \\
\text { waves }\end{array}$ & $\begin{array}{c}\text { Time lag } \\
\text { (months } \\
\text { ) }\end{array}$ & $\begin{array}{l}\text { Peer rel. } \\
\text { type }\end{array}$ & $\begin{array}{l}\text { Peer } \\
\text { context }\end{array}$ & Behavior \\
\hline \multicolumn{11}{|l|}{ Nurmi, 2015* } \\
\hline $\begin{array}{l}\text { Deutsch, Chernyavskiy, } \\
\text { Steinley, \& Slutske, } \\
2015^{\mathrm{d}}\end{array}$ & 1,190 & 3 & USA & 50 & 15.7 & 2 & 12 & $\begin{array}{l}\text { Multiple } \\
\text { friends }\end{array}$ & School & $\begin{array}{l}\text { Alcohol use, } \\
\text { Marijuana use, } \\
\text { Tobacco use }\end{array}$ \\
\hline $\begin{array}{l}\text { Donohew, Hoyle, } \\
\text { Clayton, Skinner, } \\
\text { Colon, \& Rice, } 1999\end{array}$ & 428 & 6 & USA & 60 & 14.5 & 3 & 12 & $\begin{array}{l}\text { Multiple } \\
\text { friends }\end{array}$ & $\begin{array}{l}\text { Not } \\
\text { limited to } \\
\text { school }\end{array}$ & $\begin{array}{l}\text { Alcohol use, } \\
\text { Marijuana use }\end{array}$ \\
\hline Dulli, 2006 & 3,583 & 1 & USA & 50 & 12.6 & 2 & 12 & $\begin{array}{l}\text { Multiple } \\
\text { friends }\end{array}$ & Grade & Aggression \\
\hline $\begin{array}{l}\text { Ellis \& Zarbatany, } \\
\text { 2007* }\end{array}$ & 525 & 4 & Canada & 54 & 12.1 & 2 & 3 & $\begin{array}{l}\text { Multiple } \\
\text { friends }\end{array}$ & Grade & $\begin{array}{l}\text { Aggression, } \\
\text { Problem Behavior, } \\
\text { Prosocial behavior }\end{array}$ \\
\hline $\begin{array}{l}\text { Erickson, Crosnoe, \& } \\
\text { Dornbusch, } 2000\end{array}$ & 1,503 & 2 & USA & 58 & 15.4 & 2 & 12 & $\begin{array}{l}\text { Multiple } \\
\text { friends }\end{array}$ & School & $\begin{array}{l}\text { Comp. substance use, } \\
\text { Problem behavior }\end{array}$ \\
\hline \multicolumn{11}{|l|}{ Fisher \& Bauman, 1988} \\
\hline Study 1 & 683 & 1 & USA & - & 14.5 & 2 & 12 & $\begin{array}{l}\text { Close } \\
\text { friend }\end{array}$ & $\begin{array}{l}\text { Not } \\
\text { limited to } \\
\text { school }\end{array}$ & Tobacco use \\
\hline Study 2 & 530 & 2 & USA & - & 12.5 & 2 & 12 & $\begin{array}{l}\text { Close } \\
\text { friend }\end{array}$ & $\begin{array}{c}\text { Not } \\
\text { limited to } \\
\text { school }\end{array}$ & Alcohol use \\
\hline $\begin{array}{l}\text { French, Purwono, \& } \\
\text { Rodkin, 2014 } * \text { e }\end{array}$ & 764 & 2 & Indonesia & 53 & 14.4 & 2 & 12 & $\begin{array}{l}\text { Multiple } \\
\text { friends }\end{array}$ & Grade & $\begin{array}{l}\text { Alcohol use, } \\
\text { Tobacco use }\end{array}$ \\
\hline $\begin{array}{l}\text { French, Purwono, \& } \\
\text { Triwahyuni, } 2011^{\mathrm{e}}\end{array}$ & 780 & 2 & Indonesia & 53 & 14.4 & 2 & 12 & $\begin{array}{l}\text { Multiple } \\
\text { friends }\end{array}$ & Grade & $\begin{array}{l}\text { Problem behavior, } \\
\text { Religiosity }\end{array}$ \\
\hline $\begin{array}{l}\text { Giletta, Scholte, Burk, } \\
\text { Engels, Larsen, \& }\end{array}$ & 307 & 1 & $\begin{array}{l}\text { Netherland } \\
\qquad \mathrm{s}\end{array}$ & 51 & 13.7 & 2 & 12 & $\begin{array}{l}\text { Close } \\
\text { friend }\end{array}$ & Classroom & Depressive symptoms \\
\hline
\end{tabular}




\begin{tabular}{|c|c|c|c|c|c|c|c|c|c|c|}
\hline Study & $N$ & $\begin{array}{c}N \\
\text { effect } \\
\text { sizes }\end{array}$ & Country & $\begin{array}{c}\% \\
\text { Girls } \\
\end{array}$ & $\begin{array}{c}\text { Age } \\
\text { baseline } \\
\text { (years) }\end{array}$ & $\begin{array}{c}N \\
\text { waves }\end{array}$ & $\begin{array}{c}\text { Time lag } \\
\text { (months } \\
\text { ) }\end{array}$ & $\begin{array}{l}\text { Peer rel. } \\
\text { type }\end{array}$ & $\begin{array}{l}\text { Peer } \\
\text { context }\end{array}$ & Behavior \\
\hline \multicolumn{11}{|l|}{ Prinstein, $2011^{\mathrm{f} *}$} \\
\hline $\begin{array}{l}\text { Goodwin, Mrug, Borch, } \\
\text { \& Cillessen, } 2012^{\mathrm{g}}\end{array}$ & 230 & 6 & USA & 51 & 11.5 & 6 & 12 & $\begin{array}{l}\text { Multiple } \\
\text { friends }\end{array}$ & Grade & Depressive symptoms \\
\hline $\begin{array}{l}\text { Güroğlu, Cillessen, } \\
\text { Haselager, \& van } \\
\text { Lieshout, 2012* }\end{array}$ & 201 & 2 & $\begin{array}{c}\text { Netherland } \\
\text { s }\end{array}$ & 41 & 11.0 & 2 & 36 & $\begin{array}{l}\text { Close } \\
\text { friend }\end{array}$ & Classroom & $\begin{array}{l}\text { Problem behavior, } \\
\text { Prosocial behavior }\end{array}$ \\
\hline Hall \& Valente, 2007* & 423 & 1 & USA & 54 & 12.2 & 2 & 12 & $\begin{array}{l}\text { Multiple } \\
\text { friends }\end{array}$ & Classroom & Tobacco use \\
\hline Halliday-Scher, $2000^{\mathrm{h}}$ & 290 & 1 & USA & - & 13.8 & 2 & 12 & $\begin{array}{l}\text { Close } \\
\text { friend }\end{array}$ & - & Alcohol use \\
\hline $\begin{array}{l}\text { Henry, Schoeny, } \\
\text { Deptula, \& Slavick, } \\
2007^{\mathrm{d}}\end{array}$ & 1,350 & 2 & USA & 49 & 16.7 & 2 & 12 & $\begin{array}{l}\text { Multiple } \\
\text { friends }\end{array}$ & $\begin{array}{l}\text { Not } \\
\text { limited to } \\
\text { school }\end{array}$ & Sexual behavior \\
\hline $\begin{array}{l}\text { Hiatt, Laursen, Stattin, } \\
\text { \& Kerr, } 2017\end{array}$ & 350 & 2 & Sweden & 56 & 13.9 & 2 & 12 & $\begin{array}{l}\text { Close } \\
\text { friend }\end{array}$ & $\begin{array}{l}\text { Not } \\
\text { limited to } \\
\text { school }\end{array}$ & $\begin{array}{c}\text { Alcohol use, } \\
\text { Problem behavior }\end{array}$ \\
\hline $\begin{array}{l}\text { Hogue \& Steinberg, } \\
1995\end{array}$ & 1,006 & 1 & USA & 56 & 15.5 & 2 & 12 & $\begin{array}{l}\text { Multiple } \\
\text { friends }\end{array}$ & School & Depressive symptoms \\
\hline $\begin{array}{l}\text { Kamper-DeMarco, } \\
\text { 2016* }\end{array}$ & 81 & 2 & USA & 56 & 3.9 & 2 & 6 & $\begin{array}{l}\text { Close } \\
\text { friend }\end{array}$ & Classroom & Aggression \\
\hline Kandel, 1978 & 783 & 1 & USA & - & - & 2 & 6 & $\begin{array}{l}\text { Close } \\
\text { friend }\end{array}$ & School & Marijuana use \\
\hline $\begin{array}{l}\text { Keijsers, Branje, Hawk, } \\
\text { Schwartz, Frijns, Koot, } \\
\text { van Lier, \& Meeus, } \\
2012^{i *}\end{array}$ & 497 & 3 & $\begin{array}{c}\text { Netherland } \\
\text { s }\end{array}$ & 43 & 13.0 & 3 & 12 & $\begin{array}{l}\text { Close } \\
\text { friend }\end{array}$ & $\begin{array}{l}\text { Not } \\
\text { limited to } \\
\text { school }\end{array}$ & Problem behavior \\
\hline Kiesner, Cadinu, Poulin, & 190 & 1 & Italy & 45 & 11.2 & 2 & 12 & Multiple & - & Problem behavior \\
\hline
\end{tabular}




\begin{tabular}{|c|c|c|c|c|c|c|c|c|c|c|}
\hline Study & $N$ & $\begin{array}{c}N \\
\text { effect } \\
\text { sizes }\end{array}$ & Country & $\begin{array}{c}\% \\
\text { Girls }\end{array}$ & $\begin{array}{c}\text { Age } \\
\text { baseline } \\
\text { (years) }\end{array}$ & $\begin{array}{c}N \\
\text { waves }\end{array}$ & $\begin{array}{c}\text { Time lag } \\
\text { (months } \\
\text { ) }\end{array}$ & $\begin{array}{l}\text { Peer rel. } \\
\text { type }\end{array}$ & $\begin{array}{c}\text { Peer } \\
\text { context }\end{array}$ & Behavior \\
\hline \& Bucci, 2002* & & & & & & & & friends & & \\
\hline Kindermann, 1993 & 96 & 1 & USA & 50 & 10.0 & 2 & 6 & $\begin{array}{l}\text { Multiple } \\
\text { friends }\end{array}$ & Classroom & $\begin{array}{c}\text { Academic engagement/ } \\
\text { motivation }\end{array}$ \\
\hline $\begin{array}{l}\text { Larsen, Overbeek, } \\
\text { Vermulst, Granic, \& } \\
\text { Engels, 2010 }\end{array}$ & 433 & 6 & $\begin{array}{l}\text { Netherland } \\
\text { S }\end{array}$ & 55 & 12.3 & 3 & 6 & $\begin{array}{l}\text { Close } \\
\text { friend }\end{array}$ & Grade & Alcohol use \\
\hline \multicolumn{11}{|l|}{$\begin{array}{l}\text { Li, Lu, Niu, Feng, Jin, } \\
\text { \& French, } 2017\end{array}$} \\
\hline Sample 1 & 614 & 3 & China & 49 & 13.3 & 3 & 12 & $\begin{array}{l}\text { Multiple } \\
\text { friends }\end{array}$ & Classroom & Tobacco use \\
\hline Sample 2 & 567 & 3 & China & 53 & 16.7 & 3 & 12 & $\begin{array}{l}\text { Multiple } \\
\text { friends }\end{array}$ & Classroom & Tobacco use \\
\hline \multicolumn{11}{|l|}{ Luo, 2001} \\
\hline U.S. Sample ${ }^{\mathrm{h}}$ & 217 & 2 & USA & 48 & 13.2 & 2 & 8 & $\begin{array}{l}\text { Close } \\
\text { friend }\end{array}$ & - & $\begin{array}{c}\text { Academic } \\
\text { achievement, } \\
\text { Problem behavior }\end{array}$ \\
\hline Chinese Sample & 406 & 2 & China & 45 & 13.0 & 2 & 6 & $\begin{array}{l}\text { Close } \\
\text { friend }\end{array}$ & - & $\begin{array}{c}\text { Academic } \\
\text { achievement, } \\
\text { Problem behavior }\end{array}$ \\
\hline $\begin{array}{l}\text { Marion, Laursen, Kiuru, } \\
\text { Nurmi, \& Salmela-Aro, } \\
\text { 2014* }\end{array}$ & 112 & 2 & Finland & 59 & 16.0 & 2 & 12 & $\begin{array}{l}\text { Close } \\
\text { friend }\end{array}$ & Grade & $\begin{array}{c}\text { Academic engagement/ } \\
\text { motivation }\end{array}$ \\
\hline $\begin{array}{l}\text { Marks, Cillessen, \& } \\
\text { Crick, 2012 }{ }^{\mathrm{g} *}\end{array}$ & 476 & 57 & USA & 51 & 11.5 & 7 & 12 & $\begin{array}{l}\text { Multiple } \\
\text { friends }\end{array}$ & Grade & $\begin{array}{l}\text { Aggression, } \\
\text { Prosocial behavior }\end{array}$ \\
\hline Medler, 2000h & 376 & 9 & USA & 54 & 13.0 & 3 & 12 & $\begin{array}{l}\text { Close } \\
\text { friend }\end{array}$ & - & Tobacco use \\
\hline $\begin{array}{l}\text { Mercken, Candel, } \\
\text { Willems, \& de Vries, }\end{array}$ & 1,763 & 1 & $\begin{array}{l}\text { Netherland } \\
\qquad \mathbf{S}\end{array}$ & 50 & 12.7 & 2 & 12 & $\begin{array}{l}\text { Multiple } \\
\text { friends }\end{array}$ & Grade & Tobacco use \\
\hline
\end{tabular}




\begin{tabular}{|c|c|c|c|c|c|c|c|c|c|c|}
\hline Study & $N$ & $\begin{array}{c}N \\
\text { effect } \\
\text { sizes }\end{array}$ & Country & $\begin{array}{c}\% \\
\text { Girls } \\
\end{array}$ & $\begin{array}{c}\text { Age } \\
\text { baseline } \\
\text { (years) }\end{array}$ & $\begin{array}{c}N \\
\text { waves }\end{array}$ & $\begin{array}{c}\text { Time lag } \\
\text { (months } \\
\text { ) }\end{array}$ & $\begin{array}{l}\text { Peer rel. } \\
\text { type }\end{array}$ & $\begin{array}{l}\text { Peer } \\
\text { context }\end{array}$ & Behavior \\
\hline \multicolumn{11}{|l|}{2007} \\
\hline $\begin{array}{l}\text { Meter, Casper, \& Card, } \\
2015\end{array}$ & 243 & 1 & USA & 56 & 12.3 & 2 & 12 & $\begin{array}{l}\text { Close } \\
\text { friend }\end{array}$ & Grade & Aggression \\
\hline Miklikowska, 2017 & 517 & 2 & Sweden & 51 & 13.4 & 3 & 24 & $\begin{array}{l}\text { Close } \\
\text { friend }\end{array}$ & School & $\begin{array}{l}\text { Anti-immigrant } \\
\text { attitudes/prejudice }\end{array}$ \\
\hline $\begin{array}{l}\text { Molloy, Gest, \& } \\
\text { Rulison, 2011* }\end{array}$ & 308 & 2 & USA & 46 & 10.5 & 2 & 6 & $\begin{array}{l}\text { Multiple } \\
\text { friends }\end{array}$ & Classroom & $\begin{array}{c}\text { Academic engagement/ } \\
\text { motivation }\end{array}$ \\
\hline $\begin{array}{l}\text { Moriarty, McVicar, \& } \\
\text { Higgins, 2016* }\end{array}$ & 3,667 & 2 & $\begin{array}{l}\text { Great } \\
\text { Britain }\end{array}$ & 55 & 12.5 & 3 & 12 & $\begin{array}{l}\text { Multiple } \\
\text { friends }\end{array}$ & Grade & Marijuana use \\
\hline Mounts, 2002 & 300 & 1 & USA & 60 & 14.5 & 2 & 6 & $\begin{array}{l}\text { Multiple } \\
\text { friends }\end{array}$ & Grade & Comp. substance use \\
\hline $\begin{array}{l}\text { Mrug, Borch, \& } \\
\text { Cillessen, 2011 }\end{array}$ & 126 & 9 & USA & 53 & 15.5 & 3 & 12 & $\begin{array}{l}\text { Multiple } \\
\text { friends }\end{array}$ & Grade & $\begin{array}{l}\text { Alcohol use, } \\
\text { Tobacco use, } \\
\text { Sexual behavior }\end{array}$ \\
\hline $\begin{array}{l}\text { Nijhof, Scholte, } \\
\text { Overbeek, \& Engels, } \\
2010\end{array}$ & 1,025 & 3 & $\begin{array}{l}\text { Netherland } \\
\text { s }\end{array}$ & 51 & 14.7 & 2 & - & $\begin{array}{l}\text { Close } \\
\text { friend }\end{array}$ & Classroom & Problem behavior \\
\hline Payne, 2004 & 744 & 2 & USA & 49 & 12.5 & 2 & 24 & $\begin{array}{l}\text { Multiple } \\
\text { friends }\end{array}$ & $\begin{array}{l}\text { Not } \\
\text { limited to } \\
\text { school }\end{array}$ & Academic achievement \\
\hline $\begin{array}{l}\text { Pilgrim, 1998, School } \\
\text { system } 1\end{array}$ & 175 & 2 & USA & 64 & 13.9 & 2 & 12 & $\begin{array}{l}\text { Close } \\
\text { friend }\end{array}$ & - & Comp. substance use \\
\hline $\begin{array}{l}\text { Platje, Vermeiren, } \\
\text { Raine, Doreleijers, } \\
\text { Keijsers, Branje, } \\
\text { Ponma van Lier. }\end{array}$ & 406 & 6 & $\begin{array}{l}\text { Netherland } \\
\mathrm{s}\end{array}$ & 44 & 15.0 & 3 & 12 & $\begin{array}{l}\text { Close } \\
\text { friend }\end{array}$ & $\begin{array}{l}\text { Not } \\
\text { limited to } \\
\text { school }\end{array}$ & $\begin{array}{l}\text { Aggression, } \\
\text { Problem behavior }\end{array}$ \\
\hline
\end{tabular}

Meeus, \& Jansen, 


\begin{tabular}{|c|c|c|c|c|c|c|c|c|c|c|}
\hline Study & $N$ & $\begin{array}{c}N \\
\text { effect } \\
\text { sizes }\end{array}$ & Country & $\begin{array}{c}\% \\
\text { Girls } \\
\end{array}$ & $\begin{array}{c}\text { Age } \\
\text { baseline } \\
\text { (years) }\end{array}$ & $\begin{array}{c}N \\
\text { waves }\end{array}$ & $\begin{array}{c}\text { Time lag } \\
\text { (months } \\
\text { ) }\end{array}$ & $\begin{array}{l}\text { Peer rel. } \\
\text { type }\end{array}$ & $\begin{array}{c}\text { Peer } \\
\text { context }\end{array}$ & Behavior \\
\hline \multicolumn{11}{|l|}{$2013^{i *}$} \\
\hline $\begin{array}{l}\text { Poulin, Dishion, \& } \\
\text { Haas, } 1999\end{array}$ & 182 & 1 & USA & 0 & 13.5 & 2 & 24 & $\begin{array}{l}\text { Close } \\
\text { friend }\end{array}$ & $\begin{array}{c}\text { Not } \\
\text { limited to } \\
\text { school }\end{array}$ & Problem behavior \\
\hline Prinstein, 2007 & 100 & 1 & USA & 60 & 16.5 & 2 & 18 & $\begin{array}{l}\text { Close } \\
\text { friend }\end{array}$ & Grade & Depressive symptoms \\
\hline $\begin{array}{l}\text { Prinstein, Heilbron, } \\
\text { Guerry, Franklin, } \\
\text { Rancourt, Simon, \& } \\
\text { Spirito, } 2010^{\mathrm{b}}\end{array}$ & 377 & 1 & USA & 50 & 12.5 & 2 & 11 & $\begin{array}{l}\text { Close } \\
\text { friend }\end{array}$ & Grade & Nonsuicidal self-injury \\
\hline $\begin{array}{l}\text { Rancourt, Conway, } \\
\text { Burk, \& Prinstein, 2013 }\end{array}$ & 565 & 4 & USA & 49 & 12.6 & 3 & 12 & $\begin{array}{l}\text { Multiple } \\
\text { friends }\end{array}$ & Grade & $\begin{array}{l}\text { Weight-related } \\
\text { behavior }\end{array}$ \\
\hline $\begin{array}{l}\text { Reitz, Deković, Meijer, } \\
\text { \& Engels, } 2006\end{array}$ & 141 & 7 & $\begin{array}{l}\text { Netherland } \\
\qquad \mathrm{s}\end{array}$ & 65 & 13.3 & 2 & 12 & $\begin{array}{l}\text { Close } \\
\text { friend }\end{array}$ & Grade & $\begin{array}{c}\text { Aggression, } \\
\text { Anxious/depressed } \\
\text { symptoms, } \\
\text { Withdrawal symptoms, } \\
\text { Somatic complaints, } \\
\text { Problem behavior }\end{array}$ \\
\hline $\begin{array}{l}\text { Reynolds \& Crea, } \\
2015^{\text {d* }}\end{array}$ & 9,366 & 2 & USA & 52 & 15.6 & 2 & 12 & $\begin{array}{l}\text { Multiple } \\
\text { friends }\end{array}$ & School & $\begin{array}{c}\text { Depressive symptoms, } \\
\text { Problem behavior }\end{array}$ \\
\hline $\begin{array}{l}\text { Salvas, Vitaro, } \\
\text { Brendgen, Lacourse, } \\
\text { Boivin, \& Tremblay, } \\
2011\end{array}$ & 1,555 & 2 & Canada & 52 & 6.2 & 3 & 12 & $\begin{array}{l}\text { Close } \\
\text { friend }\end{array}$ & Classroom & Aggression \\
\hline $\begin{array}{l}\text { Schwartz-Mette \& Rose, } \\
2012 *\end{array}$ & 274 & 2 & USA & 53 & 11.3 & 2 & 6 & $\begin{array}{l}\text { Close } \\
\text { friend }\end{array}$ & - & $\begin{array}{c}\text { Depressive symptoms, } \\
\text { Anxiety symptoms }\end{array}$ \\
\hline Shi \& Xie, 2012* & 245 & 2 & USA & 55 & 13.0 & 2 & 5.5 & $\begin{array}{l}\text { Multiple } \\
\text { friends }\end{array}$ & Grade & Aggression \\
\hline
\end{tabular}




\begin{tabular}{|c|c|c|c|c|c|c|c|c|c|c|}
\hline Study & $N$ & $\begin{array}{c}N \\
\text { effect } \\
\text { sizes }\end{array}$ & Country & $\begin{array}{c}\% \\
\text { Girls }\end{array}$ & $\begin{array}{c}\text { Age } \\
\text { baseline } \\
\text { (years) }\end{array}$ & $\begin{array}{c}N \\
\text { waves }\end{array}$ & $\begin{array}{c}\text { Time lag } \\
\text { (months } \\
\text { ) }\end{array}$ & $\begin{array}{l}\text { Peer rel. } \\
\text { type }\end{array}$ & $\begin{array}{l}\text { Peer } \\
\text { context }\end{array}$ & Behavior \\
\hline $\begin{array}{l}\text { Slagt, Dubas, Deković, } \\
\text { Haselager, \& van Aken, } \\
2015\end{array}$ & 176 & 1 & $\begin{array}{c}\text { Netherland } \\
\text { s }\end{array}$ & 60 & 15.5 & 2 & 12 & $\begin{array}{l}\text { Close } \\
\text { friend }\end{array}$ & $\begin{array}{c}\text { Not } \\
\text { limited to } \\
\text { school }\end{array}$ & Problem behavior \\
\hline $\begin{array}{l}\text { Stevens \& Prinstein, } \\
2005\end{array}$ & 398 & 2 & USA & 48 & 12.7 & 2 & 11 & $\begin{array}{l}\text { Close } \\
\text { friend }\end{array}$ & Grade & $\begin{array}{c}\text { Depressive symptoms, } \\
\text { Depressogenic } \\
\text { attributional style }\end{array}$ \\
\hline Veed, 2009 & 148 & 4 & USA & 51 & 15.7 & 2 & 6 & $\begin{array}{l}\text { Multiple } \\
\text { friends }\end{array}$ & School & $\begin{array}{c}\text { Aggression, } \\
\text { Depressive symptoms, } \\
\text { Anxiety symptoms, } \\
\text { Problem behavior }\end{array}$ \\
\hline $\begin{array}{l}\text { Véronneau \& Dishion, } \\
2010^{1}\end{array}$ & 1,278 & 1 & USA & 55 & 12.2 & 2 & 24 & $\begin{array}{l}\text { Multiple } \\
\text { friends }\end{array}$ & Grade & Problem behavior \\
\hline $\begin{array}{l}\text { Véronneau \& Dishion, } \\
2011^{1}\end{array}$ & 1,278 & 1 & USA & 55 & 12.2 & 2 & 24 & $\begin{array}{l}\text { Multiple } \\
\text { friends }\end{array}$ & Grade & Academic achievement \\
\hline $\begin{array}{l}\text { Véronneau, Vitaro, } \\
\text { Brendgen, Dishion, \& } \\
\text { Tremblay, } 2010\end{array}$ & 452 & 15 & Canada & 44 & 8.1 & 6 & 12 & $\begin{array}{l}\text { Multiple } \\
\text { friends }\end{array}$ & Classroom & Academic achievement \\
\hline $\begin{array}{l}\text { Vitaro, Brendgen, } \\
\text { Boivin, Cantin, Dionne, } \\
\text { Tremblay, Girard, \& } \\
\text { Perusse, } 2011\end{array}$ & 446 & 1 & Canada & 52 & 6.1 & 2 & 12 & $\begin{array}{l}\text { Close } \\
\text { friend }\end{array}$ & Classroom & Aggression \\
\hline $\begin{array}{l}\text { Vitaro, Pedersen, \& } \\
\text { Brendgen, } 2007\end{array}$ & 299 & 1 & Canada & 43 & 8.0 & 2 & 42 & $\begin{array}{l}\text { Multiple } \\
\text { friends }\end{array}$ & Classroom & Problem behavior \\
\hline $\begin{array}{l}\text { Vollet, Kindermann, \& } \\
\text { Skinner, } 2017\end{array}$ & 366 & 1 & USA & 48 & 11.5 & 2 & 6 & $\begin{array}{l}\text { Multiple } \\
\text { friends }\end{array}$ & Grade & $\begin{array}{c}\text { Academic engagement/ } \\
\text { motivation }\end{array}$ \\
\hline $\begin{array}{l}\text { Wentzel, Barry, \& } \\
\text { Caldwell, } 2004\end{array}$ & 169 & 1 & USA & 50 & 11.5 & 2 & 24 & $\begin{array}{l}\text { Close } \\
\text { friend }\end{array}$ & Grade & Academic achievement \\
\hline
\end{tabular}


PEER INFLUENCE IN CHILDHOOD AND ADOLESCENCE

\begin{tabular}{|c|c|c|c|c|c|c|c|c|c|c|}
\hline Study & $N$ & $\begin{array}{c}N \\
\text { effect } \\
\text { sizes } \\
\end{array}$ & Country & $\begin{array}{c}\% \\
\text { Girls } \\
\end{array}$ & $\begin{array}{c}\text { Age } \\
\text { baseline } \\
\text { (years) }\end{array}$ & $\begin{array}{c}N \\
\text { waves }\end{array}$ & $\begin{array}{c}\text { Time lag } \\
\text { (months } \\
\text { ) }\end{array}$ & $\begin{array}{l}\text { Peer rel. } \\
\text { type }\end{array}$ & $\begin{array}{c}\text { Peer } \\
\text { context }\end{array}$ & Behavior \\
\hline Werner \& Crick, 2004 & 517 & 2 & USA & 62 & 8.6 & 2 & 12 & $\begin{array}{l}\text { Multiple } \\
\text { friends }\end{array}$ & Classroom & Aggression \\
\hline $\begin{array}{l}\text { Woelders, Larsen, } \\
\text { Scholte, Cillessen, \& } \\
\text { Engels, } 2010^{\mathrm{f}}\end{array}$ & 344 & 2 & $\begin{array}{l}\text { Netherland } \\
\text { s }\end{array}$ & 1 & 13.7 & 2 & 12 & $\begin{array}{l}\text { Multiple } \\
\text { friends }\end{array}$ & Classroom & $\begin{array}{l}\text { Weight-related } \\
\text { behavior }\end{array}$ \\
\hline $\begin{array}{l}\text { You, Lin, Fu, \& Leung, } \\
2013\end{array}$ & 3,906 & 1 & Hong Kong & 54 & 14.8 & 2 & 6 & $\begin{array}{l}\text { Close } \\
\text { friend }\end{array}$ & Classroom & Nonsuicidal self-injury \\
\hline $\begin{array}{l}\text { Young \& Weerman, } \\
2013^{*}\end{array}$ & 1,046 & 1 & $\begin{array}{l}\text { Netherland } \\
\text { s }\end{array}$ & 56 & 14.1 & 2 & 12 & $\begin{array}{l}\text { Multiple } \\
\text { friends }\end{array}$ & Grade & Problem behavior \\
\hline
\end{tabular}

Note. * Information to compute effect sizes for these studies was provided by the authors.

"_" indicates that information was not reported or could not be coded.

The same subscripts (e.g., a, b, c) indicate that these reports used overlapping data from the same larger study (e.g., ${ }^{\mathrm{d}}$ National Longitudinal Study of Adolescent to Adult Health - Add Health). Thus, effect sizes extracted from these reports were considered to belong to the same study.

If effect sizes were extracted from dyadic analyses (e.g., longitudinal actor-partner interdependence model - APIM), the number of dyads is used as $n$. 
PEER INFLUENCE IN CHILDHOOD AND ADOLESCENCE

Table 2

Results from Multilevel Meta-regression Models Examining Moderators of Peer Influence Effects

\begin{tabular}{|c|c|c|c|c|c|c|c|c|c|c|c|c|}
\hline \multirow[b]{2}{*}{ Main moderators } & \multirow[b]{2}{*}{$k$} & \multicolumn{3}{|c|}{ Average effect size } & \multicolumn{5}{|c|}{ Moderator effect } & \multirow[b]{2}{*}{$F$} & \multirow[b]{2}{*}{$d f$} & \multirow[b]{2}{*}{$p$} \\
\hline & & $\dot{\beta}$ & 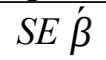 & $95 \% \mathrm{CI}$ & $p$ & $\beta$ & $S E \beta$ & $95 \% \mathrm{CI}$ & $p$ & & & \\
\hline Type of behavior & 195 & & & & & & & & & 1.383 & 2,192 & .253 \\
\hline Externalizing behaviors & $141 \cdot$ & 081 & .010 & $.061, .101$ & $<.001$ & & & & & & & \\
\hline Internalizing behaviors & 23 & & .016 & $.052, .126$ & $<.001$ & & & & & & & \\
\hline Academic behaviors & $31 \cdot$ & 053 & .013 & $.022, .084$ & $<.001$ & & & & & & & \\
\hline Peer relationship type & 233 & & & & & & & & & 1.447 & 1,231 & .230 \\
\hline Close friend & 80 & .085 & .011 & $.063, .107$ & $<.001$ & & & & & & & \\
\hline Multiple friends & 153 & .066 & .011 & $.042, .090$ & $<.001$ & & & & & & & \\
\hline Peer context & 214 & & & & & & & & & 2.813 & 3,210 & .040 \\
\hline Classroom & 48 & .043 & .009 & $.024, .062$ & $<.001$ & & & & & & & \\
\hline Grade & 125 & .092 & .018 & $.053, .131$ & $<.001$ & & & & & & & \\
\hline School & 15 & .101 & .015 & $.061, .141$ & .002 & & & & & & & \\
\hline Not limited to school & 26 & .091 & .015 & $.055, .127$ & $<.001$ & & & & & & & \\
\hline Age & 232 & & & & & .005 & .003 & $-.001, .011$ & .110 & 2.955 & 1,230 & .087 \\
\hline Time lag & 230 & & & & & & & & & 7.092 & 2,227 & .001 \\
\hline Linear & & & & & & -.026 & .010 & $-.049,-.003$ & .030 & & & \\
\hline Quadratic & & & & & & .004 & .002 & $-.001, .009$ & .089 & & & \\
\hline Other moderators & $k$ & $\dot{\beta}$ & $S E \dot{\beta}$ & $95 \% \mathrm{CI}$ & $p$ & $\beta$ & $S E \beta$ & $95 \% \mathrm{CI}$ & $p$ & $F$ & $d f$ & $p$ \\
\hline Publication type & 233 & & & & & & & & & .003 & 1,231 & .954 \\
\hline Peer-reviewed articles & 204 & .075 & .009 & $.057, .093$ & $<.001$ & & & & & & & \\
\hline Dissertations & 29 & .076 & .013 & $.045, .108$ & .001 & & & & & & & \\
\hline Publication year & 233 & & & & & -.001 & .001 & $-.003, .001$ & .303 & .691 & 1,231 & .407 \\
\hline Country & 233 & & & & & & & & & .739 & 2,230 & .479 \\
\hline North America & 173 & .079 & .011 & $.057, .102$ & $<.001$ & & & & & & & \\
\hline
\end{tabular}


PEER INFLUENCE IN CHILDHOOD AND ADOLESCENCE

\begin{tabular}{|c|c|c|c|c|c|c|c|c|c|c|c|c|}
\hline Europe & 47 & .077 & .014 & $.047, .106$ & $<.001$ & & & & & & & \\
\hline Asia & 13 & .046 & .017 & $-.002, .094$ & .056 & & & & & & & \\
\hline Gender ( $\%$ girls $)$ & 228 & & & & & .010 & .110 & $-.370, .390$ & .933 & .014 & 1,226 & .905 \\
\hline Ethnicity cat. approach & 227 & & & & & & & & & .025 & 1,225 & .875 \\
\hline Majority ethnicity & 127 & .075 & .008 & $.058, .091$ & $<.001$ & & & & & & & \\
\hline Mixed ethnicity & 100 & .078 & .023 & $.028, .128$ & .006 & & & & & & & \\
\hline Ethnicity $^{\mathrm{a}}(\%$ White) & 194 & & & & & .000 & .000 & $-.001, .001$ & .896 & .100 & 1,192 & .923 \\
\hline Report type & 233 & & & & & & & & & 1.554 & 4,228 & .188 \\
\hline Self-report & 133 & .082 & .008 & $.067, .097$ & $<.001$ & & & & & & & \\
\hline Peer-report & 69 & .055 & .030 & $-.044, .154$ & .170 & & & & & & & \\
\hline Teacher-report & 19 & .033 & .021 & $-.053, .119$ & .248 & & & & & & & \\
\hline School-record & 7 & .057 & .009 & $.026, .088$ & .012 & & & & & & & \\
\hline Multi-report & 5 & .096 & .039 & $-.044, .235$ & .109 & & & & & & & \\
\hline
\end{tabular}

Note. $k=$ number of effect sizes; $\beta=$ average effect size for each category of categorical moderator; $\beta=$ regression coefficient; $\mathrm{CI}=$ confidence interval. Standard errors and 95\% CI were all based on the robust variance estimation (RVE) method.

${ }^{a}$ In U.S. samples, we also examined whether the percentage of participants who were African American/Black, Latinx/Hispanic, or Asian American (each used as a continuous variable) moderated peer influence effects. None of these effects emerged to be significant. 
PEER INFLUENCE IN CHILDHOOD AND ADOLESCENCE

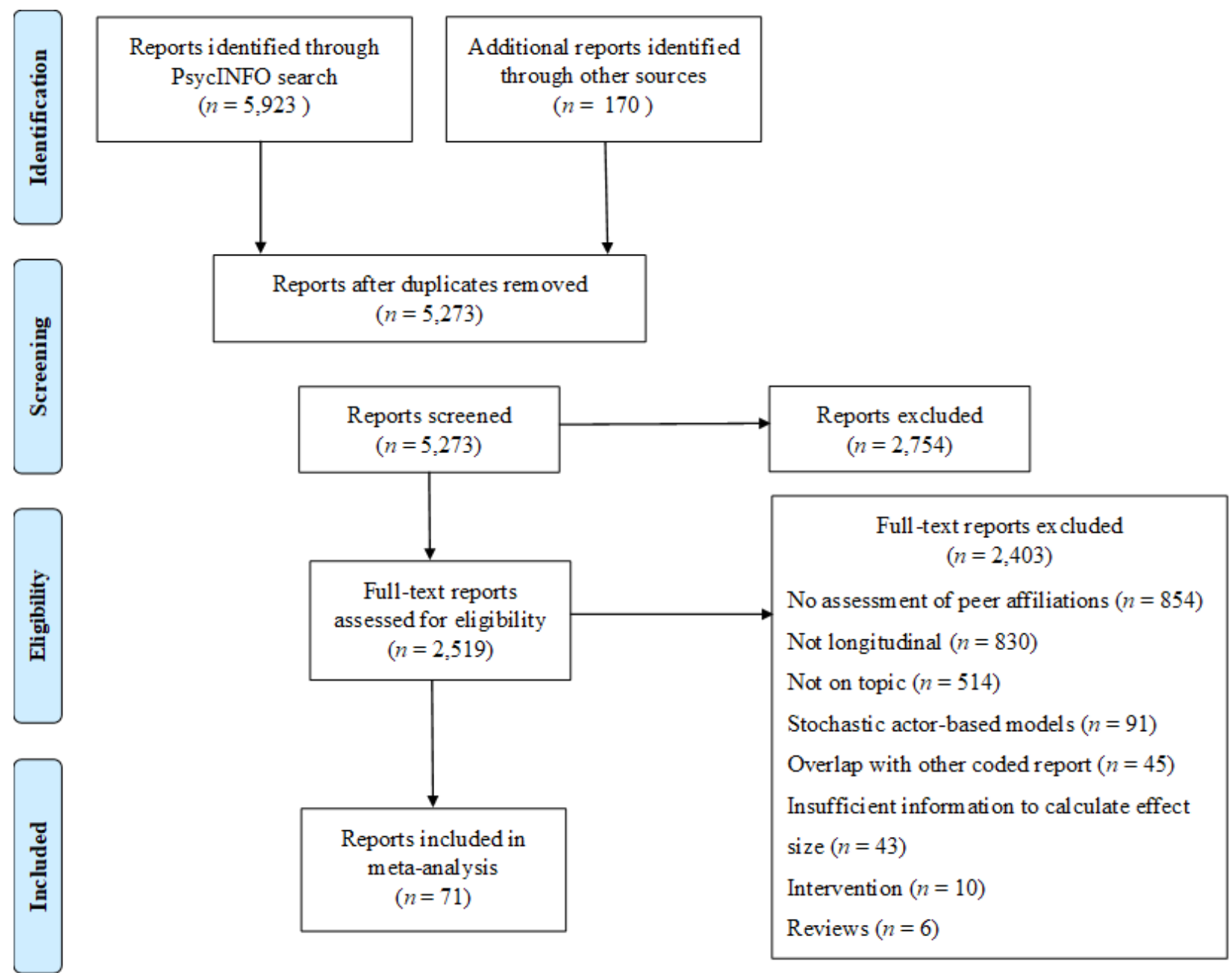

Figure 1. PRISMA flow diagram. 


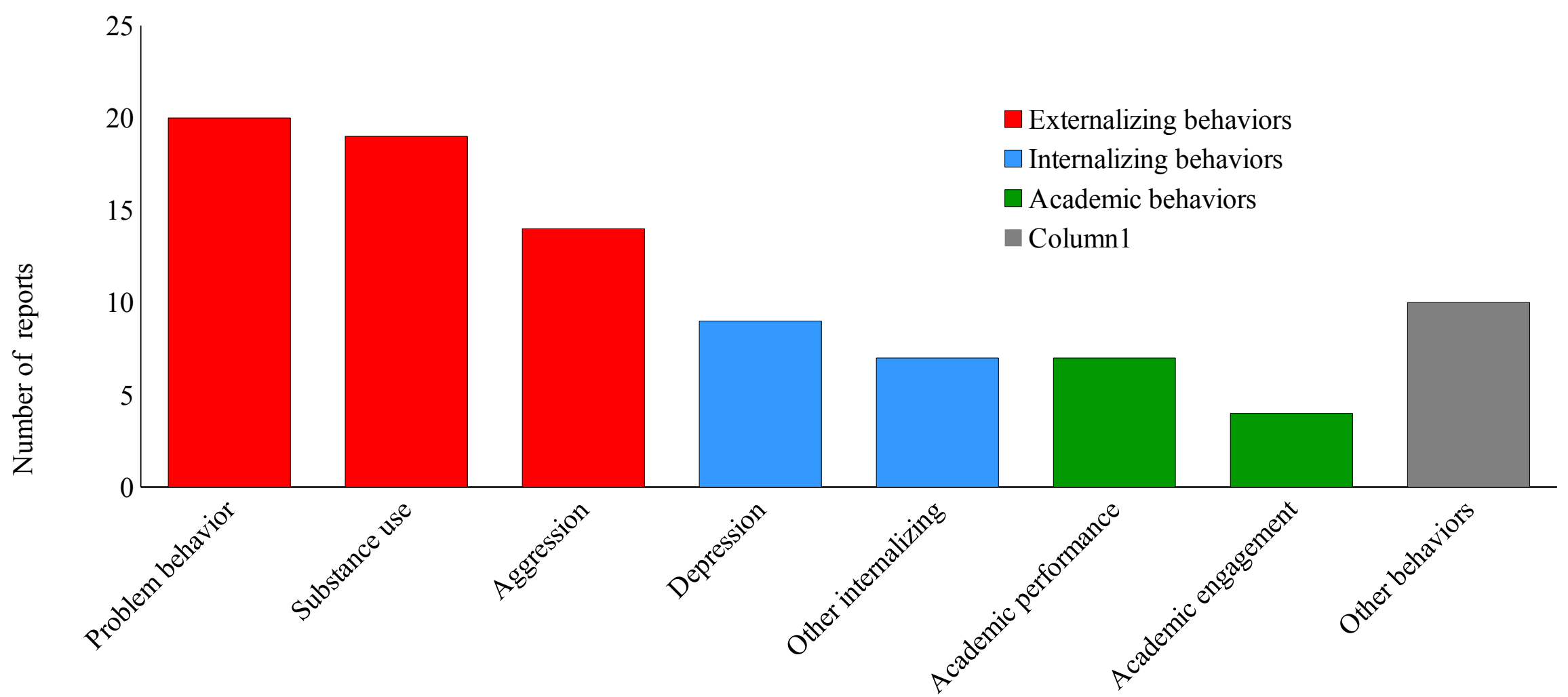

Figure 2. Types of behaviors examined across peer influence reports included in the meta-analysis.

Most behaviors were grouped in three macro-domains, that is, externalizing, internalizing, and academic behaviors. Note that the total number of reports in the $y$-axis exceeded the overall number of reports included in the meta-analytic review, as some reports examined multiple behaviors. The category "Substance use" includes alcohol, tobacco, marijuana use and measures of composite substance use.

The category "problem behavior" captures a range of behaviors including minor problem behaviors at school and home (e.g., rule- 


\section{PEER INFLUENCE IN CHILDHOOD AND ADOLESCENCE}

breaking) and more severe delinquency. The category "aggression" includes overt and relational aggression as well as bullying, but not other problem behaviors. In cases where a study used a variable that included both aggression and problem behaviors, this variable was coded as "problem behavior." The category "Other internalizing” includes all internalizing behaviors other than depression (e.g., anxiety symptoms and nonsuicidal self-injury). The category "Other behaviors" includes prosocial behaviors $(n=3)$, sexual behaviors $(n=2)$, weight-related behaviors $(n=2)$, popularity goals $(n=1)$, religiosity $(n=1)$ and anti-immigrant attitudes/prejudice $(n=1)$. 
PEER INFLUENCE IN CHILDHOOD AND ADOLESCENCE

A

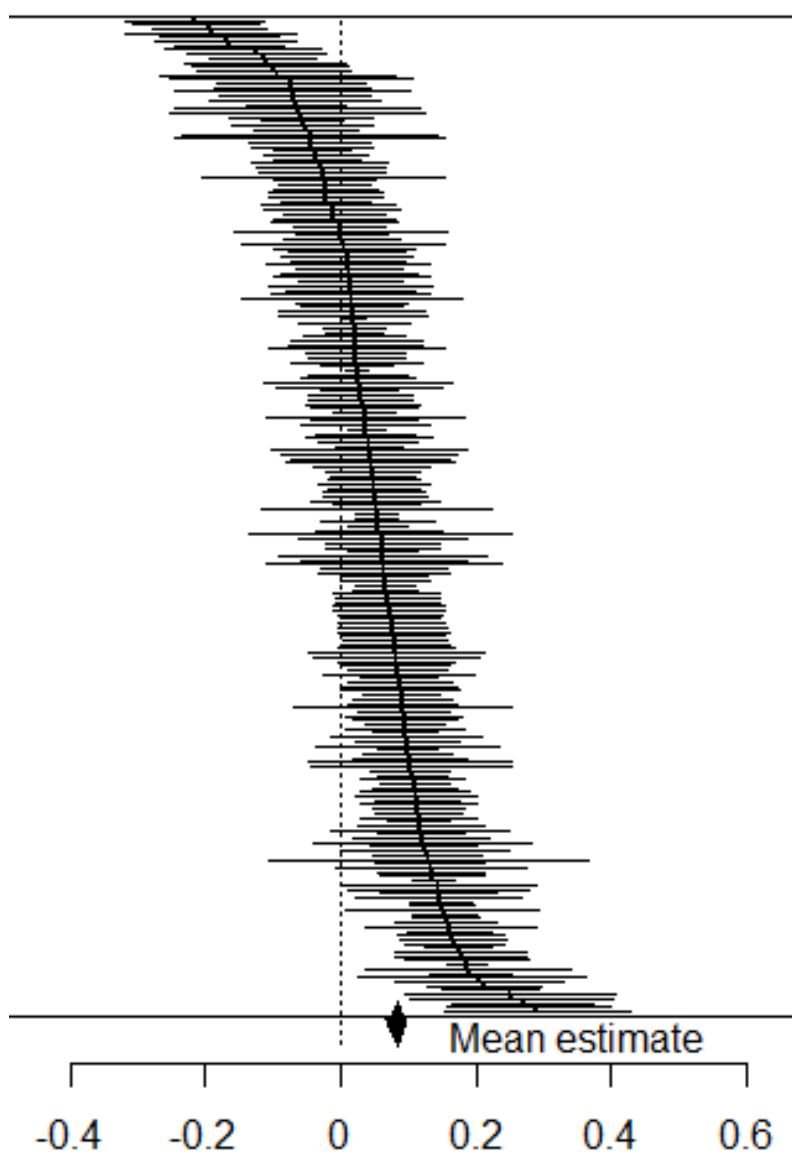

Estimated cross-lagged effects
B

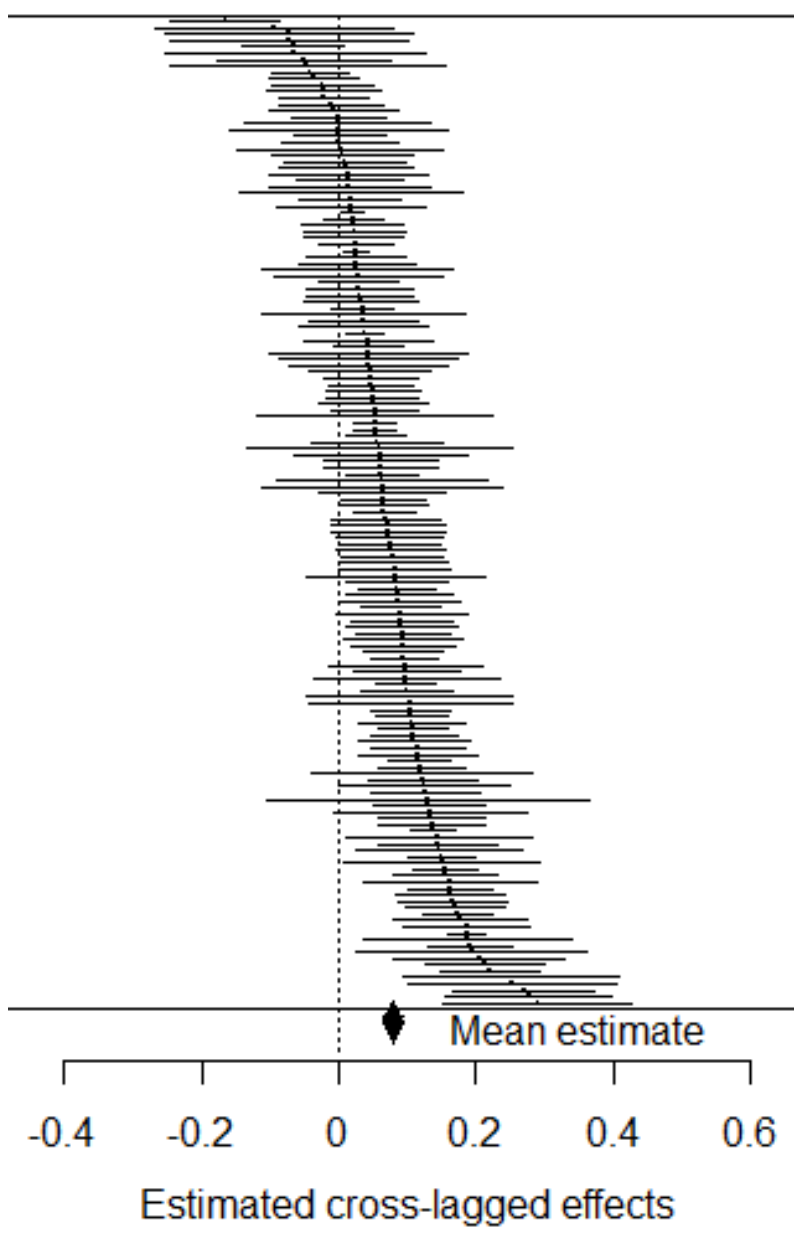

Figure 3. Caterpillar plots displaying observed cross-lagged effect sizes with $95 \%$ confidence intervals reflecting peer influence effects. Panel A includes all extracted effect sizes $(k=233)$, while panel B includes effect sizes calculated between consecutive time points only $(k=155)$. 


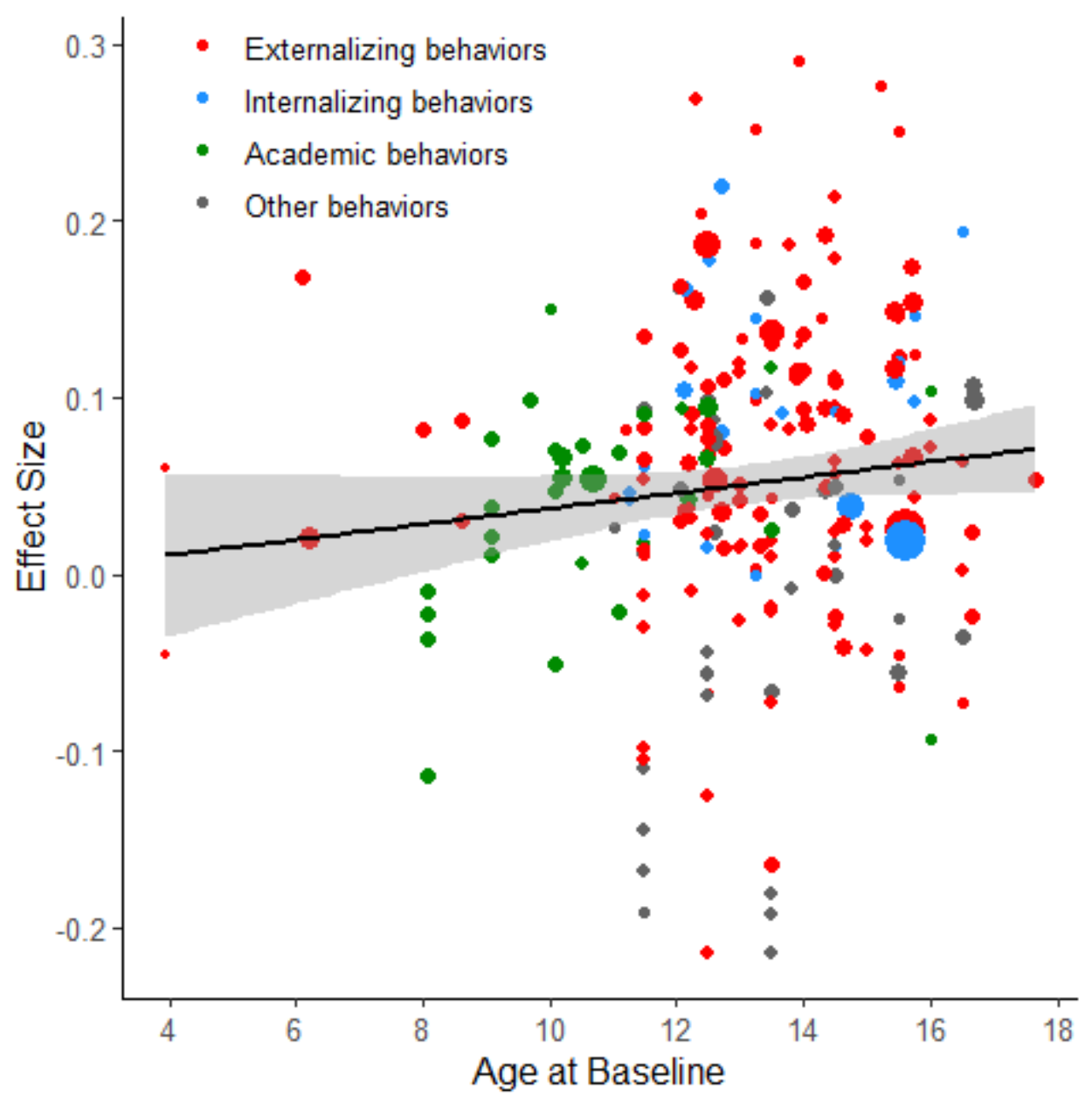

Figure 4. Scatterplot displaying the association between participants' age and peer influence effects. Each point represents a cross-lagged effect (i.e., peer influence effect). The size of the points represents the inverse variance, used to weight effect sizes; thus, larger points indicate larger sample sizes. The black line is a graphical illustration of the trend between age and peer influence effects; this effect was nonsignificant in the multilevel meta-regression model. 


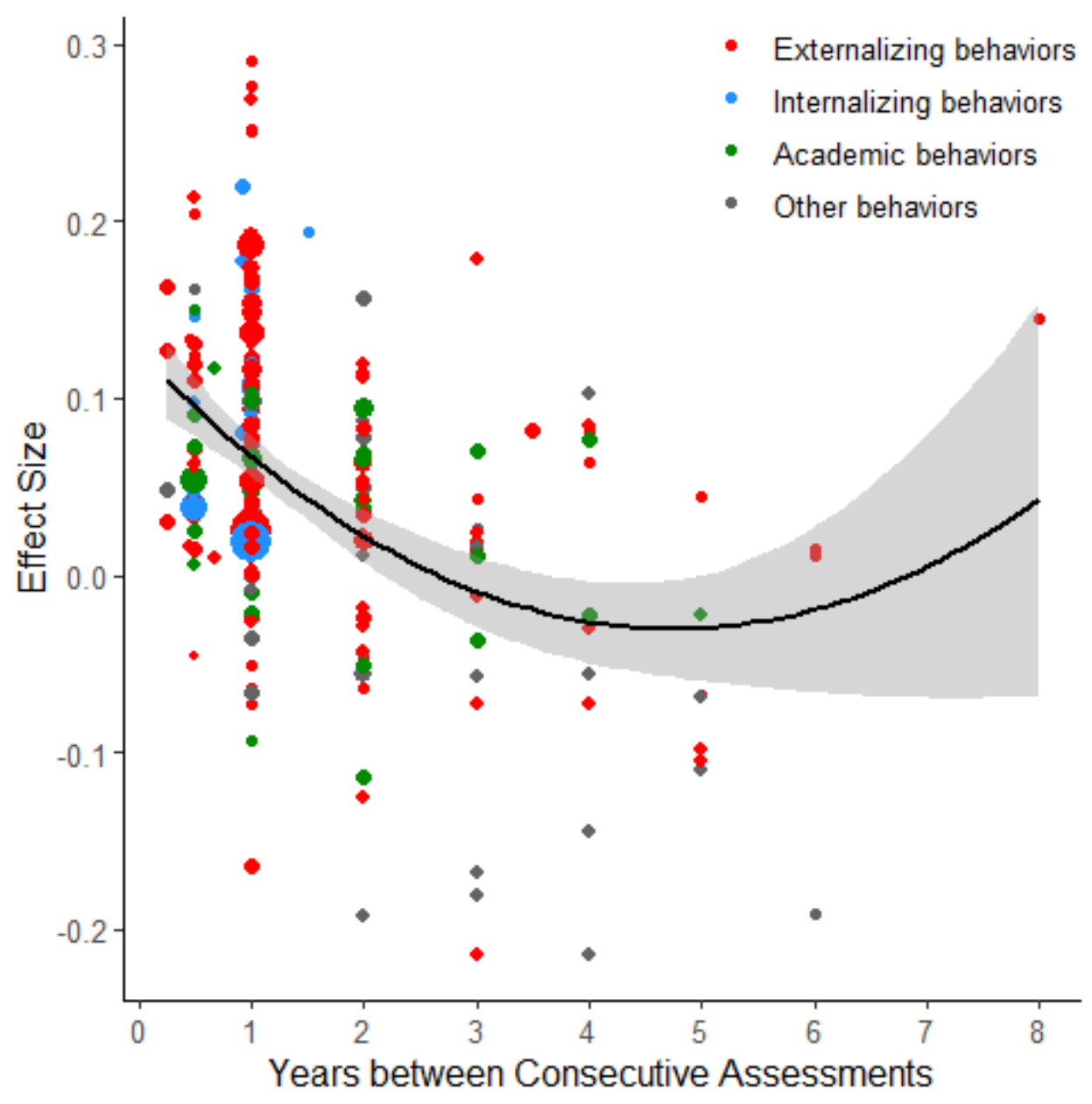

Figure 5. Scatterplot displaying the association between time lag and peer influence effects. Each point represents a cross-lagged effect (i.e., peer influence effect). The size of the points represents the inverse variance, used to weight effect sizes; thus, larger points indicate larger sample sizes. The black line is a graphical illustration of the trend between time lag and peer influence effects; in the multilevel meta-regression model, the quadratic effect was nonsignificant, but a negative significant linear effect indicated that the magnitude of effect sizes decreased when the years between assessments increased. 
107

PEER INFLUENCE IN CHILDHOOD AND ADOLESCENCE 
PEER INFLUENCE IN CHILDHOOD AND ADOLESCENCE

A
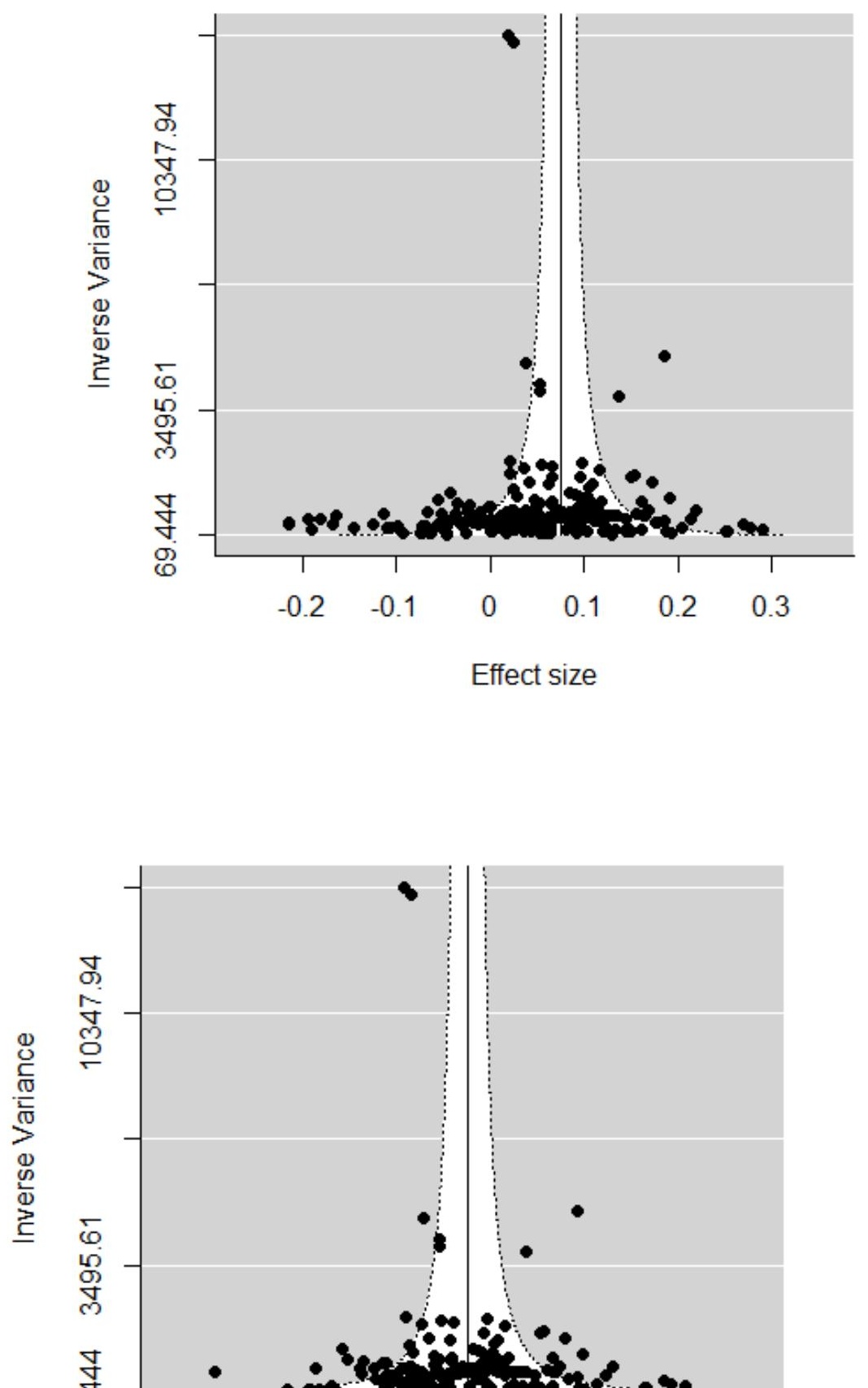
109

PEER INFLUENCE IN CHILDHOOD AND ADOLESCENCE

Figure 6. Funnel plots for the overall 233 effect sizes (panel A) and for effect sizes $(k=155)$ calculated between consecutive time points only (panel B). 